\title{
Early Phase Molten Salt Reactor Safety Evaluation Considerations
}

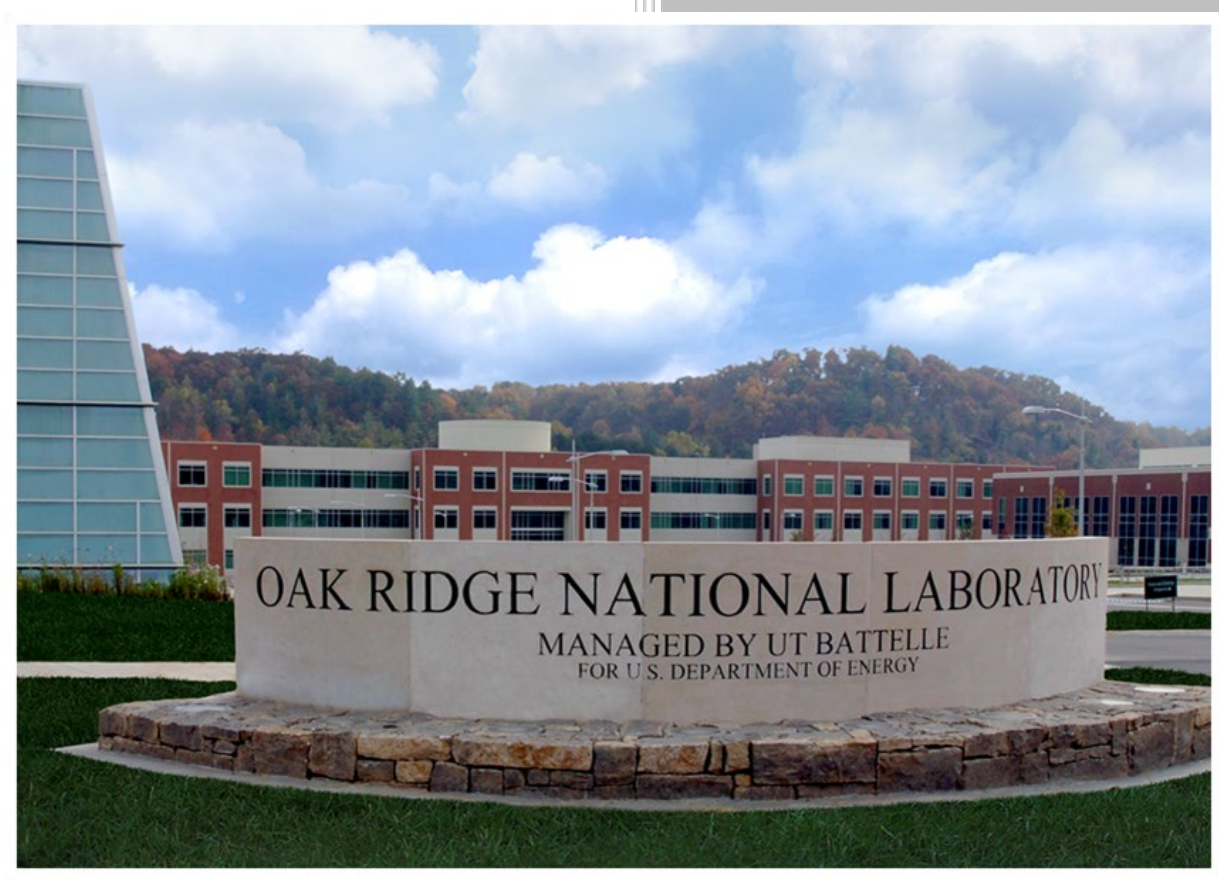

Approved for public release.

Distribution is unlimited.
David E. Holcomb ${ }^{1}$

A. L. Qualls ${ }^{1}$

Sara Thomas ${ }^{2}$

James Jerden ${ }^{2}$

Matthew Bucknor ${ }^{2}$

Nathan C. Andrews ${ }^{3}$

David L. Luxat ${ }^{3}$

1 Oak Ridge National Laboratory

${ }^{2}$ Argonne National Laboratory

${ }^{3}$ Sandia National Laboratories

September 2020 


\title{
DOCUMENT AVAILABILITY
}

Reports produced after January 1, 1996, are generally available free via US Department of Energy (DOE) SciTech Connect.

Website www.osti.gov

Reports produced before January 1, 1996, may be purchased by members of the public from the following source:

\author{
National Technical Information Service \\ 5285 Port Royal Road \\ Springfield, VA 22161 \\ Telephone 703-605-6000 (1-800-553-6847) \\ TDD 703-487-4639 \\ Fax 703-605-6900 \\ E-mail info@ntis.gov \\ Website http://classic.ntis.gov/
}

Reports are available to DOE employees, DOE contractors, Energy Technology Data Exchange representatives, and International Nuclear Information System representatives from the following source:

Office of Scientific and Technical Information

PO Box 62

Oak Ridge, TN 37831

Telephone 865-576-8401

Fax 865-576-5728

E-mail reports@osti.gov

Website http://www.osti.gov/contact.html

This report was prepared as an account of work sponsored by an agency of the United States Government. Neither the United States Government nor any agency thereof, nor any of their employees, makes any warranty, express or implied, or assumes any legal liability or responsibility for the accuracy, completeness, or usefulness of any information, apparatus, product, or process disclosed, or represents that its use would not infringe privately owned rights. Reference herein to any specific commercial product, process, or service by trade name, trademark, manufacturer, or otherwise, does not necessarily constitute or imply its endorsement, recommendation, or favoring by the United States Government or any agency thereof. The views and opinions of authors expressed herein do not necessarily state or reflect those of the United States Government or any agency thereof. 
Department of Energy Office of Nuclear Energy

Molten Salt Reactor Campaign

\title{
EARLY PHASE MOLTEN SALT REACTOR SAFETY EVALUATION CONSIDERATIONS
}

\author{
David E. Holcomb \\ Louis Qualls \\ Sara Thomas \\ James Jerden \\ Matthew Bucknor \\ Nathan C. Andrews \\ David L. Luxat
}

September 2020

Prepared by

OAK RIDGE NATIONAL LABORATORY

Oak Ridge, TN 37831-6283

managed by

UT-BATTELLE, LLC

for the

US DEPARTMENT OF ENERGY

under contract DE-AC05-00OR22725 



\section{CONTENTS}

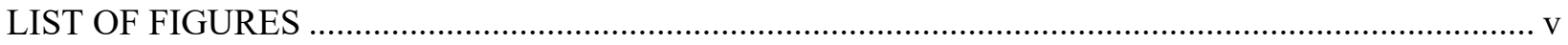

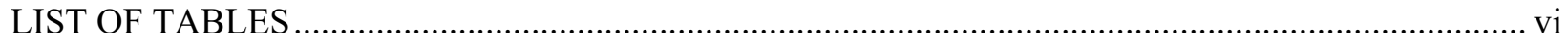

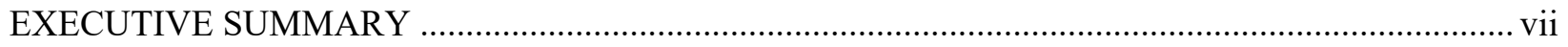

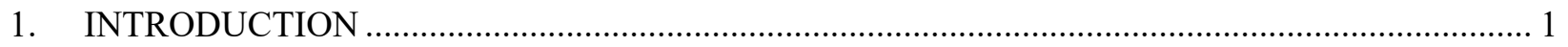

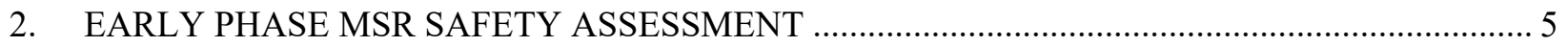

3. RATIONALE FOR AN MSR SAFETY ASSESSMENT FRAMEWORK …................................... 8

4. ACCIDENT CONSIDERATIONS FOR GENERIC MSR CONFIGURATIONS ........................... 10

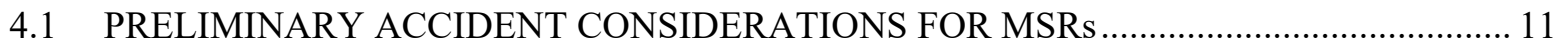

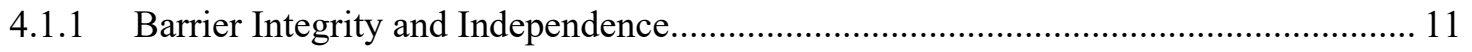

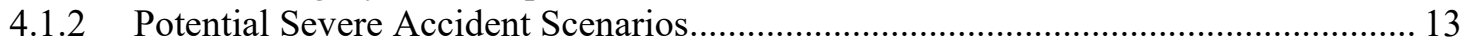

4.1.3 Failure of the Innermost Containment Layers ........................................................ 18

4.1.4 Demonstration of Adequate Safety following Severe Events ...................................... 23

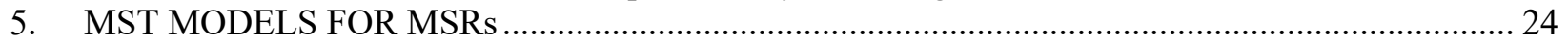

5.1 HISTORICAL SURVEY OF THE USE OF SOURCE TERM ASSESSMENTS FOR

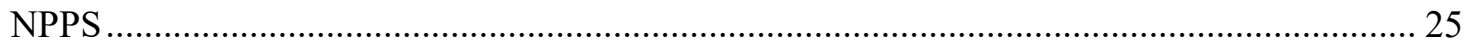

5.1.1 MST Assessment in the Context of Advanced Non-LWRs ...................................... 26

5.1.2 Modeling of Radionuclide Release and Consequence within the NRC

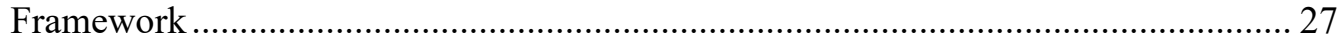

5.1.3 Communication of Source Term Assessments ..................................................... 28

5.2 RADIONUCLIDE SOURCES IN MSRS: INVENTORY DISTRIBUTION DURING

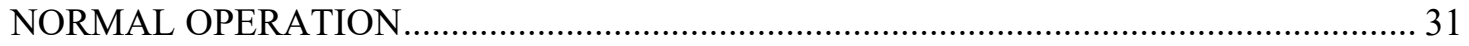

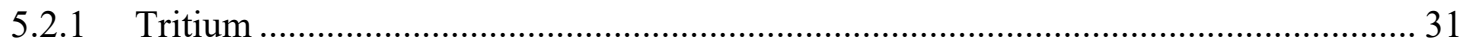

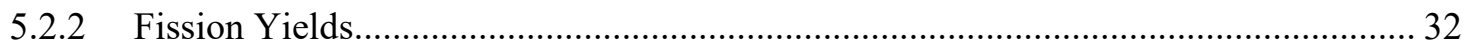

5.2.3 Identification of Major Dose Contributors to Prioritize Chemical Model

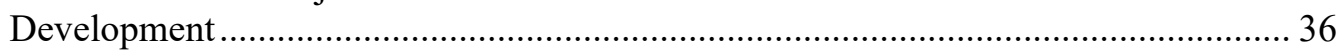

5.2.4 Inventory Distribution Based on Chemical Affinity during Normal Operation .......... 40

5.3 RADIONUCLIDE TRANSPORT AND RETENTION PHENOMENA ................................ 44

5.3.1 Transport/Retention Processes Modeling with Thermochemical Data....................... 44

5.3.2 Description of Transport and Retention Processes in a Generic MSR ....................... 45

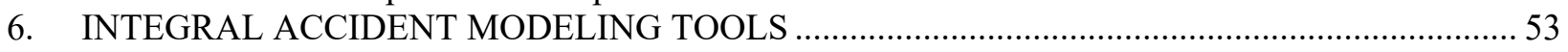

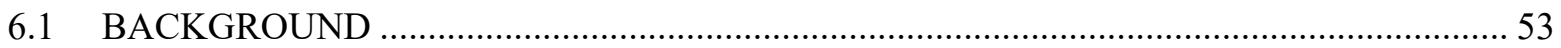

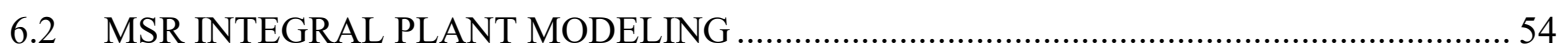

6.3 INTEGRAL ACCIDENT MODELING TECHNOLOGY CHARACTERISTICS AND

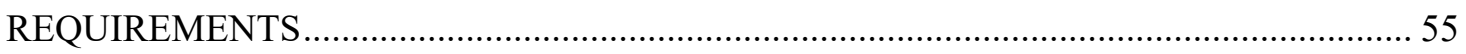

6.4 COMPONENTS IN CREATION OF A PLANT MODEL FOR AN INTEGRAL

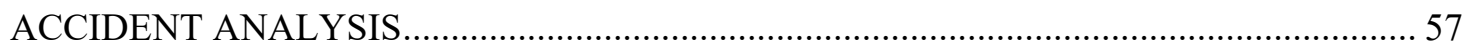

6.4.1 Development of MELCOR Radiological Facility Models..........................................5 58

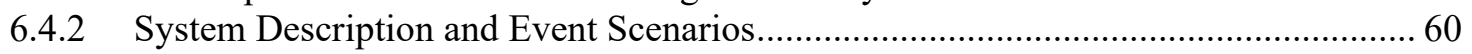

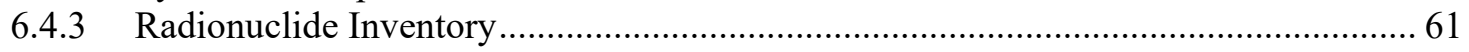

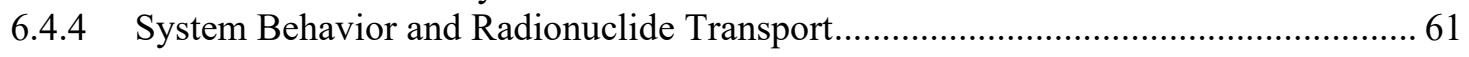

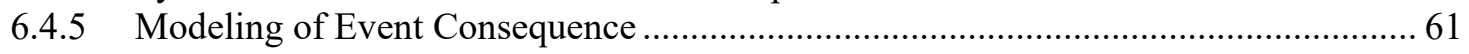

6.5 ACTIVITIES TO SUPPORT DEPLOYMENT AND APPLICATION OF MELCOR TO

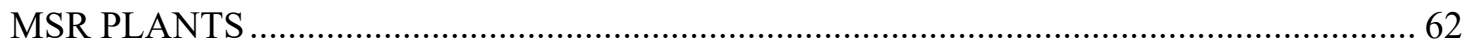

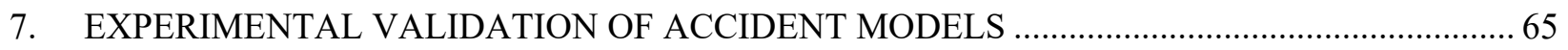

7.1 INTRODUCTION TO EXPERIMENTAL PLAN TO VALIDATE SALT SPILL

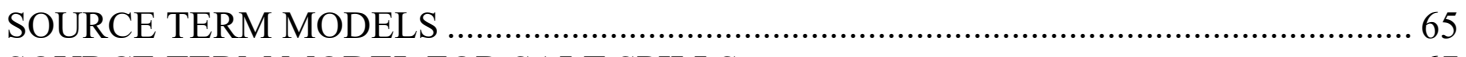

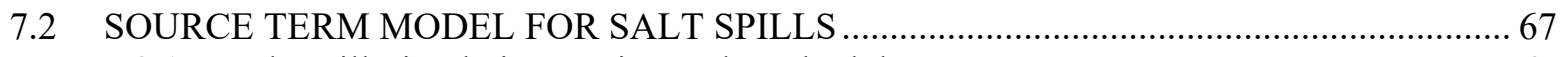

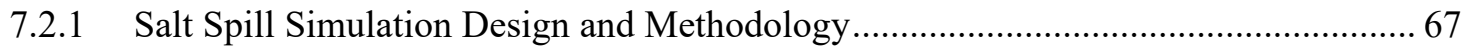


7.2.2 Conclusions and Recommendations Based on Salt Spill Simulation Case Study ....... 71

7.3 THERMO-PHYSICAL PROPERTIES NEEDS FOR THERMAL-HYDRAULIC

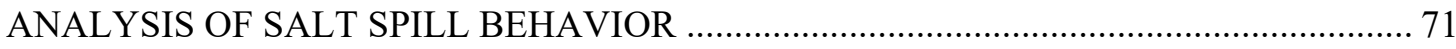

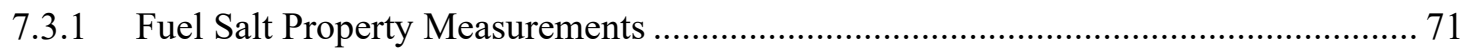

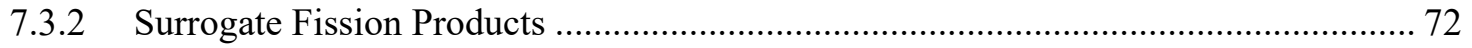

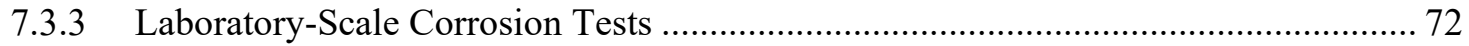

7.3.4 Engineering Scale Experiments: Salt Spill Morphology and Spreading...................... 73

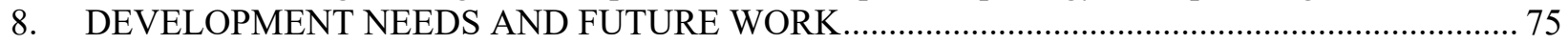

8.1 Importance of Excess Gibbs Free Energy in Thermodynamic Modeling of Vapor

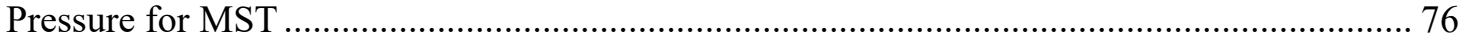

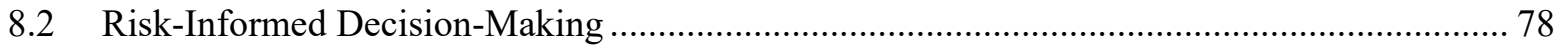

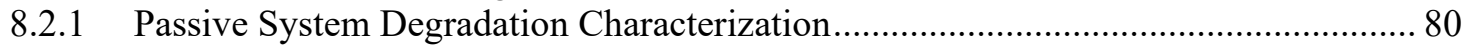

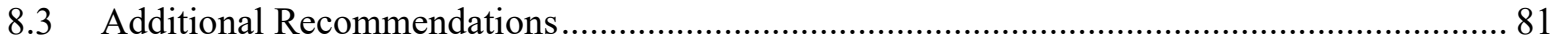

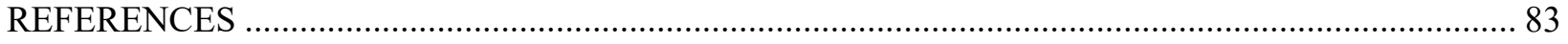




\section{LIST OF FIGURES}

Figure 1. PRACS and drain tank for decay heat removal.................................................................... 12

Figure 2. Method for developing and using an MST within the NRC framework [54]......................... 28

Figure 3. Illustration of source term reduction through multiple barriers to fission product release

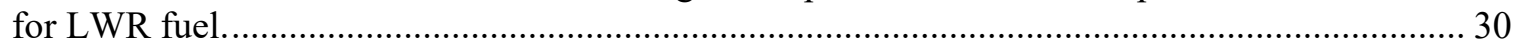

Figure 4. Calculated fission product activities for the MSRE (plotted from tabulated results of

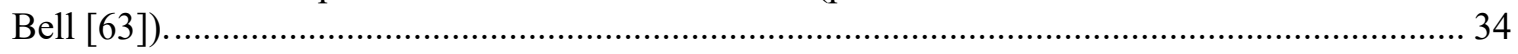

Figure 5. Actinides and fission products ranked by radiotoxicity as quantified by the effective dose equivalent (plotted from tabulated values of Eckerman et al. [68]).

Figure 6. Summary diagrams of the chemical behavior of important radionuclide elements during normal operation of typical chloride- or fluoride-fueled MSRs (temperatures between $\left.600-700^{\circ} \mathrm{C}\right)$

Figure 7. Portions of the decay chains of important fission product nuclides (fission yields are from Table 3).

Figure 8. Schematic summary of radionuclide transport and retention phenomena pertaining to MSR core.

Figure 9. Schematic information flow for the thermochemical model used to calculate radionuclide chemical speciation for the sodium fast reactor MST (from Grabaskas et al. [30]).

Figure 10. Salt droplets on a stainless-steel metal strip that formed due to exposure to the pump bowl gas space of the MSRE for 10 hours (from Compere et al. [70]). .52

Figure 11. Methodology for developing an MST assessment capability for MSRs. .54

Figure 12. Diagram showing inputs from salt chemistry studies needed to develop and parameterize an MST model for MSRs.

Figure 13. Summary of the MELCOR integral accident analysis phenomenological package.................58

Figure 14. Illustration of connection between packages supporting hydrodynamic modeling.

Figure 15. Schematic diagram of salt spill in primary containment cell due to a vessel rupture event (adapted from McWherter [106]).

Figure 16. Schematic diagram showing the major components of the MSFR primary fuel salt loop (adapted from Kloosterman [110]).

Figure 17. Simplified fuel cycle flow diagram for the MSFR showing the context of a fuel salt spill accident (adapted from Kalilainen et al.[89]).

Figure 18. Temperature and pressure evolution of fuel salt and containment atmosphere following the salt spill (adapted from Kalilainen et al.,[89]).

Figure 19. Vapor species released from evaporating salt for the Kalilainen et al. [89] Case 1 (accounts for nonideal behavior) and Case 2 (does not account for nonideal behavior) simulations (adapted from Kalilainen et al. [89]).

Figure 20. Analysis of (a) $\mathrm{UF}_{4}$ and (b) CsI volatilization after spill of $\mathrm{LiF}_{-} \mathrm{ThF}_{4}-\mathrm{UF}_{4}$ fuel salt containing Cs and I showing the importance of experimentally quantifying nonideality with Gibbs excess energy terms (adapted from Kalilainen et al.[89]).....

Figure 21. Example results comparing simulations that account for nonideality (green) and those that use pure phase vapor pressures (blue) (adapted from Kalilainen et al.[84]). .78

Figure 22. LMP frequency-consequence curve to assess event significance and classification [120]

Figure 23. Illustration of evolution paths for plant subjected to initiating perturbation. 


\section{LIST OF TABLES}

Table 1. Summary of non-LWR reactor designers that are formally interacting with the NRC. ${ }^{*} \ldots \ldots \ldots \ldots \ldots . . . . . .5$

Table 2. Basic characteristics of the MSRE, the MSBR and the MSDR............................................. 31

Table 3. Fission yields for some key radionuclides (adapted from Compere et al. [70])........................ 33

Table 4. Fission yields for ${ }^{239} \mathrm{PuCl}_{3} / \mathrm{NaCl}$ and ${ }^{235} \mathrm{UCl}_{3} / \mathrm{NaCl}$ fueled fast spectrum MSR (yields per 100 atoms of ${ }^{239} \mathrm{Pu}$ fission for 10 day irradiation).

Table 5. TRU isotopic composition of the REBUS fast spectrum MSR fueled with $45 \mathrm{~mol} \%$

(U,TRU)Cl $l_{3}+55 \mathrm{~mol} \% \mathrm{NaCl}$ (Mourogov and Bokov [67]).

Table 6. Fission product radionuclides ranked in terms of radiotoxicity as quantified by the EPA ALI, DAC, and effective dose equivalent conversion factor ("Dose factor") from Eckerman et al. [68].

Table 7. Actinides and thorium decay chain nuclides ranked in terms of radiotoxicity as quantified by the EPA ALI, DAC, and effective dose equivalent conversion factor ("Dose factor") from Eckerman et al. [68].

Table 8. Estimated distribution of important heat-producing fission products for a normally operating fluoride-fueled MSR (quantified as thermal power). Adapted from Robertson [72]......

Table 9. MSR concept fuel salt chemistry (adapted from Taira et al. [91]).......................................... 46

Table 10. Measured vapor pressures of fuel salt compounds in simulated fuel salt.................................47

Table 11. Summary of volatilization phenomena.

Table 12. Reduction potentials of primary fuel salt constituents (adapted from Williams, et al. [87]).

Table 13. Summary of precipitation phenomena.

Table 14. Initial composition of fuel salt used in salt spill simulation (adapted from Kalilainen et al. [89])

Table 15. Required salt property data and corresponding measurement techniques.

Table 16. Engineering-scale thermal-hydraulic tests to address salt behavior during large scale salt spill scenario.

Table 17. The Redlich-Kister mixing model fit parameters calculated for binary systems in the molten salt (from Kalilainen et al.[84]). 


\section{EXECUTIVE SUMMARY}

This report documents rationale to develop analytical tools and data applicable to the safety design and analysis of advanced molten salt power reactors (MSRs). It is a step in the implementation of the tasks defined by Oak Ridge National Laboratory (ORNL) in 2018 in the following sections of $A$ Safety and Licensing Roadmap to Identify the Research and Development Gaps of Commercial Molten Salt Reactors.

\subsubsection{LBE Selection for Salt-fueled MSRs \\ 5.1 Codes for Physics and Thermal Fluids \\ 5.1.1 Develop Salt-Fueled MSR Codes \\ 7. Analytical Codes and Methods \\ 7.1 Develop Required Methods and Data \\ 7.1.1 Develop MSR Performance Models}

While not a complete treatment of these subjects, this report describes first step integration of ORNL, Argonne National Laboratory (ANL), and Sandia National Laboratories (SNL) expertise to examine the adaptability of existing commercial light water reactor (LWR) accident analysis tools and data to MSR technology - in particular, chloride and fluoride molten salt fuel designs. Incompatibilities and knowledge gaps are identified, and recommendations are made for initial steps to address them, including engineering-scale tests, data collection, and numerical model development. Further, parallel efforts to continue progress in identification and refinement of a preliminary list of risk-important initiating events are described.

One starting point of the effort is the suite of detailed safety analysis tools developed and exercised over many years in the study of LWR safety performance and in the fulfillment of LWR licensing requirements. While the licensing construct of GEN-IV power reactors is emerging to be different from that of GEN-II and III+ LWRs, the fundamental technical principles of nuclear facility safety have not changed - namely, rigorous measures in design to prevent release of hazardous material and rigorous design features to mitigate the effects of an accident should it occur. An integral step to achieving and demonstrating nuclear safety has been and will continue to be the performance of analyses to examine the behavior and potential consequences of adverse events that can challenge the engineered barriers to material release.

GEN-IV nuclear designs will begin with benefits from years of evolution and advancement of commercial nuclear power and chemical industry safety analysis techniques, positioning them to better achieve safetyin-design $\left(\mathrm{SiD}^{\dagger}\right)$ than predecessor reactor generations. Integral to the modern nuclear reactor design process is the systematic identification of hazards, using industry standard methods; the formulation of postulated initiating events, which could lead to off-normal plant conditions; and the application of risk insights to rank safety concerns and inform design decisions accordingly. Quantitative modeling of accident progression and consequence is also vital to this process, which will be carried out iteratively in a graded approach as design matures and will also be utilized in the characterization of aggregated risk in the performance of design-specific probabilistic risk assessment (PRA). Therefore, safety analyses will

\footnotetext{
${ }^{*}$ G.F. Flanagan, et al., A Safety and Licensing Roadmap to Identify the Research and Development Gaps of Commercial Molten Salt Reactors. ORNL/TM-2018/944, 2018.

† The term "safety in design" is most completely described in a DOE standard for nuclear facility design, DOESTD-1189, "Safety in Design" which describes a process for integrating safety analysis into the design process for nuclear facilities.
} 
be initiated early in the design process and performed iteratively to inform design and, ultimately, the mature design will inform the final safety analyses and a PRA that will be submitted to license a specific reactor.

This iterative development of safety analyses will be a departure from previous generations where a set of stylized consequence analyses served as the centerpiece of the initial licensing basis, with a PRA later performed to consider beyond-design-basis severe accidents - which then led to broader use. However, traditional stylized adverse scenarios can be used to begin the exploration of analytical model adaptability and knowledge gaps.

The evolved tools of the previous reactor generation are highly valuable and adaptable to MSR technology. The exploration reported here concerns the suite of tools that are used to analyze the progression of LWR core melt scenarios: the behavior of the disrupted fuel material, its migration in the reactor facility, its thermal and physical interaction with facility structures, the paths the material may take to environmental release, a rationalized determination of the fraction of the material that enters the environment (the mechanistic source term), the transport and deposition of those materials in the environment, and the consequences of human uptake and exposure.

An ORNL-led workshop was held to identify postulated initiating events has been completed and the results reported ${ }^{\ddagger}$. In this report further work to identify a preliminary set of initiating events to inform early stages of reactor design is described. This work is intended to support, and be consistent with, early stages of PRA development. ${ }^{\S}$ A domestic GEN-IV MSR design is not available for this purpose; therefore, previous generation designs, the European-led Molten Salt Fast Reactor (MSFR), or generalized models of new MSR concepts can serve as stand-ins.

This report documents several avenues that DOE's National Laboratories have taken in the first steps of this exploration, including:

- Research of historical MSR design experience, analyses and data from past decades concerning molten salt testing, the operation of the Molten Salt Reactor Experiment (MSRE), and subsequent MSR design efforts to consider example fuel salt fission product speciation.

- Generalized considerations of the regions where liquid fuel would reside in an MSR and logical conceptualization of design features and strategies for effective barriers to material release.

- Logical conceptualization of radionuclide transport and retention phenomena using stylized adverse scenarios. Use of the conceptualization to identify an array of potential thermal, physical, and chemical behaviors of the salt materials which could impact accident progression and results, and therefore need to be considered in accident modeling.

- Inventory of adaptable analytical models, with a focus on SCALE, MELCOR, and MACCS.

- Performance of a MELCOR adaptability exercise using the MSRE in a case study that identified needed data, code modifications, and uncertainty propagation studies.

- Research on a European case study using MELCOR modeling a fuel salt spill accident as part of a molten salt fast reactor (MSFR) project, and examination of implications for model development and data collection.

\footnotetext{
"Holcomb, D., et al, "Molten Salt Reactor Initiating Event and Licensing Basis Event Workshop,” ORNL/TM2019/1246, July 2019.

$\S$ As described in NRC's recently promulgated Regulatory Guide 1.233, "Guidance for a Technology-Inclusive, Risk-Informed, and Performance-Based Methodology to Inform the Licensing Basis and Content of Applications for Licenses, Certifications, and Approvals for Non-Light-Water Reactors,” June 2020.
} 
- Research of other non-LWR technologies, such as liquid sodium, for commonalities in material behavior data, modeling needs, and mechanistic source term development.

This report closes with recommendations for technical tasks resulting from the above investigations and exercises. It is recommended that DOE's National Laboratories perform the tasks in further fulfillment of previously identified safety and licensing roadmap for MSRs. As part of this, the National Laboratories will support interactions between the Nuclear Regulatory Commission (NRC) and commercial industry to obtain feedback and input. It is intended that the work performed by ORNL, ANL, and SNL will provide tools that will be of use to safety analysts within commercial design organizations as part of the overall safety-in-design process for individual reactor designs.

This work does not endorse or prescribe any reactor design requirements or licensing approaches. The work describes possible MSR design features and considers events that have the potential to stress containment barriers to potentially result in external release. This work also describes and discusses representative examples of possible bounding cases. However, designers are responsible for defining and justifying their designs, safety assessment approach, and accident scenarios. 


\section{INTRODUCTION}

\subsection{PURPOSE AND STRUCTURE OF REPORT}

This report documents rationale to develop analytical tools and data applicable to the safety and design of advanced molten salt power reactors. This report represents early steps in the implementation of the tasks defined by Oak Ridge National Laboratory (ORNL) in 2018 in the following sections of A Safety and Licensing Roadmap to identify the Research and Development Gaps of Commercial Molten Salt Reactors.

\subsubsection{LBE Selection for Salt-fueled MSRs}

5.1 Codes for Physics and Thermal Fluids

5.1.1 Develop Salt-Fueled MSR Codes

7. Analytical Codes and Methods

7.1 Develop Required Methods and Data

7.1.1 Develop MSR Performance Models"

The report consists of the following elements:

- Discussion of historical evolution of NPP safety licensing and analysis methods

- The status of the licensing context for advanced non-LWR safety analysis

- The state of available technical data to support MSR safety analysis

- The state of available models to support MSR safety analysis

- The rationale for the selection of LWR modeling tools for adaptation to MSRs

- Approach to model adaptation for MSRs

- Initial identification of data collection needs and candidates for research and development

This work does not endorse or prescribe any reactor design requirements or licensing approaches. The work describes possible MSR design features and considers events that have the potential to stress containment barriers to potentially result in external release. This work also describes and discusses representative examples of possible bounding cases. However, designers are responsible for defining and justifying their designs, safety assessment approach, and accident scenarios. Furthermore, this work is an attempt to discuss the inherent features of MSRs and how they relate to FSFs and to explore and understand the possible functional containment layers available within an MSR. The effort aims to identify gaps in knowledge, phenomenology, chemistry and transport data, and analysis tools so that future research and development can be directed to those gaps to help create workable, near-term safety assessment capabilities. Specific recommendations include (1) develop validated tools to perform radionuclide transport and accountancy during representative operating conditions that can establish initial conditions for accident progression modeling, (2) enhance the capability of accident evaluation tools to evaluate MSR-specific transport phenomena within volumes and across their interfaces, and (3) evaluate the relationship between containment layer performance (i.e., leak rate and robustness to external events) and overall plant economics.

\subsection{EVOLUTION OF NUCLEAR POWER PLANT LICENSING REQUIREMENTS}

The NRC's current nuclear power plant (NPP) regulatory framework has been developed over several decades based upon the risk characteristics of large light-water cooled reactors (LWRs). Both the industry and the NRC have recognized the difficulty in applying the current regulatory framework to advanced reactors and have recently issued reports to inform the development of advanced reactor safety evaluation 
methods. Nevertheless, the fundamental safety functions (FSFs), which underlie LWR safety requirements, are common to any NPP.

\subsection{RECENT US LICENSING DEVELOPMENTS TO ACCOMMODATE NON-LWRS}

\subsubsection{Advanced Reactor Design Criteria (RG 1.232)}

GDCs establish minimum requirements for the principal design criteria for reactors. While the GDCs provided in 10 CFR 50 Appendix A are tailored for the safety characteristics of LWRs, their safety intents are generally applicable to other types of NPPs and provide guidance in establishing the principal design criteria for other designs and the NRC has provided Regulatory Guide 1.232 to map the safety intent of the GDCs to advanced reactors. The Advanced Reactor Design Criteria (ARDCs) are, thus, an acceptable means of developing principal design criteria for MSRs. The ANS 20.2 working group is working to develop a set of MSR DCs based upon mapping the safety intent of each ARDC to MSRs along with adding MSR specific design criteria.

It is noted that development of ARDCs for these more mature advanced reactors was an extended effort and substantial additional resources and time will be needed to do complete this effort for MSRs.

\subsubsection{Industry-Led Risk-Informed, Performance-Based Licensing Efforts}

\subsubsection{Licensing Modernization Project (LMP) (NEI 18-04 Rev. 1 and RG 1.233)}

The Licensing Modernization Project (LMP) was a cost-shared initiative led by nuclear utilities and supported by DOE. The LMP developed technology-inclusive, risk-informed, and performance-based non-LWR licensing methods. The LMP refined the Next Generation Nuclear Plant Program methodologies to reflect interactions with the NRC, feedback from industry, and broadening of the scope to ensure applicability to various non-LWR technologies. The LMP activities led to the publication and submittal of NEI 18-04. NEI 18-04 outlines an approach for use by reactor developers to select LBEs, classify SSCs, determine special treatments and programmatic controls, and assess the adequacy of a design in terms of providing layers of DID.

The principles and methodology in NEI 18-04, Revision 1 were endorsed by the NRC in RG 1.233 as one acceptable method for informing the licensing basis and determining the appropriate scope and level of detail for parts of applications for licenses, certifications, and approvals for non-LWRs."

\subsubsection{Technology Inclusive Content of Application Project (TICAP)}

The DOE-authorized TICAP, a utility-led project, was initiated to collaborate with the NRC to achieve the objective of modernizing the regulatory framework to improve the effectiveness and efficiency of its reviews. The project recognizes that significant levels of industry input and advocacy are needed in collaboration with the NRC to enable the regulatory changes needed for advanced reactors.

The goal of TICAP is to develop license application content guidance with the following attributes:

- Technology inclusive to be generically applicable to all non-LWR designs

- Risk-informed and performance-based (RIPB) approaches to:

$\circ$ Ensure the NRC review is focused on information that directly supports the safety case of reactors.

- Provide a consistent and coherent approach for establishing the SAR scope and level of detail requirements for various advanced technologies and designs.

- Provide for flexibility during construction. 
- Encourage innovation by focusing on the final results as opposed to the pathway taken to achieve the results."

\subsubsection{ASME/ANS Non-LWR PRA Standard (ASME/ANS RA-S-1.4-2020)}

ASME/ANS RA-S-1.4-2020 was recently endorsed by the industry and provides guidance related to the development of systematic and comprehensive quantitative models of risk (i.e., PRA models) that can be used to support the development of RIPB safety bases for non-LWRs, including MSRs.

\subsection{EARLY STAGE SAFETY ASSESSMENT APPROACHES RELEVANT TO MSR DESIGNS}

Although the efforts discussed in the preceding section are helpful to indicate the "end point" for the development of a safety basis for an MSR design that can ultimately be used within a RIPB licensing framework, at an early stage of development it may not appropriate to develop such a detailed model of risk. This document provides guidance from the international and domestic nuclear communities that can help developers analyze the safety of their design at an early enough stage of the design process that risk insights can be incorporated into the next iteration of the design process.

\subsubsection{MSR Campaign Safety and Licensing Roadmap (ORNL/TM-2018/944)}

This 2018 ORNL report indicates gaps that require additional R\&D to be closed in order to support the safety evaluation and eventual licensing of MSRs.

\subsubsection{Process Hazards Analysis (PHA) and Integrated Safety Analysis (PHA)}

PHA studies are a tool developed originally in the chemical industry that provide a flexible and systematic evaluation of hazard/risk/safety in a specific design and allow for incorporation of these risk insights into the next cycle of the design process. Furthermore, the NRC's guidance on ISAs helps show how PHAs can be used to inform early semi-quantitative (and even quantitative) models of designspecific risk.

- $\quad$ CCPS Guidelines for Hazard Evaluation Procedures

- Use of PHA in NRC's ISAs for fuel cycle facilities (NUREG-1513 and NUREG-1520)

- Use of PHA by DOE:

○ Non-reactor nuclear facility risk analysis (DOE-STD-3009)

○ Nuclear safety PRAs (DOE-STD-1628)

\subsubsection{International Guidance on Accident Scenario Analysis and Safety Assessment}

The following reports from IAEA and GIF RSWG offer detailed guidance regarding the identification and analysis of event sequences for NPPs. Although some of the IAEA guidance is based upon LWR-specific design details, the principles are applicable to non-LWRs (and MSRs).

- IAEA, "Deterministic Safety Analysis for Nuclear Power Plants" (SSG-2, Rev. 1)

- IAEA, "Best Estimate Safety Analysis for Nuclear Power Plants, Uncertainty Evaluation" (Safety Report Series No. 52)

- Generation IV Risk and Safety Working Group, “An Integrated Safety Assessment Methodology (ISAM) for Generation IV Nuclear Systems," Version 1.1, June 2011 
- Generation IV Risk and Safety Working Group, "Guidance Documents for Integrated Safety Assessment Methodology (ISAM) (GDI)” Version 1.0, May 2014

\subsection{RECENT EFFORTS TO SUPPORT EARLY STAGE SAFETY ASSESSMENT OF MSRS}

This section provides brief discussions of references that document research that could be used by MSR developers/analysts to inform the early development of their design-specific safety basis.

\subsubsection{Brookhaven's "Phenomena Important in Modeling and Simulation of Molten Salt Reactors" (BNL-114869-2018-IR)}

This report provides discussion of phenomena that are relevant to the safety of an MSR design and helps inform an MSR developer/analysist regarding what types of modeling and simulation capabilities will eventually be needed during the development of an MSR concept.

\subsubsection{ORNL's "Proposed Guidance for Preparing and Reviewing a Molten Salt Non-Power Reactor Application (ORNL/TM-2020/1478)}

This report provides guidance related to the development of an application for the NRC licensing of a non-power MSR. Specifically, Chapter 13 provides discussion of the selection and analysis of a Maximum Hypothetical Accident (MHA) that could be useful to consider during the selection of a primary list of LBEs for a RIPB safety assessment of an MSR design.

\subsubsection{ORNL's “Molten Salt Reactor Initiating Event and Licensing Basis Event Workshop Summary" (ORNL/TM-2019/1246)}

This report documents a variety of IEs that could be of use to an MSR developer/analyst to develop a preliminary set of LBEs.

A key workshop goal was to support development of a risk-informed, performance-based regulatory process for MSRs. Development of a representative set of MSR IEs supports this goal by providing a technical basis to align the event selection and evaluation process with MSR characteristics. It is otherwise unsuitable for MSR event selection to rely on the significant experience with large light-water cooled reactors (LWRs) that is embodied in the current regulatory process."

The workshop demonstrated the capability of a system-by-system evaluation process, performed by a set of MSR industry experts, to generate a list of potentially representative IEs for MSRs. However, as noted in the report: "The list of IEs is not intended to be fully encompassing for any specific liquid fueled MSR. The MSR designer must determine which representative IEs are applicable to the design and identify any additional IEs needed." The insights gained can supplement insights provided by more comprehensive, systematic evaluations, discussed below.

\subsubsection{Investigations of MSRE Safety by VU/EPRI/ORNL}

The work conducted by VU, EPRI, and ORNL demonstrates that qualitative PHA studies can be used to inform the development of more quantifiable models of risk for MSR designs using the MSRE design.

- ORNL and Vanderbilt's “A New Look at Licensing Basis Events for the Molten Salt Reactor Experiment" (ORNL/TM-2018/788) 
- EPRI/Vanderbilt/Southern Company's “Molten Salt Reactor Experiment (MSRE) Case Study Using Risk-Informed, Performance-Based Technical Guidance to Inform Future Licensing for Advanced Non-Light Water Reactors" (ADAMS Accession No: ML19249B632)

- Chisholm, B.M. et al., "A systematic approach to identify initiating events and its relationship to Probabilistic Risk Assessment: Demonstrated on the Molten Salt Reactor Experiment" (Progress in Nuclear Energy)

- EPRI's "Compilation of Technical, Hazard, and Risk Analyses Performed for the Molten Salt Reactor Experiment, in Support of the Integration of Safety-in-Design for Advanced Reactors" (3002018340)

\subsubsection{SAMOFAR Work}

The work conducted by the SAMOFAR (and the current SAMOSAFER) project(s) demonstrate the application of RIPB safety assessment approaches to the European MSFR design during its conceptual design phase.

- Gerardin, D., et al, "A methodology for the identification of the postulated initiating events of the Molten Salt Fast Reactor," Nuclear Engineering and Technology, No. 51, p 1124-1031

- Beils, S., et al, "Application of the lines of defence method to the molten salt fast reactor in the framework of the SAMOFAR project," Nuclear Science \& Technologies, Vol 5/No. 18, p $1-11$

\section{EARLY PHASE MSR SAFETY ASSESSMENT}

Given the significant time and resources required to develop and deploy a new reactor design, having an efficient and effective safety evaluation framework available early in the design process is needed to reduce development risk. Of the six advanced non-LWR reactor designers that have formally notified the NRC that they intend to engage in regulatory interactions, three are MSRs (Table 1). The range of reactor technologies in this initial set of advanced non-LWR designs indicates the need for a generic source term approach that can address specific aspects of individual designs. An MST approach was recently demonstrated for a generic metal fueled sodium fast reactor concept [42] that can inform future advanced reactor source term developments. Significant challenges for developing an MST approach for non-LWR advanced reactor designs include the need for new models, modifications of existing codes, and an extensive experimental program to obtain necessary thermochemical and thermophysical data [36].

Table 1. Summary of non-LWR reactor designers that are formally interacting with the NRC.*

\begin{tabular}{lll}
\hline \multicolumn{1}{c}{ Developer } & \multicolumn{1}{c}{ Preapplication information } & \multicolumn{1}{c}{ Technology } \\
\hline General Atomics & General Atomics & Helium-cooled fast reactor \\
X-Energy LLC & XE-100 & MHTGR \\
Kairos Power LLC & Kairos Power Fluoride Salt-Cooled, High & MSR \\
Terrestrial Energy USA Ltd & Temperature Reactor (KP-FHR) & MSR \\
TerraPower LLC & Integral MSR (IMSR) & MSR \\
Westinghouse Electric Company & eVinci & Microreactor \\
\hline
\end{tabular}

*Information from https://www.nrc.gov/reactors/new-reactors/advanced.html\#advRxWs 
The US Nuclear Regulatory Commission's (NRC's) current nuclear power plant (NPP) regulatory framework has been developed over several decades based on the risk characteristics of large light water reactors (LWRs). Molten salt reactors (MSRs) are sufficiently different from LWRs in that many of the safety characteristics do not transfer directly between the two reactor classes. Nevertheless, the fundamental safety functions (FSFs), which underlie LWR safety requirements, are common to any NPP. The NRC has indicated [1] that advanced reactors will be expected to provide enhanced safety margins. Consequently, the purpose of this effort is to describe a near-term, efficient, and effective safety evaluation option that can productively begin the safety evaluation process for liquid-fueled MSRs given the limited available operational experience, accident progression data, and reliability data. The effort aims to identify gaps in knowledge, phenomenology, chemistry and transport data, and analysis tools so that future research and development can be directed to those gaps to help create workable, near-term safety assessment capabilities.

This effort seeks to build upon and adapt industry and NRC advanced reactor safety evaluation recommendations to the distinctive characteristics of MSRs. Industry and the NRC have recognized the difficulty of applying the current regulatory framework to advanced reactors and have recently issued reports to inform the development of advanced reactor safety evaluation methods. The NRC draft document Non-Light Water Review Strategy Staff White Paper [2] indicates that applicants could choose to organize their safety analysis information in various formats and provides an example of how controls and barriers can be employed to prevent and mitigate damage that would result in fission product release. The industry-led Technology Inclusive Content of Applications Project draft report [3] describes three FSFs that, if satisfied, would provide reasonable assurance of the adequate protection of the health and safety of the public and environment. The FSFs are:

- Limiting the release of radioactive materials under all conditions from normal operations to severe accidents,

- controlling reactivity, and

- removing decay heat from the reactor and waste stores

Deterministic and probabilistic frameworks have been approved for the safety evaluation of advanced reactors. Either framework could be applied to MSRs, and both offer insights as to how to minimize MSR accident probabilities and consequences. However, both are general advanced reactor safety evaluation methods not tailored specifically to MSRs. MSR characteristics are sufficiently distinctive so that exploring a safety evaluation tailored specifically to them should improve regulatory effectiveness and efficiency and reduce development risk. Additionally, MSRs are generally less mature and have more diverse design configurations than other advanced reactor classes. Consequently, the information typically relied upon to perform higher fidelity data-driven safety assessments is currently limited.

A preliminary bounding event safety assessment exercise offers a near-term option for exploring MSR safety issues given the lack of design maturity, operational data, and reliability data. The analysis is intended to allow consideration of the fulfillment of FSFs through the integrated, performance-based radionuclide retention capabilities embodied in functional containment [4] to better understand the ability of the advantageous safety characteristics made possible by liquid salt fuel to simplify reactor design and reduce design, construction, and operational costs.

MSRs will employ multilayered containment to provide defense in depth. However, the role of each individual barrier in limiting the release of radionuclide materials does not map precisely to the barriers in LWRs. The fuel salt itself chemically retains some radionuclides that form stable, high boiling point salts. Solid radionuclides that are insoluble in the fuel salt can plate onto salt-wetted surfaces, and those that deposit onto the structural alloy can subsequently diffuse into its surface. Gaseous fission products have low solubility in the fuel salt and largely escape to the head space or into graphite pores. 
For an MSR, the innermost essentially leak-tight radionuclide barrier comprises the fuel salt and cover gas that are in contact with the material. The innermost barrier is generally referred to as inner containment. The phrase essentially leak-tight acknowledges that the barrier might have imperfections (e.g., leaks at mechanical joints or pump shaft seals). The next essentially leak-tight barrier layer between the radionuclides and the environment is typically referred to as outer containment or secondary containment. Secondary containment is not in direct contact with significant amounts of radionuclides during normal operations. MSRs, like other reactors, typically employ an additional exterior radionuclide barrier, largely to provide protection from external events, which — depending on the design — might not be leak-tight.

Some MSR designers might elect to segment containment into separate cells, similar to how processing lines at hot cell facilities can be separated into individual cells. The cells could be interconnected (e.g., via piping) when the reactor is operating, so this would not provide complete isolation. Examples of interconnected cells include dual independent cover gas filter trains, one of which would normally be mechanically separated to enable maintenance while the reactor remains at power, and a batch fuel salt cleanup system, which is only connected to the fuel salt loop for charging and discharging.

The industry-led Licensing Modernization Project (LMP) recently applied the methods pioneered in the RSS to assess advanced reactor safety adequacy. The LMP proposed a probabilistically informed advanced reactor safety evaluation strategy, which the NRC endorsed as an acceptable method in SRMSECY-19-0117 [5]. RG 1.233 provides guidance on using a technology-inclusive, risk-informed, and performance-based methodology to inform the licensing basis and content of applications for non-LWRs [6]. Comments from Advisory Committee on Reactor Safeguards (ACRS) members during the subcommittee meeting to evaluate the PRA-based methodology endorsed the use of PRA methods while - similar to the Lewis Committee - cautioning on the difficulties of application to immature technologies [7].

The LMP is a data-driven advanced reactor safety evaluation process. This effort seeks to adapt the LMP for application to MSRs by reflecting the current maturity level of MSRs and the anticipated limitations of applying PRA methodologies to the safety evaluation process. Although the complete LMP process can be directly applied to MSRs, factors such as the MSR immaturity, typical multilayer essentially leaktight containment ${ }^{* *}$ configuration, and unresolved issues with applying PRA methodologies to passive systems currently impede the adequate quantification of failure probabilities in this early phases of MSR safety evaluations. As experience is gained with MSR technologies and PRA methods for passive systems mature, higher precision, probabilistically informed processes will be applied to MSRs.

PHA and PRA are similar and differ mainly in a PRA's quantification of risks. The risk evaluation methods in PHA rely on simplified, conservative failure projections rather than detailed uncertainty analysis applied to failure scenarios employed in PRA. RG 1.233 acknowledges that reactor designers might propose to address safety adequacy by adding layers of defense and showing that the facility can contain radioactive materials with a high degree of confidence [6]. The identification of challenges to the physical barriers and the identification and evaluation of dependencies among the barriers would emerge from the PHA.

Conservatively proposed accidents supplemented by PHA provide a near-term option for designers to study their principal design criteria and overall safety case. It allows exploration of MSR safety in the

\footnotetext{
** The term essentially leak-tight derives from 10 CFR 50 Appendix J. Containment layers would be required to be sufficiently leak-tight so that the consequences of leakage would meet acceptable on-site and off-site dose consequence limits (SECY-93-092).
} 
absence of specific design detail and with limited reliability data by focusing on how containment layers perform and interact after postulated events occur.

Beyond basic credibility, the probability of an event occurring is not considered in this early phase of evaluation. The exercise follows the guidance of RG 1.233, which allows reactor designers to demonstrate adequate facility safety by assessing layers of defense, including physical barriers, and showing that the facility will contain radioactive materials with a high degree of confidence. Riskinformed approaches will later focus on demonstrating that unacceptably severe accident frequencies are adequately low. A preliminary accident assessment focuses on demonstrating that the consequences of credible accidents are adequately low; that is, they can be adequately contained.

\section{RATIONALE FOR AN MSR SAFETY ASSESSMENT FRAMEWORK}

Liquid-fueled MSR vendors have stated intentions to submit their designs for safety review within the next few years. ${ }^{\dagger \dagger}$ The DBAs for LWRs are not directly applicable to MSRs. MSR-specific exercises are needed to identify the scenarios being considered and the information needed to ultimately provide reasonable assurance that an MSR facility can be operated without undue risk to the health and safety of the public.

A regulatory framework that has been employed to license NPPs in the United States is the original method, which was based on hazard analysis and bounding accident analysis. It is instructive in the early phases of a design to use this approach to explore how credible accidents could test available containment layers designed to work together to prevent substantial radionuclide dispersal in MSRs.

The US nuclear industry has recommended integrated safety assessment (ISA), which is known as $P H A$ in other industries, for safety analysis of fuel cycle facilities. The technical basis for their recommendation relies on characteristics in fuel cycle facilities that differ from the existing fleet of LWRs but are more closely shared with MSRs.

The most significant difference between reactors and fuel cycle facilities is that fuel cycle facilities do not have large inventories of stored high-pressure fluids (such as water) that could pose a steam pressure transient risk. Fuel facilities do not require large amounts of cooling water to be available to prevent or mitigate accidents. At recycling facilities, although large amounts of radioactive fission products are stored and processed on site, these fission products are not stored in the presence of large energy sources or chemicals that could affect the integrity of the fission product barriers [8].

MSRs can be designed to eliminate or limit the potential sources of pressurization in the reactor primary systems and surrounding containment systems that are inherent to LWR designs; large quantities of highpressure or phase changing fluids and hydrogen production from high temperature water reactions. While electrical power generation cycles will include large quantities of high-pressure fluids (i.e., steam, supercritical carbon dioxide $\left[\mathrm{scCO}_{2}\right]$, or helium) they can be separated from the nuclear island by intermediate heat transfer loops and further protected by mechanisms that prevent pressure transients from propagating toward the reactor.

\footnotetext{
†Terrestrial Energy USA has begun submitting white papers to the NRC in preparation for a 10 CFR 52 standard design approval.
} 
Risk analysis is built upon addressing the risk triplet: what can happen, how likely is it, and what are the consequences? Severe accident analysis is based on positing that the serious credible accidents do occur and then evaluating containment system responses and potential consequences. Exploring this method in early design phases allows consideration of more severe events, while it avoids the principal challenge of quantifying how likely they are. Postulating physically reasonable but non-mechanistically caused accidents remains central to the safety evaluation of non-power reactors [9] and for the siting evaluation of NPPs [10] and can be used for MSRs to gain early insights.

The assessment of a NPP's safety is influenced by the magnitude of the challenge that different safety functions must accommodate and the range of challenges to be accommodated by the safety functions. Developing a bounding safety case is a useful exercise to understand the overall acceptability of an NPP. It enables the assessment of the robustness along the first dimension of safety function performance - the ability to cope with the most severe accident conditions to prevent or mitigate off-site radiological consequences.

However, overly simplistic bounding accidents can be limited in their ability to assess weaknesses in the safety functions that could make an off-site radiological release event more likely. This dimension of reactor safety assesses how a design copes with challenges presented by the full spectrum of accident scenarios that could occur. How a design interacts with a range of different accident scenarios can be different from its response to particular bounding accident scenarios.

LWR PRAs show that there is a spectrum of accident scenarios that might contribute more significantly to public health and safety risk other than a traditional bounding accident scenario. As highlighted by TMI2 , the focus on a limited set of bounding events can detract from the overall safety of a plant. Careful consideration of any safety assessment is required. However, in the early stages of a reactor design, it is useful to consider a simplified severe accident assessment of any reactor design. As a design matures, it is will be necessary to broaden the scope of accidents against which it is assessed to ensure that safety functions are robust.

MSRs are not typically described in the literature with a traditional large, dry containment designed to withstand large internal pressures. Instead, MSR concepts that have been publicly disclosed rely on a system of functional containment whose performance metric would be to adequately limit the transport of radioactive materials to the environment but not necessarily to retain pressure at all phases of operation or an accident. This is discussed extensively in SECY-18-0096 [11] which was a 2018 Staff Requirements Memorandum (SRM) [4] (reflecting the NRC's decision to approve SECY-18-0096). SECY-18-0096 summarizes the concept of functional containment as follows:

Non-LWR technologies have operating conditions, coolants, and fuel forms that differ from LWRs. These differences may allow or possibly require different approaches to fulfilling the safety function of limiting the release of radioactive materials. This has led to describing a "functional containment" as a barrier, or a set of barriers taken together, that effectively limits the physical transport of radioactive material to the environment.

The NRC approved the methodology proposed by the staff in SECY-18-0096 [11] in the 2018 SRM. [4]

The Commission has approved the staff's proposed methodology for establishing functional containment performance criteria for non-light-water-reactors (non-LWRs). The staff should continue to keep the Commission informed as it develops the licensing framework for non-LWRs and should notify the Commission if future policy issues arise as this work progresses. 
It is reasonable to expect that MSR designers will consider a functional containment strategy as part of a process of overall design optimization since MSRs are particularly attractive candidates for this approach.

For beyond design basis assessments, the NRC plans to adopt SCALE, MELCOR, and MACCS to support independent regulatory assessments. This set of tools supports the evaluation of fission product inventories, transport in fuel and away from fuel under accident conditions, and off-site consequence analysis. These assessments are essential for verifying that a given reactor design can meet the derived safety criteria, which are often expressed in terms of off-site doses at a certain distance from the site.

ACRS made several recommendations [12] in light of the likely significant safety margins for advanced non-LWRs, including the following.

- Analyses with lower fidelity are likely to be sufficient to establish the adequacy of safety in design.

- Considering uncertainty in calculations is important due to the likely lack of data for some new designs.

- Some non-LWRs might not require separate codes to perform design basis and beyond design basis analyses.

- The analysis must be complete to ensure that the risk profile is characterized sufficiently and that the most risk-significant scenarios are identified.

The ACRS comments:

The philosophy should be to start simple and only get detailed as needed. If the margins for the new reactors are substantial, simple analyses can confirm that safety is maintained. With some of the new designs and an expected lack of data, a judicious consideration of uncertainty in the associated calculations will be important. An example of an area that affects the complexity of analysis and code use is the issue of design basis accidents (DBAs) and beyond design basis accidents (BDBAs). The continued separation of DBA and BDBA codes may not be necessary for some non-LWRs. Modeling of accident phenomena that occur in LWRs changes significantly from DBA to BDBA regime because of rod ballooning, loss of geometry, oxidation, and meltdown. Some of the advanced reactors may have a much more graceful change in accident space and this should allow one toolset to do all the calculations. This characteristic should enable a great simplification of the analysis.[12]

The ACRS recommends a focus on source term calculations to identify whether or not safety criteria are met. Increasingly more detailed analysis can be developed based on the need for enhanced realism to resolve the true margin to safety criteria.

The best way to approach the stepwise application of increasing detail could be to work the problem backwards. By that we mean start with the source term. Depending on its associated hazard and the ability to mobilize it, a simple bounding analysis could show that safety criteria are met. If not, then stepwise increase the detail and realism of the analysis. [12]

\section{ACCIDENT CONSIDERATIONS FOR GENERIC MSR CONFIGURATIONS}

The application of bounding accident analysis and PHA is applicable to any MSR. The methodology is independent of the fuel salt type, spectrum, decay heat removal mechanisms, containment configuration, and fuel salt and/or cover gas processing. However, the evaluations discussed as an example in this 
document includes the following assumptions about MSR designs to direct and limit the scope of the effort.

- Multiple layers of essentially leak-tight containment will be employed.

- Segmented containment will be employed to limit accident propagation between systems.

- A core catch pan is included to prevent direct fuel salt interaction with concrete.

- First non-salt wetted containment layer will be a material with characteristics similar to stainless steel.

- Rupture disks or other methods will be employed to isolate fuel salt systems for pressure spikes that originate in the power cycle or other connected systems.

- Containments will be designed to minimize the likelihood and impact of fire.

- Large quantities of water (or other phase change/pressure generating materials) will not be used in or near containment. ${ }^{+*}$

- Containment will be primarily below grade.

- Connected fluids are at similar but higher pressure than fuel salt during normal operation.

- Elevation and/or water-tight compartments will be used to minimize flooding vulnerability.

Reactors with these design features would have the following intrinsic favorable safety characteristics:

- the potential for the release of stored nuclear energy is minimized by negative reactivity feedback and by maintaining the core in a peak reactivity configuration during normal operation;

- low system pressures;

- fuel salt with a large margin to boiling, which minimizes its potential for direct pressurization;

- fuel salts in a low chemical energy state that do not react exothermically with environmental materials; and

- limited accident escalation from smaller AOOs by avoiding stored energy sources (chemical, physical, and mechanical) within containment that could be released and cause the cascading failures needed to breach multiple layers of containment.

For this discussion, the following terms are used to define potential barriers to release.

- Fuel salt that will retain portions of radionuclides depending on composition and conditions.

- Primary system boundaries are the innermost containment layers either in direct contact the salt and/or cover gases normally maintained above the fuel salt.

- Reactor primary system containment structures represent intermediate containment layers.

- Reactor facility containment is the outermost containment layer.

\subsection{PRELIMINARY ACCIDENT CONSIDERATIONS FOR MSRs}

\subsubsection{Barrier Integrity and Independence}

Containment-based safety adequacy analysis requires developing sufficient evidence that the functional containment will continue to retain essentially all of the radionuclides during bounding accidents. This requires identification of challenges to the physical barriers and identification and evaluation of dependencies among the physical barriers. The number and characteristics of required physical barriers will depend on internal accident and external event progression. The inherent nature of molten fuel salts allows for the design of containment barriers that will remain chemically inert and at low pressures

\footnotetext{
\#Alternatively, a sufficient amount of cool water might be present so that the fuel salt does not have sufficient thermal energy to cause bulk boiling. This situation is more likely for small reactors.
} 
through any conceivable accident. This is a distinguishing feature of MSRs compared to most large-scale reactor concepts.

The distributed nature of fuel salt enables the possibility of segmenting the containment much as hot cell facilities are segmented, lowering the risk of releasing radionuclides from one segment due to the failure of containment around another segment. The fuel salt itself is a physical (albeit not leak-tight) barrier that retains a substantial fraction of the radionuclides. The vessel, cover gas boundary, and associated piping forms the first normally leak tight containment layer. Note, however, that radionuclides do leave the first containment layer during normal operations via its interface with the gaseous waste handling system. The second containment layer, which is the first containment layer not directly contacting the fuel salt or cover gas, is more typically referred to as reactor containment.

Fuel salt spill accidents are credible for liquid-fueled MSRs. Fuel salt spill accidents could heat the containment atmosphere for non-evacuated containment designs in designs that maintain a normally cooler containment atmosphere. For designs that rely upon RVACS or PRACS for decay heat removal, the environment inside the second containment layer would already be at elevated temperature. An example of PRACS configuration with an elevated temperature containment environment is shown as Figure 1. Many MSR configurations lack substantial shielding between the primary reactor boundary (i.e., the first containment layer) and the second containment layer.

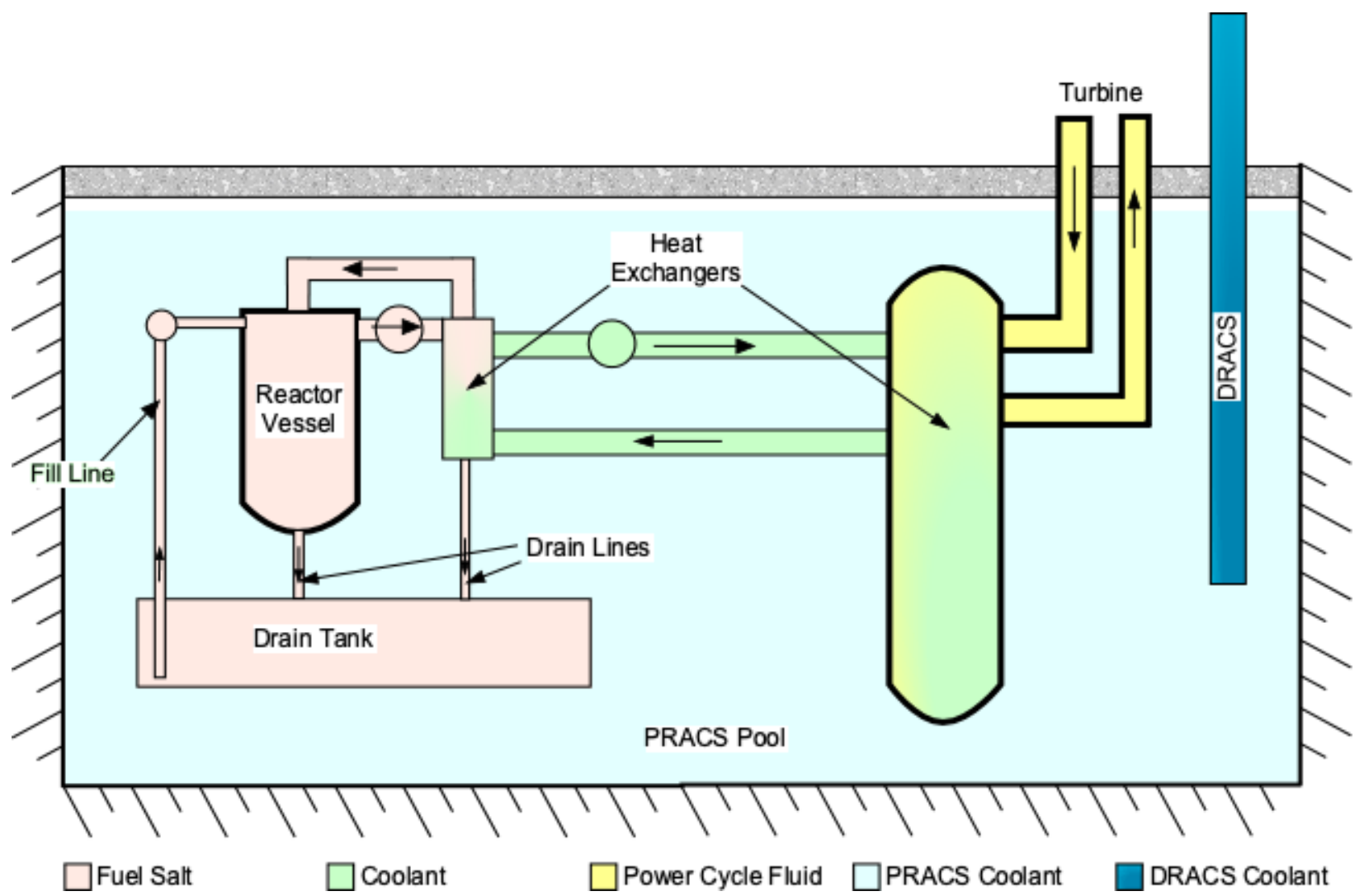

Figure 1. PRACS and drain tank for decay heat removal.

The combination of elevated temperature and high radiation dose within the reactor containment layer necessitates employing high-temperature, high-radiation dose tolerant materials for the second 
containment layer (e.g., metals and ceramics). The second container layer will be technically similar to a vessel and piping system. Consequently, its requirements will resemble those for other safety-related vessels and piping systems. A similar approach is being employed by NuScale with its integrated containment vessel and also in hybrid pool-loop SFR designs [13].

The acceptable amount of containment barrier leakage will be dependent on the safety implication of the leak. For example, leaks of inner containment layers that do not result in significant pressurization of the next containment volume have smaller safety implications because they do not cause increased stress on the next barrier. Leakage is driven by pressure or concentration differences across or through the barrier. Consequently, leakage rates include both quantity of leaking (e.g., $0.1 \% /$ day) and a pressure difference specification. The MSRE assumed a $1 \%$ per day leakage from its secondary containment layer to the surrounding reactor building when pressurized to peak accident pressure.

All of the postulated severe accidents start with failure of the fuel salt or cover gas boundary. Consequently, the fuel salt system boundary is not credited in bounding accident safety performance apart from not failing in a manner that damages the adjacent containment layer. The exterior containment layers perform safety functions under bounding accident conditions and, consequently, have safety-related performance requirements.

One of the key issues in maintaining reasonable assurance of the continued performance of functional containment is assessing the impact of aging, use, operations, and maintenance on the barrier layers. Pressure testing is typically used to verify that new, modified, aged, or repaired boundaries can withstand their rated pressure and are leak-tight. The principal normal operations stressor on the second containment layer is radiation from the fuel salt and/or cover gas. Otherwise, the materials (mainly metals and ceramics) that comprise the second containment layer are not exposed to conditions that result in performance degradation during normal operations. Surveillance coupons can be employed to validate material continued adequate material properties (MPs). Unstressed metal and ceramic piping systems have very long lifetimes. Validation of continued containment performance would, consequently, only be needed periodically or upon barrier modification. A strict penetration control and monitoring program is assumed.

The second containment layer is assumed contained within a third barrier layer, typically thought of as a reactor building. The interface between the second containment layer and this third layer determines anticipated loadings entering the third layer and therefore help to establish its functional requirements with respect to containment during accident scenarios. The operating conditions outside of the second containment layer are assumed much less severe than inside the second containment layer by design. The third containment layer is also more likely to contain typical building services which could lead to the potential for more complex interactions. The leakage rate from the third containment layer must also be well understood and controlled. Seals on containment layers outside of the second containment layer are likely to resemble conventional air-lock systems as they would not be anticipated to be exposed to high temperatures or radiation under normal operations.

\subsubsection{Potential Severe Accident Scenarios}

Assessing what can go wrong is typically based on a detailed mechanistic evaluation of the specific plant design and vulnerabilities by an expert panel. A limited initiating event identification workshop for a generic liquid-fueled MSR was held in 2019 [14]. However, for this discussion, accidents are postulated accidents without a mechanistic origin. Accidents are not required to have a specific cause. Both NUREG 1537 and 10 CFR 100.11 employ bounding accidents to assess siting acceptability. However, neither relies on mechanistic initiating events for their bounding accidents. Instead, they postulate that the event has occurred. 
NUREG 1537 does not provide specific guidance on how to select the maximum hypothetical accident, but it does require that enough events be considered to include any accident with significant radiological consequences and that the rejection of potential events be justified in the discussions [15]. NUREG 1537 also indicates that the maximum hypothetical accident should bound all credible potential accidents yet be an event that is unlikely to occur. The MSR safety adequacy discussion in the next section follows the guidance of NUREG 1537 by discussing why alternate events are rejected as bounding. Significant safety aspects of the MSR SSCs with passive decay heat rejection and multilayer containments result from their common characteristics. However, specific accident sequences for any reactor design will be dictated by its design and construction. Consequently, a design-specific discussion of the rationale for the exclusion of events as bounding events would be expected for each license application.

The primary FSF is preventing the release of radionuclides. The evaluation discussed is a search for accidents that result in the potential failure to achieve this FSF. Defense in depth involves a multilayered containment strategy to achieve the primary FSF to retain radionuclides. Much of the expense of employing a multiple, independent layer containment system for high-pressure reactors comes from the potential for the pressure-driven failure of an interior layer to stress adjacent outer layers. Therefore, maintaining low pressure within each containment layer throughout all credible accidents is key to avoiding cascading containment layer failure.

The MSRE's general design considerations began with the requirement that the "containment be adequate to prevent escape of large amounts of radioactivity to the surrounding area during operation and maintenance and in the event of any credible accident" [16]. The MCA for the MSRE was having fuel salt spill out of the primary system onto the intermediate containment floor along with rupturing the containment floor water-cooled shielding layer or other component cooling water lines. This accident would have resulted in a containment pressure spike due to steam formation that was to be minimized by a rupture disk bursting, providing access to a suppression pool and downstream vapor retention tank [16].

Radionuclides were modeled to be released from the exterior containment due to leaking at an assumed rate of $1 \%$ per day at peak accident pressure into the reactor building, the outermost confinement layer. The reactor building was normally vented up the stack by using a fan. Significant releases to the environment required the building ventilation fan to not be shut down in response to the accident. In other words, the MSRE MCA was for two independent containment failures compounded by actively venting the leaking radionuclides.

Similar to how the basic heat generation and transfer processes are common to MSRs, a comparable reasoning is applicable to selecting the severe accidents for modern MSRs with a notable difference between the MSRE and modern MSR concepts in the lack of a power cycle on the MSRE. Power cycles will have significant quantities of high-pressure fluids presumably separated from the inner containments by heat transfer loop(s). Thus, a reasonable presumed MSR design criterion is to provide adequate overpressure protection to prevent high-pressure power cycle fluid from rupturing any containment layer. Rupture disks, a proven high-reliability technology, can be used to achieve this.

More generally, an MSR safety design criterion would be to avoid the generation of significant quantities of phase-change or high-pressure materials (e.g., water) that could significantly interact with fuel salt, even in the event of a dual failure. In this case, a significant quantity is defined as an amount that would cause the pressure to rise sufficiently to challenge a containment layer.

Two coincident independent failures, including the potential for the failure of the barrier layer in contact with each significant quantity of radioactive material, are proposed as a conservative severe accident class for preliminary MSR safety evaluation. If chosen correctly, two independent failure criteria are more conservative than the "single equipment failure or operational error that would result in the most 
hazardous release of fission products" [17] that AEC initially promulgated as adequate for reactor site selection.

The simultaneous failure of all containment layers between the source and environment would be required to release significant quantities of radionuclides. The generation of pressure differentials across barriers would also be required to cause the substantial transfer of radionuclides between containment layers and for the possibility of cascading containment layer failure.

The MSRE design would not have continued to fully achieve the FSFs following a two independent failure accident because it only had two leak-tight containment layers within an actively vented confinement: the reactor primary boundary and the reactor containment volume. However, the external confinement of the MSRE could have provided significant source term reduction if designed to do so.

It is reasonable to assume dual failure accident progression models to perform early safety assessments if they can inform containment performance during and following severe accidents. Failure to credit the structure in direct contact with the radioactive materials (i.e., fuel salt or cover gas) during normal operations for safety adequacy evaluation provides substantial design flexibility and the potential for cost reduction. The NuScale design team's decision to employ a qualified pressure vessel as the second container layer provides an example of the implications of the shift in safety roles among multiple containment layers. Similarly, reactors that employ tristructural-isotropic fuel primarily credit the radionuclide retention provided within the fuel particles, affording additional design flexibility to other SSCs.

\subsubsection{External Events}

New reactors are required to withstand credible site-specific external events, including flooding, earthquakes, tornadoes, seiches, and large civilian aircraft impact. The requirement to withstand large civilian aircraft impact (10 CFR 150) provides strong economic incentive to locate low-pressure containments below grade. The expense of constructing aircraft impact resistant structures above grade has generally led to the below grade placement of emerging advanced reactors that do not otherwise require high-pressure containments.

MSRs will require shielding between the fuel salt and cover gases and the workers, sensitive equipment, and environment. In practice, this implies that substantial mass will be needed above the fuel salt circuit. The shielding mass - whether in the form of an earthen berm, coolant salt pool, or solid shielding blocks - could also serve to absorb and/or deflect impacts from above. Underground structures exhibit excellent earthquake performance because they are constrained and supported by the surrounding medium (i.e., soil or rock) and generally do not move independently of the medium or are subjected to vibration amplification [18] [19].

By definition, passively safe reactors [20] do not require connection to outside services, such as electrical power or cooling water, so they are not vulnerable to indirect external events that could remove access to external services but do not affect external containment. To be passively safe, MSRs must continue to reject decay heat to the environment following external events, assuming that the reactor is shut down. MSRs can reject decay heat to outside air, water, or ground. Credible external events that could impede decay heat rejection to the environment include large civilian aircraft impact, flooding, and earthquakes.

The inherent characteristics of MSRs (e.g., quantity of heat being produced, thermal storage potential within containment, practical temperature limits of engineering materials) dictate how decay heat can be passively transferred from the fission products to the environment. As with any fission reactor, immediately following shutdown after extended operation, the fission products produce $\sim 7 \%$ of full 
power. For the MSRs that rapidly and proactively remove and isolate fission gases, roughly $40 \%$ of the decay heat could be generated in the cover gas handling and storage systems. This reduces the cooling needed in the reactor core but adds locations that need passive cooling.

Roughly 1 day after shutdown following extended operation, decay heat production from a reactor is reduced to $\sim 1 \%$ of full power. For a large reactor $\left(2,500 \mathrm{MW}_{\text {th }}\right)$, several tens of megawatts must be rejected for days. Even medium-sized reactors $\left(500 \mathrm{MW}_{\text {th }}\right)$ require an extended heat rejection capacity on the order of a few MWs.

Radiative heat transfer can be effective for transferring heat from hot salt or the reactor vessel to lower temperature systems. However, megawatts of heat cannot be readily transferred across multiple barriers by conduction or radiation without unacceptably raising the driving temperature. This creates the likely need for a moving fluid (i.e., thermal hydraulic) heat transfer system. Passive heat transfer within and from containment can be performed with natural circulation heat exchange loops or heat pipes.

Practical heat rejection to air generally employs a structural chimney to drive natural air circulation past an air draft heat exchanger. MSR chimneys must be mechanically robust to withstanding severe natural phenomena such as tornadoes and airborne missiles. Large civilian aircraft impacts, especially engine impacts, could damage or destroy even a reasonably robust chimney or cooling tower. The principles of separation and redundancy can be considered to limit the loss of multiple cooling towers to the point where inadequate decay heat removal would not occur.

Surface flooding and water table rise have the potential to increase the heat transfer from external natural draft heat exchangers so much so that the heat transfer fluid could freeze, block flow and reduce cooling. Flooding could also simultaneously damage equipment used in normal operations for heat rejection. Airbased natural circulation heat rejection systems can be hardened against flooding by locating the air contact heat exchangers in watertight compartments and by elevating both the air inlet and outlet well above the height of any credible flood. Floodwaters also must be separated from the fuel salt by multiple barriers in order for an MSR to continue to fulfill FSFs following barrier failure accidents during a flooding event.

Water in cooling ponds or tanks can also be used as a heat sink for MSR decay heat rejection. Cooling ponds must be adequately separated by multiple barriers from the fuel salt to avoid the potential of water entering and potentially pressurizing containment layers. Multiple redundant water-cooling systems can be employed to avoid single failure vulnerability, and to limit the amount of water available in a single system to escalate an accident.

As with all reactors, MSR cooling towers and cooling ponds must be robust against earthquakes. The engineering principles for hardening chimneys against earthquakes are well known. Verifying adequate seismic design and construction would be part of an MSR licensing process.

\subsubsection{Internal Events}

MSRs only necessarily have two appreciable sources of labile radionuclides - the fuel salt and the cover gas. To release fuel salt or cover gas radionuclides, all of their containment barriers must either fail or be bypassed.

MSRs that employ previously used reactor fuel as their fissile material source must consider bounding accidents related to incoming fuel. Used fuel salt containing substantial amounts of radionuclides may be in multiple locations within a MSR plant and failure of used fuel salt containment could constitute a bounding accident. MSR designs that perform on-site fuel salt processing can also have substantial 
amounts of labile radionuclides in the fuel processing system and must consider failure modes of the fuel processing system as a potential bounding accident.

Failure of the reactor vessel is simply the most rapid means for most of the fuel salt to escape the innermost containment. Although MSR vessel failure would be unlikely, it is credible, and as such is perhaps the best candidate for a bounding event.

To release radionuclides into the environment after a vessel failure an accident must cascade to breach or bypass all remaining containment layers. An MSR's lower pressure and the potential for a lack of significant water within containment can reduce the potential for energetic release resulting from internal accidents. Steam explosions, hydrogen explosions, pipe whip, etc. are not likely for low-pressure reactors that lack significant quantities of water within containment.

The only large moving components connected to the fuel salt are the primary system pumps. Fuel salt pump mechanical failures must be included in the analysis of possible accidents that could damage containment layers. The power cycle will also include large, pressurized equipment with substantial kinetic energy. The reactor containment needs to be adequately separated or shielded from power cycle components that could generate energetic projectiles.

A layer beyond the reactor primary boundary (the innermost containment layer) is not normally stressed or exposed to fuel salt or vapor. It can likely to be made from a commonly used structural metals, like stainless steel, due to reasonable costs, availability, and well-known performance characteristics. Stainless steel containers are highly thermal-shock resistant for situations such as a rapid exposure to fuel salt that could occur from a large failure or direct spray from smaller break [21]. The fabrication of an adequately qualified containment layer that is not normally exposed to fuel salt, high temperatures, or too much radiation damage, and is used in conjunction with a well-designed primary boundary system may be less costly than qualifying an MSR fuel system boundary equivalently to that of an LWR.

MSRs generally should avoid internal stores of other nonthermal energy (i.e., chemical, kinetic, and/or potential), such that the loss of fuel salt from the reactor primary boundary will not be able to challenge the adjacent containment layer.

\subsubsection{Bypass}

MSRs will need provisions to prevent significant quantities of radionuclides from bypassing containment layers. This discussion focuses potential piping configurations connecting heat transfer systems across containment layer boundaries but there may be others to consider. In a system with an intermediate heat transfer loop, fuel salt might only be separated from the intermediate coolant by thin-walled heat exchanger boundaries. The same loop connects to the power cycle on an outer containment layer. Failure of the primary heat exchanger walls could provide a direct path for fuel salt radionuclides to bypass two interfaces; that is, an entire containment layer. Therefore, rupture of fuel salt heat exchanger boundaries are strong candidates for severe accident evaluation. (The consequences of fuel salt heat exchanger tube ruptures were investigated during the MSBR design [22] but were not considered safety significant because the coolant-salt piping contained the emerging radionuclides.)

Bypass could also happen in reverse with coolant fluid being driven into containment. High-pressure fluids should not have a credible means to significantly interact with the fuel salt or the primary boundary system or the containment could become pressurized resulting in pressure driven radionuclide dispersal beyond the innermost containment barrier. However, as halide salts are in a low chemical energy state, they should not vigorously react with any of the common power cycle fluids. 
During maintenance activities, outer containment layers might be opened, and large openings might be necessary to introduce or remove components. Adequate safety physical and administrative measures must be in place to prevent the escape of significant quantities of radionuclides due to events that could occur when outer containment hatches are open for maintenance.

\subsubsection{Failure of the Innermost Containment Layers}

Accident sequences are discussed at a conceptual level in this section and are organized based upon containment failure location. The failures described are postulated, not mechanistic. The individual containment failures are subdivided into a set of assumed safety significant design variants (e.g., the capability for decay heat removal following a bounding accident depends on the method of decay heat removal employed). The accident sequences considered explore how accident progression could challenge remaining containment layers (challenging the radionuclide retention FSF), challenge the ability to reject decay heat removal, or prevent inadvertent criticality. The discussed accidents sequences are intended to (1) illustrate how MSRs have the potential to continue to perform FSFs following severe accidents and (2) identify the data and models needed to credibly evaluate the safety performance of specific designs.

\subsubsection{Fuel Salt Loop Rupture}

Accident sequences for fuel salt loop failure are dependent on the location of the failure. The fuel salt system can fail near its hydraulic top, middle, or bottom. Failure of ex-vessel fuel salt loop piping (if part of the design) would be analogous to failure of a reactor vessel near the hydraulic top, so is not differentiated in the high-level accident sequence. Fuel salt above a breach would drain from the loop. If the fuel salt pumps are not shut down, they will continue to drive fuel salt out of breaches until losing prime. Failure above the liquid fuel salt fill line is a failure of cover gas containment and only vapors and aerosols would be lost. Failure near the hydraulic middle results in partial loss of fuel salt whereas failure near the bottom or gross vessel rupture results in loss of most or all of the fuel salt.

Failure of a primary heat exchanger boundary could allow coolant fluid (which may or may not be a salt) to mix with fuel salt. The coolant would typically be at a higher pressure than the fuel salt to ensure that flow is inward, maintaining the radionuclide retention FSF. A second break in the fuel salt loop would be required to leak most of the coolant into containment as inflow would stop once the fuel salt loop is filled to capacity or the pressure between the systems equilibrates. If the power cycle heat exchanger were to also fail, the intermediate heat transfer coolant could experience a pressure spike until the pressure is relieved. Pressure relief could leave a pathway through the coolant and failed primary heat exchanger for radionuclides to escape. Models for mixing of fuel and coolant (especially before pump shutoff) would be required to assess the potential release of radionuclides in this case.

Directly pouring large amounts of fuel salt directly onto concrete could result in concrete dehydration and gas and aerosol generation, which could increase radionuclide mobility and containment pressurization. Thus, a guard vessel, with some type of core catcher, is a likely element of a MSR and for this discussion is presumed to be a second, essentially leak-tight, containment layer. With a guard vessel, a leak would result in a fuel salt being spilled or sprayed directly onto the guard vessel material. A core catcher would be within or form the bottom of the guard vessel. Decay heat could be removed from the spilled fuel salt either by directly cooling the fuel salt, the guard vessel, or the core catcher, or by transferring the heat from the guard vessel and core catcher to the walls of the next external containment layer, which would in turn require cooling. (Any underlying concrete must remain well below the boiling point of water.)

MSRs could also use gravity-fed subcritical drain tank(s) for the fuel salt and the guard vessel or core catcher can be sloped to allow spilled fuel salt to flow into the tanks. The fuel salt decay heat must be 
removed regardless of whether the salt remains in the fuel salt loop or has been spilled into the guard vessel, core catcher, or drain tank. Estimates of how much salt could collect at any location will need to be made as part of a safety assessment.

Accident progression following fuel salt loop rupture depends on the configuration of the passive decay heat removal system. Passive decay heat removal mechanisms are grouped here according to their means of thermal coupling to the fuel salt [23]. Direct Reactor Auxiliary Cooling Systems (DRACS) couple to the fuel salt via direct contact with the fuel salt or reactor vessel (i.e., heat exchangers inside the reactor vessel or part of the reactor vessel) and/or drain tank. DRACS usually employ natural circulation to transfer the heat to an environmentally coupled heat exchanger [24]. Reactor Vessel Auxiliary Cooling Systems (RVACS) rely on radiative heat transfer from the reactor vessel, spilled fuel salt, or drain tank and (usually) convective heat transfer by a containment atmosphere to remove heat from the vessel. Pool Reactor Auxiliary Cooling Systems (PRACS) immerse the fuel salt loop in a tank or pool of liquid coolant (typically a different salt) to provide shielding during operation and additional thermal mass for extended coping times during accidents. PRACS systems eventually transfer decay heat to other heat removal system (DRACS or RVACS).

DRACS systems that couple to the fuel salt via a heat exchanger high in the reactor vessel could cease to provide adequate heat transfer for primary system leaks that occur at the hydraulic middle or bottom of the fuel salt loop. A closely fitting guard vessel, along with adequate fuel salt volume, can ensure that the DRACS heat exchangers remain immersed. Alternatively, a gravity drain system from the vessel and core catcher into passively cooled drain tanks could be employed to provide continued fuel salt cooling. Failure of DRACS heat exchanger boundaries in contact with the fuel salt would allow mixing of the DRACS coolant with the fuel salt through draining of the DRACS loop via gravity but should leave the environmentally coupled heat exchanger tubing as an intact, unstressed barrier to radionuclide release. The environmentally coupled heat exchanger may be enclosed within a tank providing a third radionuclide release barrier. DRACS coolant should be physically and chemically compatible with the safety functions of the fuel salt. For example, mixing with the fuel salt should not result in chemical reactions or cause fissile materials to precipitate out.

RVACS systems reject decay heat through cooling the wall of an exterior containment layer. Heat is coupled to the wall both radiatively and via natural convection of the containment atmosphere. Radiative heat transfer increases with absolute temperature to the fourth power and becomes increasingly and immediately effective as the temperature of the fuel salt and reactor vessel exceeds $\sim 700^{\circ} \mathrm{C}$. RVACS cooled systems do not insulate the reactor vessel as this would defeat their function. RVACS systems can include the guard vessel or a core catcher as radiative heat transfer can occur from a guard vessel or the surface of a spilled salt pool. Systems that employ a guard vessel with a RVACS may need to accommodate the reactor vessel reaching a higher temperature in the event of a loss of offsite power event as the guard vessel serves as a heat baffle between the intact reactor vessel and cooled wall. Radiative cooling of a spilled salt pool could be impeded by any optical absorbers in the containment atmosphere such as mists or smoke particles. Consequently, the potentially salt-contacted surfaces for inner containment rupture accidents in RVACS cooled systems would be selected to avoid vapor or particle generation when contacted by hot fuel salt (e.g., stainless steel).

The heat transfer characteristics from spilled fuel salt pools have significant remaining uncertainty. Mechanisms that could impede radiative heat transfer such as a cooler, opaque crust forming on a spilled salt pool or production of aerosols from the surface of the pool, are insufficiently understood to accurately model. Additionally, the fuel salt could form a frozen layer on the bottom surface inhibiting natural circulation or blocking flow to drain tanks. Models for more complex configurations, such as multiple fluids leaking and mixing, might require development and validation. Models for fuel salt flow and freezing on cool surfaces also have significant remaining uncertainty. Fluid in an RVACS cooling system 
can be a liquid or a gas. The RVACS loops may be open or closed, meaning that they reject heat to the environment (open) or another loop (closed). During power operation neutrons may impact the RVACS fluid to cause activation. Argon-41 activation would be a specific concern for an open, air-cooled loop.

PRACS transfer decay heat to a larger vessel of liquid (likely salt) that surrounds the fuel salt loop (potentially including drain tanks). PRACS systems provide a substantial amount of thermal mass, limiting the rate of temperature rise following a fuel salt loop rupture. In a passive system, heat is coupled from the PRACS pool to the environment using other natural circulation loops (i.e., via a DRACS or RVACS system). The initial stages of the cover gas management system can also be immersed in the PRACS pool to provide decay heat removal.

MSRs can operate with limited excess reactivity due to the ability to add or remove liquid fuel as needed. Fuel salt leaks will tend to drive the fuel salt into a less neutronically efficient geometry. The reactivity of the salt remaining in the reactor may or may not reduce the power level of the reactor depending on the amount of fuel salt lost. Fuel from thermal spectrum reactors is unlikely to become critical outside of the core due to the need for an optimized moderating geometry to achieve criticality. Fast spectrum reactor fuel, because of its higher fissile material content, could become critical outside of the core if moderation is somehow provided. Consequently, fast spectrum reactors may need to consider both neutron absorber materials and sub critical geometry for spilled salt.

\subsubsection{Cover gas system rupture}

An MSR's cover gas system will contain the radionuclides emerging from the free surface above the fuel salt. The noble gas yield is nearly one atom from each fission. Since each megawatt-day of thermal power requires the fission of approximately one gram of actinide material, a large MSR ( $1 \mathrm{GWe}$ ) would produce slightly more than a kilogram of noble fission gas per day or about 210 liters of noble gas per day at standard temperature and pressure. The off-gas total decay heat load for the MSBR (a large MSR) was estimated to be $21.3 \mathrm{MW}$ with roughly $9 \%$ entrained as aerosols or mists, almost $80 \%$ of the gaseous heat load generated in the first hour following release from the fuel salt, and well less than one percent of decay heat remaining in the gas stream after two days [25].

Generally, MSRs have two cover gas system design variants relevant to accident progression. In one, the fission gases are removed from the reactor vessel after a period of decay. The removal is to primarily avoid pressurization of the fuel salt circuit. Gas transport delay can be accomplished by providing a flow resistant escape path within the reactor vessel (for example through a multi-chamber or baffled pathway). Holding the gaseous fission products within the reactor vessel can significantly reduce the decay heat removal requirements for the emerging fission gases. The other design alternative is to immediately and proactively remove gases emerging from the fuel salt from the reactor vessel. This design slows the buildup of fission products in the salt and reduces the quantity of labile radionuclides within the vessel.

Although removing radionuclides from the vessel decreases the inventory that can be released in the event of a core-related accident, the radionuclides will be in the cover gas handling system, increasing its decay heat removal requirements and the potential severity of the consequences of a cover gas system leak. 
Two predominate methods have been proposed to delay and treat the emerging gas stream:

(1) a combination of mechanical filters, a $\sim 2$ hour delay tank, and a series of activated carbon beds, or

(2) a caustic scrubber followed by one or more activated carbon beds for which the long-lived ${ }^{85} \mathrm{Kr}$ $\left(t_{1 / 2}=10.76 y\right)$ would be separated and sequestered for decay.

A breach of the cover gas system could cause stress on the next containment layer through the following:

- increasing internal pressure on the next containment layer;

- bursting the cover gas system, resulting in thermal and/or mechanical shock;

- corrosion;

- indirectly through reaction with other materials within containment;

- overheating of the next layer; or

- admitting oxygen or water into the carbon bed (oxidation).

Cover gas piping can build up pressure after plug formation from deposited material and progressively build up pressure within the reactor vessel. The potential for the build-up of material in the cover gas lines suggests that capability must exist to detect the build-up and correct it as part of normal operations, perhaps mechanically. Some products in the off-gas stream will be chemically reactive.

Rupture of off-gas systems could provide an escape path from the innermost containment layer and, so could constitute an element of a bounding accident. The vapors, aerosols, and mists emerging from the fuel salt may include both suspended noble metal particles (noble meaning insoluble in fuel salt) and fuel salt droplets [26], which may require cooling to remove decay heat. Release of cover gases that have not adequately decayed could necessitate cooling the next containment layer.

Caustic scrubbers, mechanical filters, and activated carbon beds were all demonstrated as part of the historic MSR program [27][28] and recently reviewed under the DOE MSR campaign [29]. The upstream portions of the cover gas system could have a significant thermal load during normal operations and thus require an active cooling system and potentially passive cooling. Rupture of a scrubber could cause the caustic soda and its radionuclide inventory to be released, potentially thermally, or mechanically, or chemically affecting the next containment layer. The caustic scrubber and its piping must be resistant to corrosion from the molten caustic, as does the facing surfaces of the next containment layer. High-nickel alloys are excellent material candidates for a caustic scrubber and piping due to corrosion resistance [30], and stainless steel is an excellent candidate for the next containment layer due to its availability, reasonable cost, thermal shock resistance, and acceptable short-term corrosion performance.

Decay of radionuclides in fuel salt vapors can add heat to all of the elements of the cover gas handling system and activated carbon could react if heated in the presence of oxygen. The MSBR design called for piping containing the carbon beds to be immersed in an unpressurized water tank to isolate the beds from oxygen and to cool the system, precluding the possibility of ignition. This is not likely to be employed in modern MSRs, however, because of the risk of leakage from the water into the cover gas system.

Segmenting containment is a key conceptual underpinning of functional containment. The cover gas piping may pass out of the liquid fuel salt containment cell before beginning to be cooled by water to minimize the potential for water entering and pressurizing the fuel salt containment cell. Rupture of the carbon bed piping could allow radionuclides to pass a cooling water tank if used. To maintain defense in depth, the cooling water tank may need to be sealed or be within another credited containment layer. Both caustic feed and removal lines, as well as coolant lines, could provide pathways to bypass containment 
layers, and so may require mechanisms to prevent radionuclide releases during off-normal conditions such as valves that close upon loss of power. Maintenance activities (e.g., for filter replacement) also could temporarily reduce the number of barriers to radionuclide release. Plant maintenance must be thoroughly considered in the safety assessment.

\subsubsection{Fuel Processing System Failure}

The fuel processing systems of MSRs can vary significantly with the fuel system design. For example, a fast spectrum breed and burn MSR operating on a U-Pu fuel cycle may require little (if any) fuel processing beyond perhaps redox adjustment to compensate for fission being an oxidative process. In contrast, a single-fluid, thermal-spectrum MSR operating implementing a Th-U fuel cycle will require substantial fuel salt processing to achieve breeding gain.

Fuel processing may likely be performed in containment cells separated from the reactor core to minimize the potential for disruptions in one system from affecting the other.

The safety of separated MSR fuel salt processing facilities might normally be evaluated for licensing purposes using augmented PHA as described NUREG 1513 as is routinely done for traditional fuel processing facilities. However, the proximity to and integration with an operating reactor requires consideration.

The potentially corrosive agents that were planned for use in the MSBR fuel processing system included fluorine gas, hydrogen fluoride, and liquid bismuth. Introducing these into the fuel salt loop could corrode the container alloy. Excessive amounts of fissile material could be returned to the reactor core (causing a reactivity excursion) through rapidly introducing fissile materials that have been stored or inadvertently accumulated in the fuel processing system.

The MSBR planned to employ quasi-batch processing by extracting a bypass stream of salt into an accumulation tank and then processing the salt in the filled tank as a batch. The MSBR design incorporated a number of safety features [31].

- "Drain tanks, connected to the process via freeze valves, are provided for all process vessels and lines" [115].

- "A separate, passively cooled floor drain tank is provided" [115].

- "All process lines are sloped to be self-draining" [115].

- “All pumps, valves, and vessels are cooled with an active NaK system" [115].

- "Drain tanks incorporate a passive NaK cooling system" [115].

- "Cells are run at a slight negative pressure with all venting through a central off-gas management system” [115].

Processing schemes that are substantially different from those planned at the MSBR are possible (e.g., employing high-temperature distillation or electrorefining). However, a distinct advantage of isolating the chemical processing system (no matter the design) from the fuel salt loop is that accidents within one system can only affect the other via the connecting piping.

\subsubsection{Used Fuel Salt Storage System Failure}

Used fuel salt will contain safety significant quantities of radionuclides. MSRs might employ previously used fuel in their feed fuel, in which case all of the on-site fuel salt must be addressed as part of achieving the FSF to retain radionuclides. 
MSR fuel salt can be reused indefinitely provided it has adequate fissile content has not sufficiently changed to prevent it from performing its functions. Consequently, MSRs do not necessarily have an equivalent to semi-permanent spent fuel storage. Nevertheless, MSR fuel salt must be stored between uses. Processing may be performed off-site, requiring fuel salt to sufficiently decay to permit transportation before off-site processing. Additionally, the radionuclides that separate from the liquid fuel salt (gases, vapors, and insoluble materials) require containment. Used fuel salt will require cooling while in storage. Used fuel salt containers may be stored in a cooling pool similar to that employed to hold spent LWR fuel.

At sufficiently low temperatures recombination no longer dominates salt radiolysis and fuel salts can generate fluorine or chlorine gas (depending on their composition) pressurizing their storage containers. If the fuel salt is subsequently reheated to mobilize the frozen materials, the fluorine gas can react with uranium fluoride in the fuel salt and may generate gaseous $\mathrm{UF}_{6}$, which could then migrate to a location with conditions favorable for criticality [32]. In contrast, chemical recombination of uranium into other solid forms does not significantly affect the potential for off-site dose.

\subsubsection{Demonstration of Adequate Safety following Severe Events}

The bounding accident evaluation portion of an MSR SAR begins with a list of bounding accidents identified for the plant. A preliminary set of bounding accidents for any individual plant can be developed (as described in preceding sections) by postulating the failure of the innermost containment layer at each location at the time when the location contains its maximum quantity of labile radionuclides - i.e., drain tank fails immediately following draining. An accident is then exacerbated by postulating another independent failure, creating a dual simultaneous failure.

NPP accident progression is typically represented using event trees that show the sequence of barriers and/or mitigating factors that must fail for radionuclide release to occur. Under the proposed early phase safety evaluation approach for MSRs, event trees would be developed for each postulated, bounding accident. The event trees would include the barriers and mechanisms designed to fulfill of each of the FSFs - radionuclide retention, decay heat rejection, and reactivity control. As proposed, failure events are postulated, not mechanistic, so fault trees need not be developed for early assessments, but they can be.

Effectively modeling the transport of radionuclides in an MSR severe accident conditions requires understanding the condition and properties of the plant safety related SSCs and knowing the radionuclide inventory, their chemical and physical states, and location at the start of the event. Developing adequate knowledge of the state of radionuclides during normal operations involves the use of a specialized set of tools and processes. Adequate knowledge of fuel salt performance under both normal and accident conditions is developed through fuel salt qualification (a process currently under development). Validated reactor physics tools, particularly those familiar to the NRC, as largely available but may require some modification. The SCALE [33] code suite can be employed to provide information about how many radionuclides have been generated and consumed through reactor operations. Hydraulics codes, such as TRACE [34], provide information about the fuel motion and heat transfer. The NRC's PARCS reactor physics code does not currently include the capability to perform transport of delayed neutron precursors, so must be modified adequately model MSR reactor physics if it is to be used.

Radionuclide tracking/accountancy is a distinctive modeling capability required to accommodate liquid fuel. Radionuclide accountancy is fundamentally different with liquid fuel as the fuel moves and radionuclides can be both added to and removed from the fuel during power operations. Tracking radionuclides includes tracking fissile materials, which is a central element in assuring that fissile materials have not been diverted from peaceful uses. Hence, radionuclide tracking tools will serve multiple purposes for MSR design and evaluation. 


\section{MST MODELS FOR MSRs}

Source term calculations model the phenomenological processes and radionuclide transport from event sequences within volumes and across barriers. Source term models are complex, and simplified calculations can be accompanied by significant uncertainties in source term evolution. As the event sequences move from the anticipated operational occurrence (AOO) region to the design basis events (DBE) region and the beyond DBE (BDBE) region, the uncertainties associated with consequence calculations generally become larger.

Mechanistic Source Term (MST) calculations must use best-estimate phenomenological models of radionuclide transport from the fuel to the environment, taking into account the mitigation features and barriers. The NRC has approved employing MST at advanced reactors provided that the reactor, fuel, and accident progression are adequately understood [35], stated as follows.

1. "The performance of the reactor and fuel under normal and off normal conditions is sufficiently well understood to permit a mechanistic analysis" [96].

2. "The transport of fission products can be adequately modeled for all barriers and pathways to the environs, including specific consideration of containment design" [96].

3. "The events considered in the analyses to develop the set of source terms for each design are selected to bound severe accidents and design-dependent uncertainties" [96].

One challenge of developing MSTs for MSRs is that it requires collecting new data and possibly developing new modeling tools or significantly altering existing codes. A robust experimental program to obtain the fundamental chemical and transport data needed to implement mechanistic models is a priority. Initial work defining data needs for the development of an MST model for liquid fueled MSRs was discussed in Jerden et al. [36], and an experimental program providing the type of thermophysical and thermochemical properties information and modeling tools was implemented within the Molten Salt Reactors Campaign.

Source term estimation is essential for reactor licensing [37] and is defined in 10 CFR 50.2 as:

The magnitude and mix of the radionuclides released from the fuel, expressed as fractions of the fission product inventory in the fuel, as well as their physical and chemical form, and the timing of their release.

Source term analyses are used to evaluate the consequences of licensing basis events that involve normal reactor operations, anticipated off-normal conditions, design basis transients, and beyond design basis transient scenarios. Additionally, source term analyses can play a key role in reactor siting and developing emergency planning zones and reactor site boundaries [38] [39] [40]. For new generation MSRs, source term analyses can provide valuable feedback into the design process and facilitate risk-informed engineering decisions [41] [42] [43].

Traditionally, source term analyses for LWRs have used conservative bounding assumptions [37]. However, for a source term analysis to provide useful feedback into the reactor design process and be convincing as a justification for minimizing the size of reactor site emergency planning zones, it must involve realistic (i.e., mechanistic) models that do not require overly conservative assumptions regarding radionuclide release during postulated accidents/transients.

The NRC has recognized the need for MST analyses since the 1990s [38] [39] [40]. Although no formal definition for MST has been established, the NRC has described an MST in SECY-93-092 as [38]: 
...the result of an analysis of fission product release based on the amount of cladding damage, fuel damage, and core damage resulting from the specific accident sequences being evaluated. It is developed using best-estimate phenomenological models of the transport of the fission products from the fuel through the reactor coolant system, through all holdup volumes and barriers, taking into account mitigation features, and finally, into the environs.

Such models are referred to as mechanistic because they take into account the real transport/retention processes (e.g., solubility, precipitation, vaporization, adsorption, aerosolization) based on fundamental chemistry (e.g., thermodynamics, electrochemistry, kinetics).

NRC staff recommendations for new license applications for advanced reactors established the essential characteristics of an MST [38]:

...source terms should be based upon a mechanistic analysis and will be based on the staff's assurance that the provisions of the following three items are met:

- The performance of the reactor and fuel under normal and off-normal conditions is sufficiently well understood to permit a mechanistic analysis. Sufficient data should exist on the reactor and fuel performance through the research, development, and testing programs to provide adequate confidence in the mechanistic approach.

- The transport of fission products can be adequately modeled for all barriers and pathways to the environs, including specific consideration of containment design. The calculations should be as realistic as possible so that the values and limitations of any mechanisms or barrier are not obscured.

- The events considered in the analyses to develop the set of source terms for each design are selected to bound severe accidents and design-dependent uncertainties.

\subsection{HISTORICAL SURVEY OF THE USE OF SOURCE TERM ASSESSMENTS FOR NPPS}

Source term assessment was first developed in the early stages of the US commercial industry in the 1960 s by using conservative assumptions and data that were available at the time. As technology advanced and the state of knowledge improved, adjustments to source term methods were made to stress a more realistic mechanistic approach.

The process of developing source terms was initially very prescriptive and was defined in TID-18444, Calculations of Distance Factors for Power and Test Reactor Sites [44]. It was replaced by a mechanistic process as defined in NUREG-1465, Accident Source Terms for Light-Water Nuclear Power Plants [45]. Both source term characterizations are focused on LWRs and thus are inappropriate for direct application to non-LWRs. Even so, the MST described in NUREG-1465 provides the framework for developing methods and codes, such as MELCOR, for severe accident analysis:

The NRC staff has concluded that an ongoing code development process is appropriate for incorporating new information on non-LWR accident source terms especially as priorities regarding the different technologies emerge. An applicant may propose changes in source term parameters (timing, release magnitude, and chemical form) from those contained in the applicable guidance, based on and justified by design-specific features. Regulatory Position 2 of Regulatory Guide 1.183 [46] provides attributes of an acceptable alternative source term.

The source term described in TID-14844 took an overly conservative and simplistic approach due to a lack of information on the chemical and physical processes that can occur during LWR operation and postulated accident scenarios. For example, radionuclides were assumed to be instantaneously released to 
containment. More realistic models are required for a source term analysis to provide useful feedback into the reactor design process and to justify the size of reactor site emergency planning zones. Considering the significant progress in the technical understanding of reactor accident behavior for LWRs since TID14844 was issued, the NRC recognized the need for and feasibility of a mechanistic approach to source term assessment in the early 1990s and released SECY-93-092 as a result.

\subsubsection{MST Assessment in the Context of Advanced Non-LWRs}

The guidance inspired by TID-14844 and promulgated in RG 1.183 was explicitly for LWRs due to their historical prevalence and market dominance. By definition, the designs of advanced reactors differ significantly from LWRs, and thus the source term approaches historically applied to LWRs are not necessarily appropriate for MSRs. By considering the interest from advanced reactor vendors during preliminary licensing efforts in the early 1990s, the NRC formally addressed the need to develop an MST approach for reactor licensing with the issuance of SECY-93-092 and affirmed their approval for the use of MSTs in licensing decisions related to containment and siting in SECY-03-0047 [39]. The staff noted that MST use would be effort-intensive but necessary for accommodating unique advanced reactor designs that could affect the source term.

With the establishment of the Next Generation Nuclear Plant (NGNP) project under the Energy Policy Act in 2005, the US Department of Energy (DOE) and INL were asked to develop the licensing application, including an MST, for the modular HTGR (MHTGR). In a white paper submitted to the NRC, DOE and INL outlined their anticipated approach for developing an MST for MHTGRs that is generic enough for both possible fuel types (i.e., pebble bed and prismatic block) and proposed an MST for each license basis event [47]. The white paper sought feedback from the NRC on the following issues:

- Issue 1: "Agreement that the definition of event specific mechanistic source terms for the HTGR is acceptable" [47].

- Issue 2: "Agreement that the approach to calculating event-specific mechanistic source terms for the HTGR technology is acceptable, subject to validation of the design methods and supporting data that form the bases of the calculations" [47].

- Issue 3: "Agreement on the acceptability of the approach of the planned fission product transport tests of the NGNP/Advanced Gas Reactor (AGR) Fuel Development and Qualification Program, as supplemented by the existing irradiation and post-irradiation heating data bases, to validate these fission product transport analytical tools" [47].

The approach referred to in Issue 2 is an analysis of several barriers of functional containment that limit the release of radionuclides to the environment for each postulated event under normal operating conditions, abnormal operations conditions, and accident conditions. Specifically, DOE and INL proposed the following detailed methods for quantifying key factors:

- the generation and transport of each radiologically significant species of fission product from the fuel kernel to the reactor coolant,

- the concentration and form of each radiologically significant chemical species in the helium primary circuit during normal operations,

- the concentration and form of each radiologically significant chemical species in helium released during depressurization events, and

- the effects of radionuclide form, condensation, settling, vent-path configuration, and vent filtering on the time-dependent transport of radionuclides through the reactor building and to the atmosphere for each postulated event. 
In their most recent response to DOE and INL, NRC staff concluded that the proposed methodology for generating an MST for MHTGRs is in alignment with the staff's current position on the treatment of advanced reactor MSTs with caveats [48]. The NRC suggested that, in addition to considering licensing basis events, DOE and INL could also include bounding events, such as those identified in NUREG-1338, in their MST approach. Generally, the NRC's main regulatory concerns appear to be related to the development and validation of models that can accurately represent the phenomenological behavior of fission product generation and transport. Uncertainty evaluation is crucial to limit accident consequences when there is a lack of operating and experimental data.

To provide clarity to advanced reactor-related decision-making, the American Society of Mechanical Engineers (ASME) and the American Nuclear Society (ANS) released the technology-neutral standard Probabilistic Risk Assessment Standard for Advanced Non-LWR Nuclear Power Plants in 2013 [49]. This standard lists several qualitative objectives and high-level requirements for an MST analysis for advanced reactors.

The six objectives for an MST analysis are the "identification of inventories available for release within the reactor coolant system pressure boundary, identification and characterization of the phenomena affecting radionuclide transport, definition of reactor-specific release categories for use in end state and event sequence grouping, determination of release parameters (e.g., chemical phase, release timing and duration), identification and evaluation of relevant uncertainties, and documentation of the mechanistic analysis" [49].

The five high-level requirements are as follows [49].

- "Release categories shall be defined for defining event sequence end states and for grouping event sequences and event sequence families with the same or similar mechanistic source terms".

- The mechanistic source term analysis shall include a method for determining the mechanistic source term for each release category".

- The mechanistic source term analysis shall include calculations to quantitatively characterize the mechanistic source terms for each release category".

- Uncertainties in the mechanistic source terms and associated radionuclide transport phenomena shall be characterized and quantified to the extent practical. Key sources of model uncertainty and assumptions shall be identified, and their potential impact on the results shall be understood. Those sources of uncertainty that are not quantified shall be addressed via sensitivity analysis".

- The mechanistic source term analysis shall be documented consistent with the applicable supporting requirements".

Following the recommendations provided by ASME and ANS, the NRC released SECY-16-0012, Accident Source Terms and Siting for SMRs and Non-LWRs, [50] in 2016, which discussed the issues associated with using MSTs in DBA dose analyses and siting. NRC staff stated that venders could use MSTs in the licensing application for non-LWR designs given the availability of tools and data for an adequate analysis. Another focus of the document was that MST use in a license application could lead to reduced exclusion area boundaries and closer proximity to population centers for certain advanced reactors. For example, small modular reactors that contain smaller amounts of fuel and use passive safety design features are expected to have smaller source terms than existing LWRs.

\subsubsection{Modeling of Radionuclide Release and Consequence within the NRC Framework}

Currently, the NRC develops and accounts for radionuclide source terms from postulated accident scenarios in the manner shown in Figure 2 for LWRs. The SCALE code is used to develop radionuclide inventories with sensitivity analysis and uncertainty quantification. These inventories are then used as an 
input to the severe accident analysis software MELCOR, which models reactor behavior during normal, off-normal, and accident conditions. MELCOR computes radionuclide release to the site and the environment as a radionuclide source term.

The consequence of the radionuclide source term is then assessed. This is done through calculations with the Radionuclide Transport, Removal, and Dose (RADTRAD) code for calculations onsite, such as control room dose calculations [51]. RADTRAD uses a combination of realistic system behavior and atmospheric dispersion characteristics to model radionuclides as they move from the primary containment to elsewhere onsite. For calculations of consequence offsite, such as dose to the public resultant from an event, the MACCS software is primarily used. It accounts for the atmospheric transport, dispersion, and deposition of radionuclides. From there, it allows the assessment of dose and economic consequence [52]. The RASCAL software is a response tool used to make recommendations regarding emergency response decisions. During a radiological release event, it is used by the NRC, state governments, and others, such as local responders, to provide guidance on evacuation decisions [53].

The combination of these code systems provides regulators with the necessary information to make decisions regarding safety reviews and environmental impact reviews, which are necessary for the licensing of reactors within the United States. Efforts are underway to enhance existing software-such as MELCOR, SCALE, and MACCS - to adequately capture the behavior radionuclides within MSR systems.

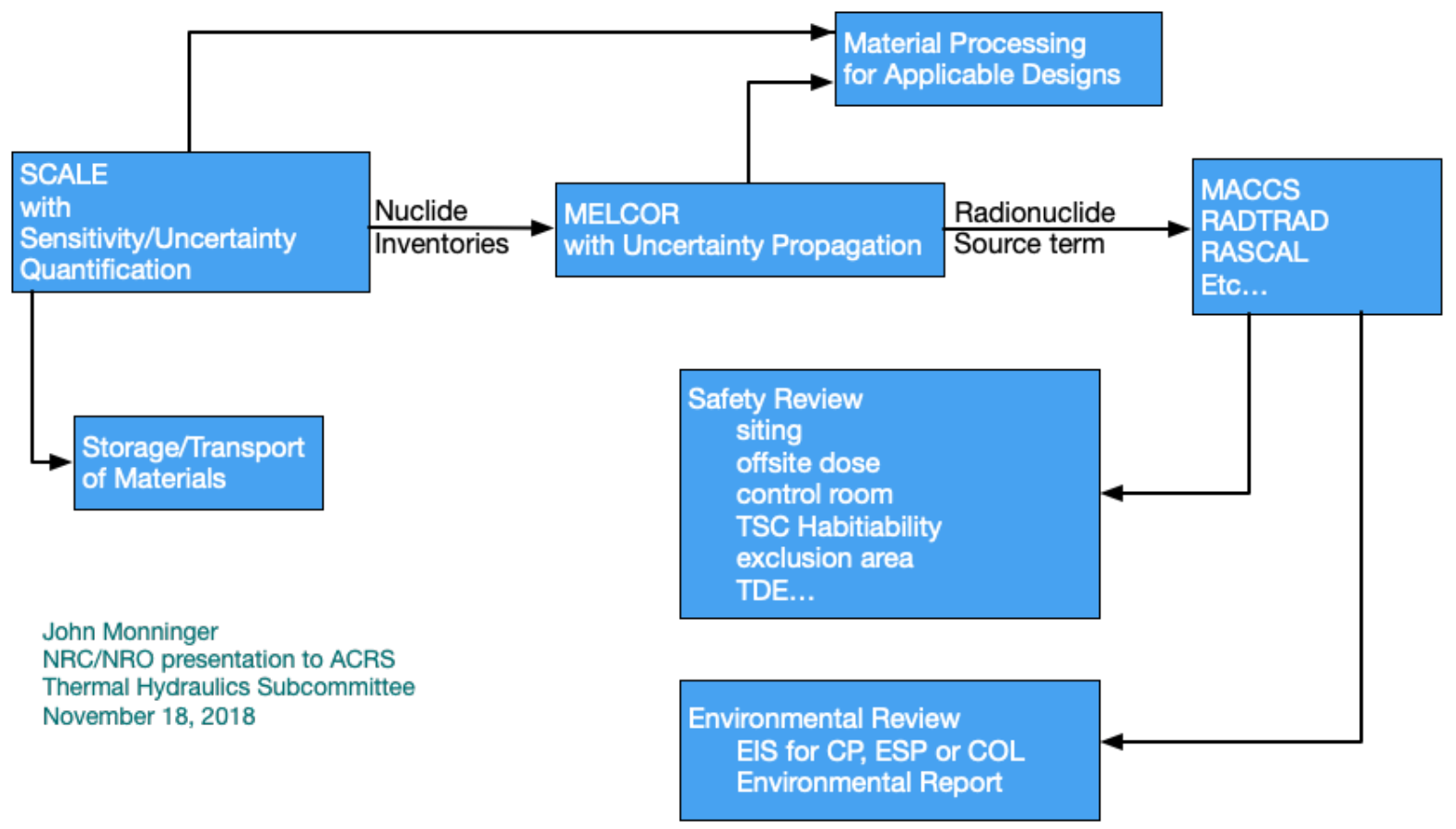

Figure 2. Method for developing and using an MST within the NRC framework [54].

\subsubsection{Communication of Source Term Assessments}

Additional guidance on how to account for non-LWR source terms in a mechanistic manner can be gleaned from the treatment of DOE radiological facilities, which use leak path factor analysis to determine what fraction of radionuclides move from a contaminated area to the environment during postulated accidents and other events. Such assessments are routinely performed with severe accident analysis tools (e.g., MELCOR), which contain the necessary physical models for adaption to non-LWR 
events. MSRs do not have traditional core degradation. The fuel is liquid during normal operations. Thus, the methodology applicable to core degradation accidents could help inform the treatment of radionuclides that are released from MSRs and similar off-gas systems [55].

Leak path analysis provides a way to characterize the barriers that intercept and remove fission products that move along a pathway toward the environment. It might be directly relevant for simpler scenarios, such as an off-gas system release. More broadly, it illustrates the role of release mitigation strategies introduced in the design. This particularly valuable when a functional containment concept is adopted in which multiple barriers might be relevant to reducing the extent of off-site radiological release.

To conceptualize how reactor design is influenced by source term evaluations, it is helpful to describe source terms in a somewhat simplified manner. This enables a description of how the capabilities of reactor designs influence the mitigation of classes of fission product releases to the environment. The following must be considered:

- the physical processes that characterize the transport of radionuclides released from fuel through various regions of an NPP until ultimately being released into the environment or stabilized within the power plant, and

- the range of anticipated operational occurrences (AOOs), design basis events (DBEs), and beyond design basis events (BDBEs) that may challenge barriers to release from systems containing radioactive material.

A simplified structured approach to source term communication can be used to generalize the range of release mitigation measures that could be used in any reactor design into a limited number of factors that reflect the different barriers to fission product release. This approach adopts the methods formulated for DOE radiological facilities [56] [57].

A release mitigation strategy can be assessed in terms of the contribution of various release mitigation measures that limit the overall release to the environment. This is summarized in terms of the following multifactor formula that correlates release of a radionuclide, $\mathrm{X}\left(R_{E}^{X}\right)$, to the environment with retention by various barriers encountered generically across a range of reactor designs:

$$
R_{E}^{X}=I_{X}\left(1-f_{d}^{X}\right)\left(1-f_{f S}^{X}\right)\left(1-f_{r}^{X}\right)\left(1-f_{e}^{X}\right)\left(1-f_{l}^{X}\right)
$$

where:

- $R_{E}^{X}$ is the total release of radionuclide $X$ given by Eq. (1),

- $I_{X}$ is the initial fission product inventory at the time of the reactor accident for radionuclide $X$,

- fraction of radionuclide $X$ retained through dissolution in the fuel $\left(f_{d}^{X}\right)$,

- fraction of radionuclide $X$ retained by fuel system structures enclosing the fuel $\left(f_{f s}^{X}\right)$,

- fraction of radionuclide $X$ retained in the reactor heat removal system $\left(f_{r}^{X}\right)$,

- $\quad$ fraction of radionuclide $X$ retained in the reactor enclosure $\left(f_{e}^{X}\right)$, and

- fraction of radionuclide $X$ retained along leakage pathways connecting the reactor enclosure with the environment $\left(f_{l}^{X}\right)$.

This overall process of reducing the products being transported through multiple barriers that interrupt a transport pathway to the environment is illustrated in Figure 3. The factors $f_{e}^{X}$ and $f_{l}^{X}$ correspond to the overall leak path factor. They have been separated out in this context due to their relevance to generically 
treat a range of scenarios in which products released from fuel and the reactor system might not bypass the reactor enclosure. ${ }^{\S \S}$

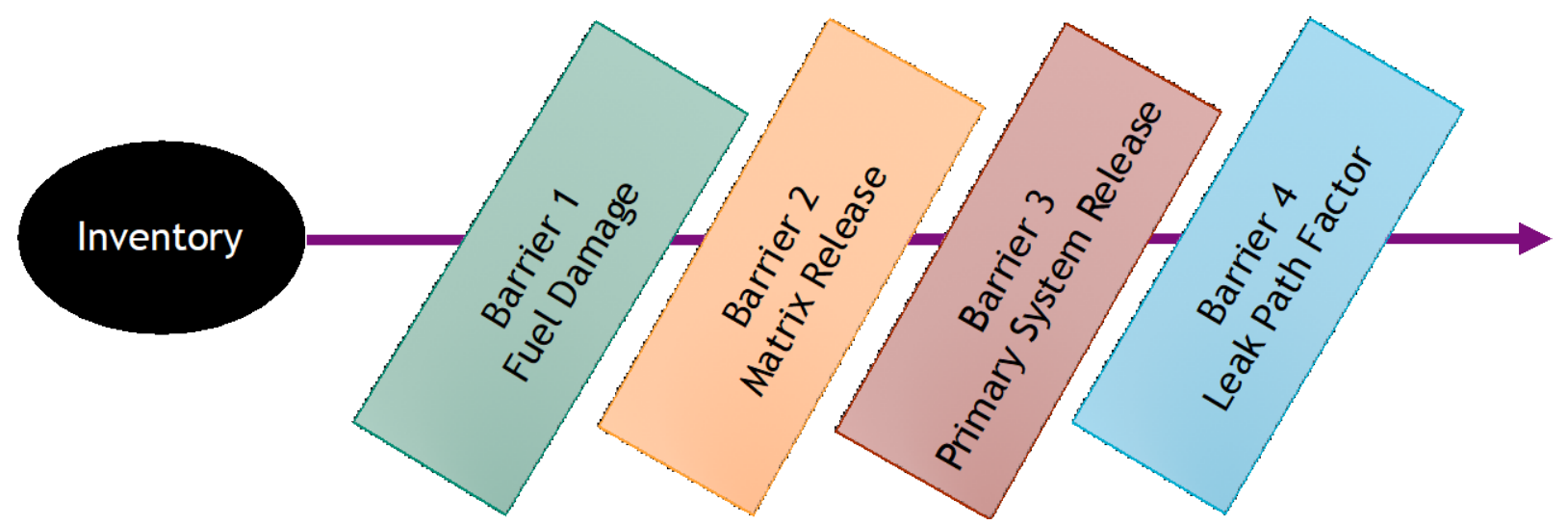

Figure 3. Illustration of source term reduction through multiple barriers to fission product release for LWR fuel.

NPP safety design is based on a concept of multiple levels of defense against release to the environment. These barriers prevent the transport of radionuclides from one region of the plant to another. These can be physical barriers, such as vessel walls. Alternatively, barriers can be physical processes (i.e., active filtration) that limit the degree to which radionuclides can move from one region of the plant to another. For example, in an LWR, the fuel matrix serves as a barrier to the release of some products from fuel rods, and in an MSR, some products remain in the salt.

Additional barriers can impede the motion of radionuclides into the environment. Some classes of radionuclides can evolve as gases and do not remain bound in the fuel, such as fission product noble gases (e.g., xenon, krypton). Other fission products typically remain bound within the fuel. These classes of fission products can only be released from fuel through a chemical or physical process. In molten-fueled systems, fission products dissolved in the fuel will be convected within the bulk pool toward the surface of the molten pool in contact with the cover gas. Diffusion across the surface boundary and, ultimately, vaporization allow these dissolved fission products to move out of the salt and into gas spaces above. Fission products dissolved in molten fuel can also be entrained by rising bubbles and transported into the cover gas when these bubbles leave the molten pool and burst.

The temperature of the salt influences both the chemical state of the radionuclides and how different classes of fission products move. Those that are initially dissolved but able to leave the solution and are transported into interfacing fluid at lower temperatures are typically referred to as volatile fission products. However, classes with low transport rates out of solution into interfacing fluid tend to have low diffusional release rates. These are classified into two broad categories: semi-volatile and nonvolatile fission products.

Once released from the fuel, fission products can be delayed in auxiliary systems or deposited on reactor structures, intentionally or not. Those retained within cover gas systems might leak into adjacent reactor enclosures and/or the environment through bypass flow paths. Radioactive products transported into a reactor enclosure can similarly be delayed in the atmosphere or deposited onto structures. Product leakage of from the containment atmosphere to the environment could be attenuated due to a variety of design choices and equipment conditions [58] [59].

\footnotetext{
${ }^{\S}$ Scenarios with a bypass of the reactor enclosure correspond to bypass scenarios in LWRs.
} 


\subsection{RADIONUCLIDE SOURCES IN MSRS: INVENTORY DISTRIBUTION DURING NORMAL OPERATION}

The radionuclide inventory must be characterized as part of an MSR-MST assessment to establish initial states (i.e., the starting distribution of radionuclides) for hypothetical accident scenarios. The MST approach being developed will be technology-inclusive, and radionuclide distribution processes for both fluoride and chloride fueled reactors are considered.

The Molten Salt Reactor Experiment (MSRE), Molten Salt Breeder Reactor (MSBR), and Molten Salt Demonstration Reactor (MSDR) are used as historical references. These projects were the culmination of years of research on molten salt-fueled reactors performed at Oak Ridge National Laboratory (ORNL), which included the investigation of MSR technology for powering aircraft (1950s) (e.g., Ergen et al [60]). The Aircraft Reactor Program led to the testing of a high-temperature (up to $860^{\circ} \mathrm{C}$ ) MSR core fueled by highly enriched uranium dissolved in a NaF- $\mathrm{ZrF}_{4}$ eutectic salt. The MSRE was a 7.3 MWt reactor operated at ORNL from 1965 to 1969 as a demonstration of the basic reactor technology needed to develop a commercial MSR, such as the proposed MSBR, a large 2,250 MWt breeder. In the 1970s, the MSDR concept was developed as a larger (750 MWt) demonstration of eventual MSBR technology [61]. The fuel types and characteristics of the MSRE, MSBR, and MSDR are summarized in Table 2.

Table 2. Basic characteristics of the MSRE, the MSBR and the MSDR.

\begin{tabular}{lccc}
\hline & MSRE & MSBR & MSDR \\
\hline Power (MWt) & 7.3 & 2,250 & 750 \\
Fuel Salt (mol\%) & & & \\
$\mathrm{LiF}$ & 65 & 71.7 & 71.5 \\
$\mathrm{BeF}_{2}$ & 29.1 & 16 & 16 \\
$\mathrm{ThF}_{4}$ & None & 12 & 12 \\
$\mathrm{UF}_{4}$ & 0.9 & 0.3 & 0.5 \\
$\mathrm{ZrF}_{4}$ & 5 & None & None \\
Core inlet $\mathrm{T}\left({ }^{\circ} \mathrm{C}\right)$ & 632 & 566 & 566 \\
Core outlet T $\left({ }^{\circ} \mathrm{C}\right)$ & 654 & 704 & 677 \\
Average power density & 4 & 46 & 46 \\
of fuel salt $\left(\mathrm{MW} / \mathrm{cm}^{3}\right)$ & & & \\
Coolant salt & $\mathrm{LiF}^{3}-\mathrm{BeF}_{2}$ & $\mathrm{NaBF}_{4}-\mathrm{NaF}$ & $\mathrm{LiF}^{2}-\mathrm{BeF}_{2}$ \\
\hline
\end{tabular}

However, a principal challenge to providing a general layout for an MSR and its containment SSCs is the diverse potential set of design variants, nearly all of which are currently being pursued. For example, layouts that feature a pool-type reactor auxiliary cooling system or liquid fuel naturally circulating within rods have substantially different overall plant layouts and accident progression scenarios than historic loop-type designs. To be inclusive, much of the containment/barrier discussion is kept at a general level while providing additional discussion on the available historic examples.

\subsubsection{Tritium}

All MSRs will produce tritium during normal operation, which can result in a normal operations source term. MSRs that employ lithium or beryllium in high neutron flux regions will produce substantially more tritium on the order of $1 \mathrm{Ci}$ per $\mathrm{MW}_{\text {th }}$ per day [62]. Unbound tritium readily absorbs into and diffuses through structural alloys at high temperatures (above $\sim 300^{\circ} \mathrm{C}$ ), so is not contained by the fuel salt boundary. However, unbound tritium is highly mobile and diffuses readily into air and water. 
Consequently, tritium rapidly disperses into the environment and cannot contribute significantly to dose at the site boundary, but it does contribute to overall societal dose. 10 CFR 20 Appendix B, Table 2, provides the allowable tritium release concentrations of tritium into air $(1 \mathrm{e}-7 \mu \mathrm{Ci} / \mathrm{ml})$ and water (1e-3 $\mu \mathrm{Ci} / \mathrm{ml})$. Diffusion through the fuel salt boundary can result in the containment atmosphere becoming too contaminated for free release. Similarly, the fuel salt coolant can become contaminated by tritium and subsequently pass the contamination into the power cycle fluid. During normal operation, containment contamination can be removed by trapping the released tritium into a stable waste form. However, tritium escape through the power cycle must be reduced sufficiently to comply with the effluent concentration limits. An MSR's safety analysis report (SAR) must describe the means by which tritium effluent concentration will be reasonably assured to be below release limits. However, tritium release through the power cycle will be a normal operations issue so that compliance can be measured and corrective actions taken. Consequently, the SSCs relied upon to control tritium effluent releases through the power cycle are not safety related. ${ }^{* *}$

\subsubsection{Fission Yields}

The full array of fission products will be produced within the fuel salt of an MSR. The concentration of an isotope will depend on the balance between the rate of production and the rate of loss due to decay and transmutation or physical removal, intentional or not. The fission yields and decay rates of the key isotopes considered in the MSRE project are shown in Table 3. The actual fission product inventory at any time will vary with reactor power and the fissile composition of the fuel (i.e., the ratios of ${ }^{233} \mathrm{U} /{ }^{235} \mathrm{U} /{ }^{239} \mathrm{Pu}$ ). The calculated elemental fission product inventory for MSRE under ${ }^{235} \mathrm{U}$ operation is summarized in Figure 4. This inventory was calculated by Bell [63] via ORIGEN for a reactor power of $4.18 \mathrm{MW}$, a flux of $2.35 \times 10^{12} \mathrm{~N} / \mathrm{cm}^{2} \mathrm{~s}$, and a burnup of $2,983 \mathrm{MWd}$, assuming the continuous stripping of xenon and krypton gases from the core.

\footnotetext{
${ }^{* * *}$ The term safety related (https://www.nrc.gov/reading-rm/basic-ref/glossary/safety-related.html) refers to systems, structures, components, procedures, and controls of a facility or process that are relied upon to remain functional during and following design-basis events.
} 
Table 3. Fission yields for some key radionuclides (adapted from Compere et al. [70]).

\begin{tabular}{|c|c|c|c|c|c|}
\hline \multirow{2}{*}{ Chain } & \multirow{2}{*}{ Isotope } & \multirow{2}{*}{ Half-life (days) } & \multicolumn{3}{|c|}{ Cumulative fission yield ${ }^{*}$} \\
\hline & & & ${ }^{233} \mathbf{U}$ & ${ }^{235} \mathbf{U}$ & ${ }^{239} \mathrm{Pu}$ \\
\hline 89 & $\mathrm{Sr}$ & 52 & 5.86 & 4.79 & 1.711 \\
\hline 90 & $\mathrm{Sr}$ & $1.0 \mathrm{E}+04$ & 6.43 & 5.77 & 2.21 \\
\hline 91 & $\mathrm{Sr}$ & 0.4 & 5.57 & 5.81 & 2.43 \\
\hline 91 & $\mathrm{Y}$ & 59 & 5.57 & 5.81 & 2.43 \\
\hline 95 & $\mathrm{Zr}$ & 65 & 6.05 & 6.2 & 4.97 \\
\hline 95 & $\mathrm{Nb}$ & 35 & 6.05 & 6.2 & 4.97 \\
\hline 99 & Mo & 2.79 & 4.8 & 6.06 & 6.1 \\
\hline 99 & $\mathrm{Tc}$ & $7.7 \mathrm{E}+07$ & 4.8 & 6.06 & 6.1 \\
\hline 103 & $\mathrm{Ru}$ & 39.5 & 1.8 & 3 & 5.67 \\
\hline 106 & $\mathrm{Ru}$ & 368 & 0.24 & 0.38 & 4.57 \\
\hline 110 & $\operatorname{Ag}(m)^{* *}$ & 253 & ---- & ---- & --- \\
\hline 111 & $\mathrm{Ag}$ & 7.5 & 0.0242 & 0.0192 & 0.232 \\
\hline 125 & $\mathrm{Sb}$ & 985.5 & 0.084 & 0.021 & 0.115 \\
\hline 127 & $\mathrm{Te}(\mathrm{m})$ & 100 & 0.6 & 0.13 & 0.39 \\
\hline 129 & $\mathrm{Te}(\mathrm{m})$ & 34 & 2 & 0.8 & 2 \\
\hline 131 & I & 8.05 & 2.9 & 2.93 & 3.78 \\
\hline 132 & $\mathrm{Te}$ & 3.25 & 4.4 & 4.24 & 5.1 \\
\hline 134 & $\mathrm{Cs}^{*}$ & 750 & ---- & ---- & ---- \\
\hline 135 & $\mathrm{Xe}$ & 0.38 & 6.16 & 6.41 & 7.17 \\
\hline 137 & Cs & $1.1 \mathrm{E}+04$ & 6.58 & 6.15 & 6.63 \\
\hline 140 & $\mathrm{Ba}$ & 12.8 & 5.4 & 6.85 & 5.56 \\
\hline 141 & $\mathrm{Ce}$ & 32.3 & 6.49 & 6.4 & 5.01 \\
\hline 141 & $\mathrm{Ce}$ & 32.5 & 6.49 & 6.4 & 5.09 \\
\hline 143 & $\operatorname{Pr}$ & 13.57 & 6 & 5.73 & 4.56 \\
\hline 144 & $\mathrm{Ce}$ & 284 & 4.61 & 5.62 & 3.93 \\
\hline 147 & $\mathrm{Nd}$ & 11.1 & 1.98 & 2.36 & 2.07 \\
\hline 147 & $\mathrm{Pm}$ & 967.25 & 1.98 & 2.36 & 2.07 \\
\hline 147 & $\mathrm{Pm}$ & 949 & 1.98 & 2.36 & 2.07 \\
\hline 148 & $\mathrm{Pm}$ & 5.36 & 1.34 & 1.71 & 1.73 \\
\hline 149 & $\mathrm{Pm}$ & 2.21 & 0.76 & 1.13 & 1.32 \\
\hline 151 & $\mathrm{Sm}$ & $3.2 \mathrm{E}+04$ & 0.34 & 0.44 & 0.8 \\
\hline 155 & $\mathrm{Eu}$ & $1.7 \mathrm{E}+03$ & 0.02 & 0.03 & 0.23 \\
\hline
\end{tabular}

${ }^{*}$ Fission yields given as atoms produced per 100 atoms of fissile isotope.

${ }^{* *}$ Yield values for ${ }^{110(\mathrm{~m})} \mathrm{Ag}$ and ${ }^{134} \mathrm{Cs}$ are not shown because these isotopes are produced by neutron absorption by lighter chain nuclides. 

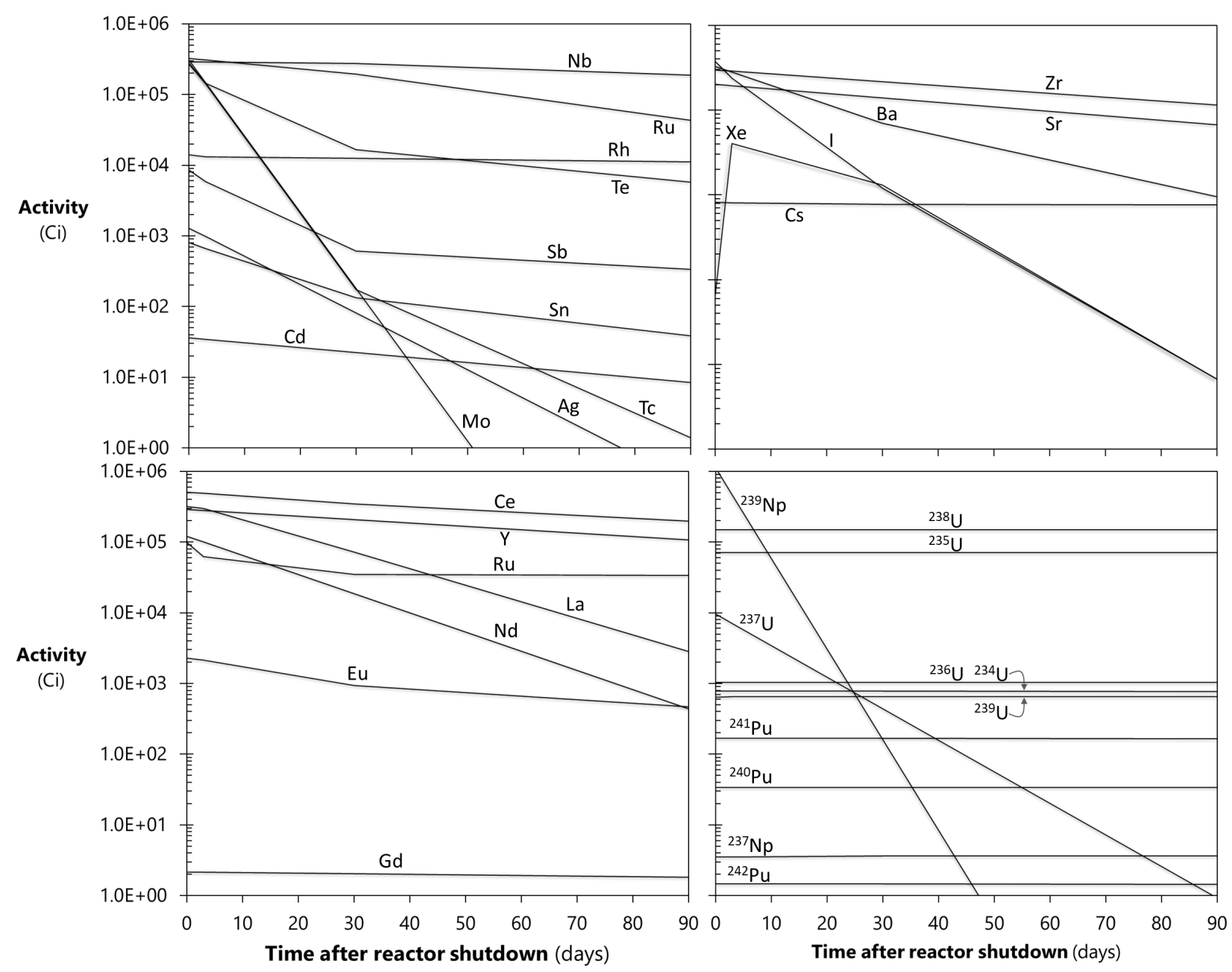

Figure 4. Calculated fission product activities for the MSRE (plotted from tabulated results of Bell [63]).

Taube [64] gives an example of the projected fission product inventory for a 2,000 MW(t) chloride-fueled fast breeder reactor that contains a mixture of $15 \mathrm{~mol} \% \mathrm{PuCl}_{3}+85 \mathrm{~mol} \% \mathrm{NaCl}$ as the fuel and a fertile blanket salt consisting of $65 \mathrm{~mol} \%{ }^{238} \mathrm{UCl}_{3}+35 \mathrm{~mol} \% \mathrm{NaCl}$. The elemental fission yields for this system are shown in Table 4. This table also indicates the predicted valence state and chloride chemical compatibility. 
Table 4. Fission yields for ${ }^{239} \mathrm{PuCl}_{3} / \mathrm{NaCl}$ and ${ }^{235} \mathrm{UCl} / \mathrm{NaCl}$ fueled fast spectrum $\mathrm{MSR}$ (yields per 100 atoms of ${ }^{239} \mathrm{Pu}$ fission for 10 day irradiation). (Adapted from Taube [64] and Burris and Dillon [65].)

\begin{tabular}{|c|c|c|c|c|}
\hline Element & ${ }^{238} \mathrm{Pu}$ yield & ${ }^{235} \mathrm{U}$ yield & Oxidation state & Chloride species \\
\hline $\mathrm{Br}$ & 0.003 & 0.142 & 0 & none \\
\hline I & 6.177 & 4.014 & 0 & none \\
\hline $\mathrm{Kr}$ & 0.942 & 3.021 & 0 & none \\
\hline $\mathrm{Pd}$ & 12.657 & 1.31 & 0 & none \\
\hline $\mathrm{Rh}$ & 1.736 & 0.557 & 0 & none \\
\hline $\mathrm{Ru}$ & 31.445 & 18.265 & 0 & none \\
\hline $\mathrm{Se}$ & 0.008 & 0.396 & 0 & none \\
\hline Tc & 4.014 & 4.217 & 0 & none \\
\hline $\mathrm{Xe}$ & 21.234 & 21.793 & 0 & none \\
\hline $\mathrm{Ag}$ & 1.88 & 0.125 & +1 & $\mathrm{AgCl}$ \\
\hline Cs & 13.355 & 14.161 & +1 & $\mathrm{CsCl}$ \\
\hline In & 0.06 & 0.029 & +1 & $\mathrm{InCl}$ \\
\hline $\mathrm{Rb}$ & 1.05 & 3.723 & +1 & $\mathrm{RbCl}$ \\
\hline $\mathrm{Ba}$ & 9.502 & 10.642 & +2 & $\mathrm{BaCl}_{2}$ \\
\hline $\mathrm{Cd}$ & 0.66 & 0.206 & +2 & $\mathrm{CdCl}_{2}$ \\
\hline Mo & 18.16 & 20.857 & +2 & $\mathrm{MoCl}_{2}$ \\
\hline $\mathrm{Sn}$ & 0.324 & 0.388 & +2 & $\mathrm{SnCl}_{2}$ \\
\hline $\mathrm{Sr}$ & 5.487 & 12.176 & +2 & $\mathrm{SrCl}_{2}$ \\
\hline $\mathrm{Te}$ & 7.654 & 4.251 & +2 & $\mathrm{TeCl}_{2}$ \\
\hline $\mathrm{Ce}$ & 13.986 & 16.112 & +3 & $\mathrm{CeCl}_{3}$ \\
\hline $\mathrm{Eu}$ & 0.595 & 0.144 & +3 & $\mathrm{EuCl}_{3}$ \\
\hline $\mathrm{Gd}$ & 0.028 & 0.007 & +3 & $\mathrm{GdCl}_{3}$ \\
\hline $\mathrm{La}$ & 5.79 & 6.808 & +3 & $\mathrm{LaCl}_{3}$ \\
\hline $\mathrm{Nd}$ & 11.87 & 13.626 & +3 & $\mathrm{NdCl}_{3}$ \\
\hline $\mathrm{Pm}$ & 1.44 & 1.249 & +3 & $\mathrm{PmCl}_{3}$ \\
\hline $\operatorname{Pr}$ & 4.278 & 5.029 & +3 & $\mathrm{PrCl}_{3}$ \\
\hline $\mathrm{Sb}$ & 0.674 & 0.339 & +3 & $\mathrm{SbCl}_{3}$ \\
\hline $\mathrm{Sm}$ & 3.737 & 1.592 & +3 & $\mathrm{SmCl}_{3}$ \\
\hline $\mathrm{Y}$ & 3.028 & 5.71 & +3 & $\mathrm{YCl}_{3}$ \\
\hline $\mathrm{Zr}$ & 21.52 & 29.732 & +4 & $\mathrm{ZrCl}_{3}$ \\
\hline $\mathrm{Nb}$ & 0.289 & 0.37 & +5 & $\mathrm{NbCl}_{5}$ \\
\hline
\end{tabular}

An example actinide inventory for a molten chloride fast reactor is shown in Table 5. This table is based on the REBUS concept, which is powered by a $\mathrm{UCl}_{3}+$ transuranic (TRU) fuel mixture of $45 \mathrm{~mol} \%$ (U + 15.6 atom $\%$ TRU) $\mathrm{Cl}_{3}+55 \mathrm{~mol} \% \mathrm{NaCl}$ [66]. As shown in Table 5, the fission products yields for ${ }^{235} \mathrm{U}$ and ${ }^{239} \mathrm{Pu}$ indicate the fission products $\mathrm{Zr}, \mathrm{Ru}, \mathrm{Xe}, \mathrm{Mo}, \mathrm{Ce}, \mathrm{Cs}, \mathrm{Pd}, \mathrm{Nd}, \mathrm{Ba}, \mathrm{Te}, \mathrm{I}, \mathrm{La}, \mathrm{Sr}, \mathrm{Pr}, \mathrm{Tc}$, and $\mathrm{Nb}$ will be the most abundant on mass and activity bases (Table 3, Table 4, and Figure 4). 
Table 5. TRU isotopic composition of the REBUS fast spectrum MSR fueled with $45 \mathrm{~mol} \%$ (U,TRU)Cl $3+55 \mathrm{~mol} \% \mathrm{NaCl}$ (Mourogov and Bokov [66]).

\begin{tabular}{ccc}
\hline Isotopes & $\begin{array}{c}\text { Initial composition } \\
\text { (atom\% of TRU) }\end{array}$ & $\begin{array}{c}\text { Equilibrium composition } \\
\text { (atom\% TRU) }\end{array}$ \\
\hline${ }^{238} \mathrm{Pu}$ & 2.13 & 2.23 \\
${ }^{239} \mathrm{Pu}$ & 48.33 & 58.02 \\
${ }^{240} \mathrm{Pu}$ & 22.17 & 27.63 \\
${ }^{241} \mathrm{Pu}$ & 9.05 & 3.35 \\
${ }^{242} \mathrm{Pu}$ & 6.38 & 4.05 \\
${ }^{237} \mathrm{~Np}$ & 4.8 & 0.65 \\
${ }^{239} \mathrm{~Np}$ & 0 & 0.07 \\
${ }^{241} \mathrm{Am}$ & 5.17 & 1.5 \\
${ }^{242 \mathrm{~m}} \mathrm{Am}$ & 0.01 & 0.12 \\
${ }^{243} \mathrm{Am}$ & 1.48 & 1.05 \\
${ }^{242} \mathrm{Cm}$ & 0 & 0.07 \\
${ }^{243} \mathrm{Cm}$ & 0 & 0.01 \\
${ }^{244} \mathrm{Cm}$ & 0.43 & 1.02 \\
${ }^{245} \mathrm{Cm}$ & 0.04 & 0.19 \\
${ }^{246} \mathrm{Cm}$ & 0 & 0.05 \\
\hline
\end{tabular}

\subsubsection{Identification of Major Dose Contributors to Prioritize Chemical Model Development}

The ranking of radionuclides in terms of radiotoxicity allows particular chemical systems to be prioritized for experimental and model development work. The US Environmental Protection Agency (EPA) defined three measures of radiotoxicity that may be used to control internal exposure to radionuclides in the workplace. These measures are the annual limit on intake (ALI), the derived air concentration (DAC), and the effective dose equivalent conversion factor that quantifies the absorbed dose to tissues and organs for specific isotopes [67].

The $D A C$ is defined as the concentration of a radionuclide in the air that, if breathed for a work year, would result in an intake corresponding to the ALI of that radionuclide [67]. DACs are used to limit radionuclide intake through the breathing of contaminated air, and ALIs are used to assess doses due to the accidental ingestion of radionuclides. The ALI and DAC values are derived from the stochastic and non-stochastic effects of radioactive dose to organs due to radionuclide inhalation or ingestion. The relative organ damage caused by various radionuclides is quantified by the dose equivalent factor [67].

Table 6 and Table 7 rank the primary fission products and actinides, respectively, in terms of the dose equivalent factor and also show the ALI and DAC values for each isotope. The relative radiotoxicity derived from these tables is plotted in Figure 5. From a radiotoxicity perspective, the 10 most important fission products within the MSR fuel salts will be: Cs, I, Sr, Ru, Ce, Cd, Sn, Y, Te, and Ba (Table 6 and Figure 5). However, all of the primary actinides- $\mathrm{U}, \mathrm{Pu}, \mathrm{Th}, \mathrm{Np}, \mathrm{Am}$, and $\mathrm{Cm}$-have nuclides that are generally much more radiotoxic than the fission products (Table 7 and Figure 5). 
Table 6. Fission product radionuclides ranked in terms of radiotoxicity as quantified by the EPA ALI, DAC, and effective dose equivalent conversion factor ("Dose factor") from Eckerman et al. [68].

\begin{tabular}{|c|c|c|c|c|c|c|c|}
\hline Element & $\begin{array}{c}\text { Mass } \\
\text { number }\end{array}$ & $\begin{array}{c}\text { Half-life } \\
\text { (days) }\end{array}$ & $\begin{array}{l}{ }^{235} U \\
\text { yield }\end{array}$ & $\begin{array}{l}\text { Dose factor } \\
\text { (mrem/mCi) }\end{array}$ & $\begin{array}{c}\text { DAC } \\
\left(\mathbf{M B q} / \mathbf{m}^{3}\right)\end{array}$ & $\begin{array}{l}\text { Inhalation } \\
\text { ALI (MBq) }\end{array}$ & $\begin{array}{c}\text { Ingestion } \\
\text { ALI (MBq) }\end{array}$ \\
\hline $\mathrm{Cs}$ & 135 & $7.7 \mathrm{E}+08$ & 6.361 & 706.7 & $2.0 \mathrm{E}-02$ & 40 & 30 \\
\hline I & 129 & $6.2 \mathrm{E}+09$ & 0.671 & 276.0 & $1.0 \mathrm{E}-04$ & 0.3 & 0.2 \\
\hline $\mathrm{Sr}$ & 90 & $1.0 \mathrm{E}+04$ & 4.420 & 142.5 & $3.0 \mathrm{E}-04$ & 0.7 & 1 \\
\hline I & 131 & $8.0 \mathrm{E}+00$ & 1.102 & 53.3 & $7.0 \mathrm{E}-04$ & 2 & 1 \\
\hline $\mathrm{Cs}$ & 137 & $9.9 \mathrm{E}+03$ & 5.790 & 50.0 & $2.0 \mathrm{E}-03$ & 6 & 4 \\
\hline $\mathrm{Ru}$ & 106 & $3.7 \mathrm{E}+02$ & 0.454 & 27.4 & $1.0 \mathrm{E}-03$ & 3 & 7 \\
\hline $\mathrm{Ce}$ & 144 & $2.8 \mathrm{E}+02$ & 4.650 & 21.0 & $4.0 \mathrm{E}-04$ & 0.9 & 8 \\
\hline $\mathrm{Cd}$ & $115 \mathrm{~m}$ & $4.3 \mathrm{E}+01$ & 0.004 & 16.2 & $8.0 \mathrm{E}-04$ & 2 & 10 \\
\hline $\mathrm{Sn}$ & 125 & $9.4 \mathrm{E}+00$ & 0.026 & 12.3 & $1.0 \mathrm{E}-02$ & 30 & 10 \\
\hline $\mathrm{Y}$ & 90 & $2.5 \mathrm{E}+00$ & 0.001 & 10.8 & $3.0 \mathrm{E}-03$ & 30 & 20 \\
\hline $\mathrm{Te}$ & $129 \mathrm{~m}$ & $3.4 \mathrm{E}+01$ & 0.112 & 10.7 & $1.0 \mathrm{E}-02$ & 20 & 20 \\
\hline I & 133 & 2.7E-01 & 0.273 & 10.4 & 4.0E-03 & 10 & 5 \\
\hline $\mathrm{Y}$ & 91 & $5.7 \mathrm{E}+01$ & 4.360 & 9.5 & $4.0 \mathrm{E}+00$ & 9,000 & 20 \\
\hline $\mathrm{Ba}$ & 140 & $1.3 \mathrm{E}+01$ & 2.909 & 9.5 & $2.0 \mathrm{E}-02$ & 50 & 20 \\
\hline $\mathrm{Te}$ & 132 & $3.2 \mathrm{E}+00$ & 0.690 & 9.4 & 4.0E-03 & 9 & 8 \\
\hline $\mathrm{Sr}$ & 89 & $5.3 \mathrm{E}+01$ & 3.465 & 9.3 & $1.0 \mathrm{E}-02$ & 30 & 20 \\
\hline $\mathrm{Eu}$ & 156 & $1.5 \mathrm{E}+01$ & 0.007 & 9.2 & $7.0 \mathrm{E}-03$ & 20 & 20 \\
\hline $\mathrm{Se}$ & 79 & $2.4 \mathrm{E}+07$ & 0.042 & 8.7 & $1.0 \mathrm{E}-02$ & 30 & 20 \\
\hline $\mathrm{La}$ & 140 & $1.7 \mathrm{E}+00$ & 0.361 & 8.4 & $2.0 \mathrm{E}-02$ & 50 & 20 \\
\hline $\mathrm{Te}$ & $127 \mathrm{~m}$ & $1.2 \mathrm{E}+02$ & 0.032 & 8.3 & $4.0 \mathrm{E}-03$ & 10 & 20 \\
\hline $\mathrm{Ag}$ & 111 & $7.6 \mathrm{E}+00$ & 0.023 & 5.1 & $2.0 \mathrm{E}-02$ & 60 & 30 \\
\hline $\mathrm{Rb}$ & 87 & $2.2 \mathrm{E}+13$ & 2.879 & 4.9 & $2.0 \mathrm{E}-02$ & 60 & 40 \\
\hline $\operatorname{Pr}$ & 143 & $1.4 \mathrm{E}+01$ & 2.505 & 4.7 & $1.0 \mathrm{E}-02$ & 30 & 30 \\
\hline $\mathrm{Y}$ & 93 & 4.2E-01 & 0.108 & 4.6 & 4.0E-02 & 100 & 40 \\
\hline $\mathrm{Sb}$ & 127 & $3.9 \mathrm{E}+00$ & 0.048 & 4.4 & $3.0 \mathrm{E}-02$ & 80 & 30 \\
\hline $\mathrm{Nd}$ & 147 & $1.1 \mathrm{E}+01$ & 1.478 & 4.4 & $1.0 \mathrm{E}-02$ & 30 & 40 \\
\hline $\mathrm{Pm}$ & 149 & $2.3 \mathrm{E}+00$ & 0.129 & 4.0 & $3.0 \mathrm{E}-02$ & 70 & 40 \\
\hline $\mathrm{Zr}$ & 95 & $6.5 \mathrm{E}+01$ & 5.790 & 3.8 & $2.0 \mathrm{E}-03$ & 5 & 50 \\
\hline $\mathrm{Ru}$ & 103 & $4.0 \mathrm{E}+01$ & 3.125 & 3.0 & $3.0 \mathrm{E}-02$ & 60 & 70 \\
\hline Mo & 99 & $2.8 \mathrm{E}+00$ & 0.832 & 3.0 & $4.0 \mathrm{E}-02$ & 100 & 60 \\
\hline $\mathrm{Cl}$ & 36 & $1.1 \mathrm{E}+08$ & ---- & 3.0 & $4.0 \mathrm{E}-02$ & 90 & 60 \\
\hline $\mathrm{Ce}$ & 141 & $3.3 \mathrm{E}+01$ & 3.858 & 2.9 & $1.0 \mathrm{E}-02$ & 30 & 60 \\
\hline $\mathrm{Sb}$ & 125 & $9.9 \mathrm{E}+02$ & 0.097 & 2.8 & $4.0 \mathrm{E}-02$ & 90 & 80 \\
\hline $\mathrm{Nb}$ & 95 & $3.5 \mathrm{E}+01$ & 0.797 & 2.6 & $2.0 \mathrm{E}-02$ & 50 & 80 \\
\hline $\mathrm{Sr}$ & 91 & $4.0 \mathrm{E}-01$ & 0.014 & 2.5 & $9.0 \mathrm{E}-02$ & 200 & 80 \\
\hline $\mathrm{Zr}$ & 93 & $3.5 \mathrm{E}+08$ & 5.317 & 1.7 & $1.0 \mathrm{E}-04$ & 0.2 & 50 \\
\hline $\mathrm{Eu}$ & 155 & $6.2 \mathrm{E}+02$ & 0.029 & 1.5 & $1.0 \mathrm{E}-03$ & 3 & 100 \\
\hline $\mathrm{Rh}$ & 105 & $3.7 \mathrm{E}+01$ & 0.075 & 1.5 & $2.0 \mathrm{E}-01$ & 400 & 100 \\
\hline Tc & 99 & $7.7 \mathrm{E}+07$ & 5.303 & 1.5 & $8.0 \mathrm{E}-02$ & 200 & 100 \\
\hline $\mathrm{Sn}$ & $119 \mathrm{~m}$ & $2.5 \mathrm{E}+02$ & 0.052 & 1.4 & 4.0E-02 & 90 & 100 \\
\hline
\end{tabular}


Table 6. Fission product radionuclides ranked in terms of radiotoxicity as quantified by the EPA ALI, DAC, and effective dose equivalent conversion factor ("Dose factor") from Eckerman et al. [68] (continued).

\begin{tabular}{lccccccc}
\hline Element & $\begin{array}{c}\text { Mass } \\
\text { number }\end{array}$ & $\begin{array}{c}\text { Half-life } \\
\text { (days) }\end{array}$ & $\begin{array}{c}{ }^{235} \mathbf{U} \\
\text { yield }\end{array}$ & $\begin{array}{c}\text { Dose factor } \\
\text { (mrem/mCi) }\end{array}$ & $\begin{array}{c}\text { DAC } \\
\left(\mathbf{M B q} / \mathbf{m}^{3}\right)\end{array}$ & $\begin{array}{c}\text { Inhalation } \\
\text { ALI (MBq) }\end{array}$ & $\begin{array}{c}\text { Ingestion } \\
\text { ALI (MBq) }\end{array}$ \\
\hline $\mathrm{Sn}$ & $117 \mathrm{~m}$ & $1.4 \mathrm{E}+01$ & 0.027 & 1.2 & $2.0 \mathrm{E}-02$ & 50 & 60 \\
$\mathrm{Pm}$ & 147 & $9.5 \mathrm{E}+02$ & 1.748 & 1.0 & $2.0 \mathrm{E}-03$ & 5 & 200 \\
$\mathrm{Sn}$ & 121 & $1.1 \mathrm{E}+00$ & 0.002 & 0.9 & $2.0 \mathrm{E}-01$ & 600 & 200 \\
$\mathrm{Sm}$ & 151 & $3.0 \mathrm{E}+00$ & 0.438 & 0.4 & $2.0 \mathrm{E}-03$ & 4 & 500 \\
$\mathrm{Pd}$ & 107 & $2.6 \mathrm{E}+09$ & 0.280 & 0.1 & $3.0 \mathrm{E}-01$ & 800 & 1,000 \\
$\mathrm{Br}$ & 83 & $9.7 \mathrm{E}-02$ & 0.002 & 0.1 & $1.0 \mathrm{E}+00$ & 2,000 & 2,000 \\
$\mathrm{H}$ & 3 & $4.5 \mathrm{E}+03$ & ---- & 0.1 & $8.0 \mathrm{E}-01$ & 3,000 & 3,000 \\
$\mathrm{Tc}$ & $99 \mathrm{~m}$ & $2.5 \mathrm{E}-01$ & 0.065 & 0.1 & $2.0 \mathrm{E}+00$ & 6,000 & 3,000 \\
$\mathrm{Kr}$ & 85 & $3.4 \mathrm{E}+03$ & 0.264 & ---- & $5.0 \mathrm{E}+00$ & ---- & ---- \\
$\mathrm{Kr}$ & $85 \mathrm{~m}$ & $1.8 \mathrm{E}-01$ & 0.010 & ---- & $8.0 \mathrm{E}-01$ & ---- & ---- \\
$\mathrm{Xe}$ & 133 & $5.3 \mathrm{E}+00$ & 1.665 & ---- & $4.0 \mathrm{E}+00$ & ---- & ---- \\
$\mathrm{Xe}$ & 135 & $3.8 \mathrm{E}-01$ & 0.110 & ---- & $5.0 \mathrm{E}-01$ & ---- & ---- \\
\hline
\end{tabular}

${ }^{*}$ The dose factor is the effective dose equivalent that uses a weighted sum of doses to all irradiated organs and tissues. 
Table 7. Actinides and thorium decay chain nuclides ranked in terms of radiotoxicity as quantified by the EPA ALI, DAC, and effective dose equivalent conversion factor ("Dose factor") from Eckerman et al. [68].

\begin{tabular}{|c|c|c|c|c|c|c|}
\hline Element & $\begin{array}{c}\text { Mass } \\
\text { number }\end{array}$ & $\begin{array}{c}\text { Half-life } \\
\text { (years) }\end{array}$ & $\begin{array}{c}\text { Dose factor } \\
(\mathrm{mrem} / \mathrm{mCi})\end{array}$ & $\begin{array}{c}\text { DAC } \\
(\mathbf{M B q} / \mathbf{m} 3) \\
\end{array}$ & $\begin{array}{c}\text { Inhalation } \\
\text { ALI (MBq) }\end{array}$ & $\begin{array}{c}\text { Ingestion } \\
\text { ALI (MBq) } \\
\end{array}$ \\
\hline $\mathrm{Np}$ & 237 & $2.1 \mathrm{E}+06$ & $4,440.0$ & $6.0 \mathrm{E}-08$ & $2.0 \mathrm{E}-04$ & 0.02 \\
\hline $\mathrm{Cm}$ & 245 & $5.8 \mathrm{E}+03$ & $3,737.0$ & $9.0 \mathrm{E}-08$ & $2.0 \mathrm{E}-04$ & 0.03 \\
\hline $\mathrm{Cm}$ & 246 & $4.7 \mathrm{E}+03$ & $3,700.0$ & $9.0 \mathrm{E}-08$ & $2.0 \mathrm{E}-04$ & 0.03 \\
\hline $\mathrm{Am}$ & 241 & $4.3 \mathrm{E}+02$ & $3,640.8$ & $1.0 \mathrm{E}-07$ & $2.0 \mathrm{E}-04$ & 0.03 \\
\hline $\mathrm{Am}$ & 243 & $7.4 \mathrm{E}+03$ & $3,622.3$ & $1.0 \mathrm{E}-07$ & $2.0 \mathrm{E}-04$ & 0.03 \\
\hline $\mathrm{Pu}$ & 239 & $2.4 \mathrm{E}+04$ & $3,537.2$ & $1.0 \mathrm{E}-07$ & $2.0 \mathrm{E}-04$ & 0.03 \\
\hline $\mathrm{Pu}$ & 240 & $6.5 \mathrm{E}+03$ & $3,537.2$ & $1.0 \mathrm{E}-07$ & $2.0 \mathrm{E}-04$ & 0.03 \\
\hline $\mathrm{Am}$ & $242(\mathrm{~m})$ & $1.5 \mathrm{E}+02$ & $3,515.0$ & $1.0 \mathrm{E}-07$ & $2.0 \mathrm{E}-04$ & 0.03 \\
\hline $\mathrm{Pu}$ & 242 & $3.8 \mathrm{E}+05$ & $3,359.6$ & $1.0 \mathrm{E}-07$ & $2.0 \mathrm{E}-04$ & 0.03 \\
\hline $\mathrm{Pu}$ & 238 & $8.8 \mathrm{E}+01$ & $3,200.5$ & $1.0 \mathrm{E}-07$ & $3.0 \mathrm{E}-04$ & 0.03 \\
\hline $\mathrm{Cm}$ & 242 & 162.8 (days) & $2,512.3$ & $4.0 \mathrm{E}-06$ & $1.0 \mathrm{E}-02$ & 1 \\
\hline $\mathrm{Cm}$ & 243 & $2.9 \mathrm{E}+01$ & $2,512.3$ & $1.0 \mathrm{E}-07$ & $3.0 \mathrm{E}-04$ & 0.04 \\
\hline $\mathrm{Cm}$ & 244 & $1.8 \mathrm{E}+01$ & $2,016.5$ & $2.0 \mathrm{E}-07$ & $4.0 \mathrm{E}-04$ & 0.05 \\
\hline $\mathrm{U}$ & 234 & $2.4 \mathrm{E}+05$ & 283.4 & $2.0 \mathrm{E}-05$ & $5.0 \mathrm{E}-02$ & 0.4 \\
\hline U & 236 & $2.3 \mathrm{E}+07$ & 268.6 & $2.0 \mathrm{E}-05$ & $5.0 \mathrm{E}-02$ & 0.5 \\
\hline $\mathrm{U}$ & 235 & $7.0 \mathrm{E}+08$ & 266.0 & $2.0 \mathrm{E}-05$ & $5.0 \mathrm{E}-02$ & 0.5 \\
\hline $\mathrm{U}$ & 238 & $4.5 \mathrm{E}+09$ & 254.6 & $2.0 \mathrm{E}-05$ & $5.0 \mathrm{E}-02$ & 0.5 \\
\hline $\mathrm{Pu}$ & 241 & $1.4 \mathrm{E}+01$ & 68.5 & $5.0 \mathrm{E}-06$ & $1.0 \mathrm{E}-02$ & 1 \\
\hline $\mathrm{Np}$ & 239 & 2.355 (days) & 3.3 & $1.0 \mathrm{E}-03$ & $2.0 \mathrm{E}+00$ & 60 \\
\hline $\mathrm{U}$ & 237 & 6.75 (days) & 3.1 & 4.0E-02 & $1.0 \mathrm{E}+02$ & 60 \\
\hline \multicolumn{7}{|c|}{ Prominent thorium fuel cycle nuclides } \\
\hline Th & 232 & $1.4 \mathrm{E}+10$ & 2730.6 & $2.0 \mathrm{E}-08$ & $4.0 \mathrm{E}-05$ & 0.03 \\
\hline $\mathrm{U}$ & 233 & $1.6 \mathrm{E}+05$ & 1309.8 & $2.0 \mathrm{E}-05$ & $4.0 \mathrm{E}-02$ & 0.4 \\
\hline Th & 228 & $1.9 \mathrm{E}+00$ & 395.9 & $3.0 \mathrm{E}-07$ & $4.0 \mathrm{E}-04$ & 0.2 \\
\hline $\mathrm{Ra}$ & 224 & 3.66 (days) & 365.9 & $3.0 \mathrm{E}-05$ & $6.0 \mathrm{E}-02$ & 0.3 \\
\hline $\mathrm{U}$ & 232 & $7.2 \mathrm{E}+01$ & 289.0 & $3.0 \mathrm{E}-06$ & $8.0 \mathrm{E}-03$ & 0.08 \\
\hline $\mathrm{Pa}$ & 233 & $27($ days $)$ & 3.6 & $1.0 \mathrm{E}-02$ & $3.0 \mathrm{E}+01$ & 50 \\
\hline
\end{tabular}

${ }^{*}$ The dose factor is the effective dose equivalent that uses a weighted sum of doses to all irradiated organs and tissues. 


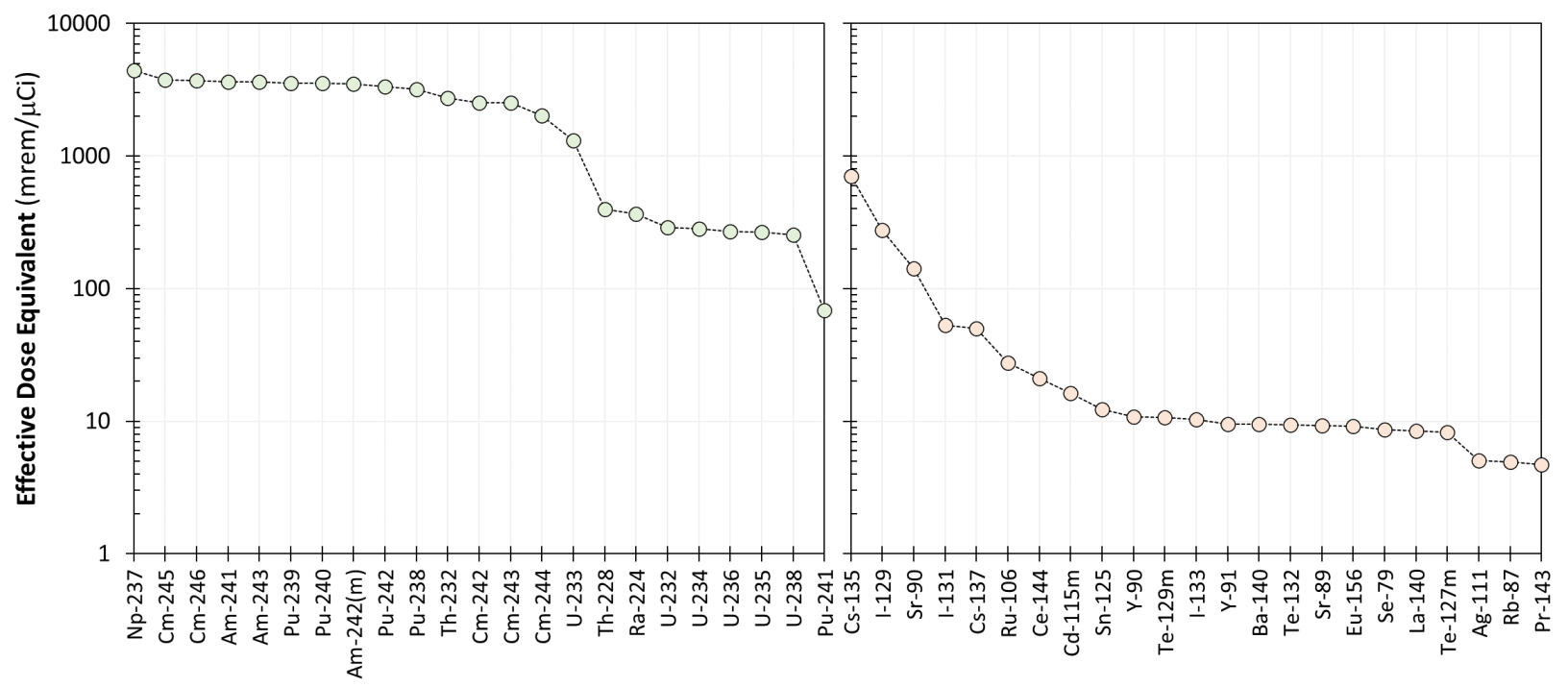

Figure 5. Actinides and fission products ranked by radiotoxicity as quantified by the effective dose equivalent (plotted from tabulated values of Eckerman et al. [68]).

\subsubsection{Inventory Distribution Based on Chemical Affinity during Normal Operation}

Observations from the MSRE project led to sorting of fission products into three categories: (1) saltseeking elements, (2) noble elements, and (3) volatile elements. As shown in Figure 6, salt-seeking elements include $\mathrm{Rb}, \mathrm{Sr}, \mathrm{Y}, \mathrm{Zr}, \mathrm{Cs}, \mathrm{Ba}, \mathrm{La}, \mathrm{Ce}$, and the lanthanides and noble-acting elements include $\mathrm{Nb}$, Mo, Tc, Ru, Rh, Pd, Ag, Sb, Te, and possibly Cd, In, and Sn. 
Chloride Salts

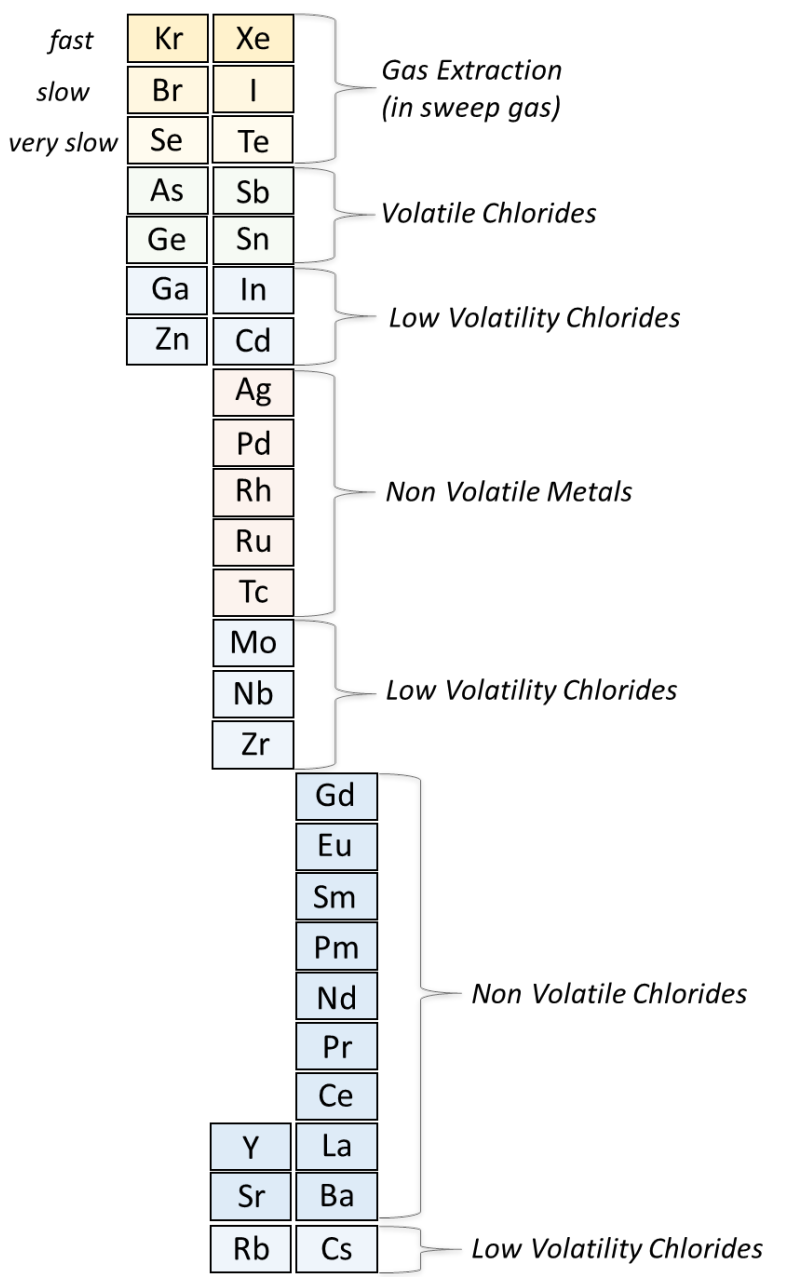

Fluoride Salts

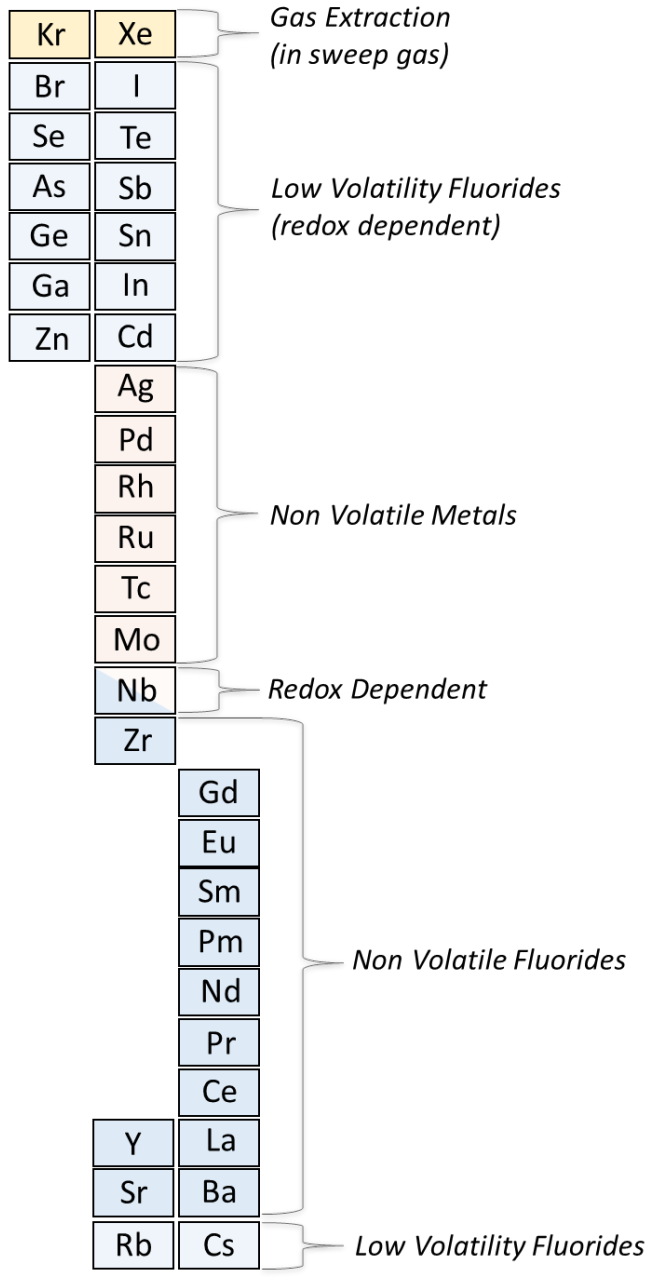

Figure 6. Summary diagrams of the chemical behavior of important radionuclide elements during normal operation of typical chloride- or fluoride-fueled MSRs (temperatures between $600-700^{\circ} \mathrm{C}$ ).

The chloride salt diagram (left) is adapted from Taube [64], and the fluoride salt diagram (right) is based on observations made during the MSRE [71].

Niobium can act as a salt-seeking or noble-acting element, depending on the redox conditions of the fuel. Iodine can form iodides that remain in the salt but could also volatilize as $\mathrm{I}_{2}$ or $\mathrm{ICl}_{\text {or }} \mathrm{IF}_{7}$ depending on salt conditions if the salt redox potential increases significantly above the optimal operating conditions (e.g., due to an oxygen-bearing gas contacting the fuel).

The disposition of some important elements will depend on their precursors. For example, some isotopes of $\mathrm{Rb}, \mathrm{Sr}, \mathrm{Y}, \mathrm{Cs}$, and $\mathrm{Ba}$ that are important to the source term have noble-gas progenitors with half-lives long enough to enable their escape into the cover gas before decaying (Figure 7). This could lead to an accumulation of some key source term radionuclides in the off-gas system. Similarly, the precursor of ${ }^{131} \mathrm{I}$ is ${ }^{131} \mathrm{Te}$, and iodine will be produced in locations where tellurium has been deposited (e.g., on metal surfaces, within the off-gas system). 


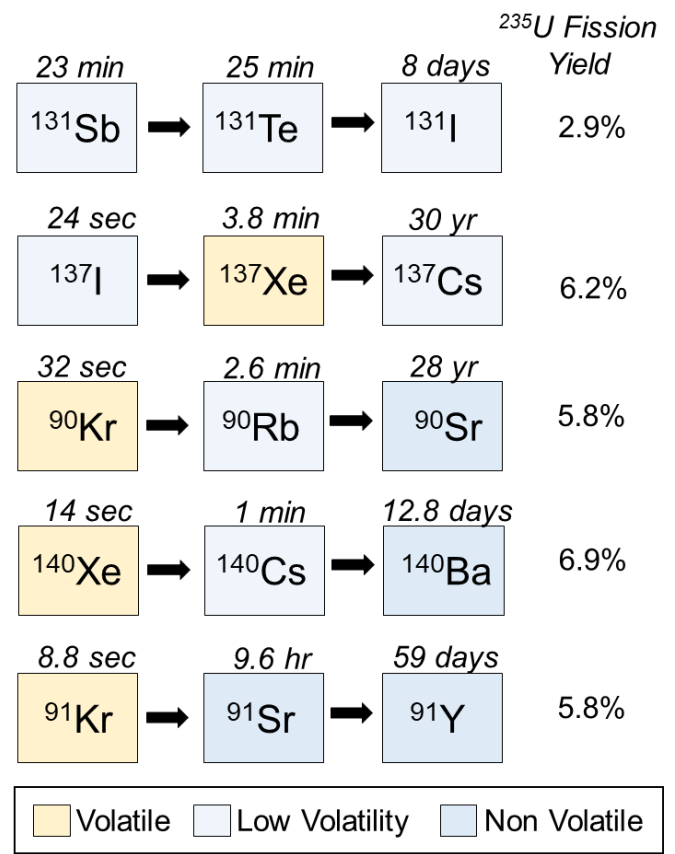

Figure 7. Portions of the decay chains of important fission product nuclides (fission yields are from Table 3).

There is less information regarding the disposition of fission products during the operation of a chloride fuel salt-based reactor due to the lack of test reactor experience. However, the chemistry of fission products in molten chloride salts has been studied in some detail from the perspective of MSR development [64] and its use in technologically mature pyroprocessing schemes [68] [69]. For example, Taube [64] suggests that I, Br, Se, and Te would all be extracted by an inert gas purge through the fuel while the important fission products $\mathrm{Ag}, \mathrm{Pd}, \mathrm{Rh}, \mathrm{Ru}$, and $\mathrm{Tc}$ would remain in the salt as nonvolatile metals [64]. Molybdenum, $\mathrm{Nb}, \mathrm{Zr}, \mathrm{Rb}$, and $\mathrm{Cs}$ are identified as forming low-volatility chloride species, whereas the lanthanides, $\mathrm{Sr}$ and $\mathrm{Ba}$, are predicted to remain in the salt as nonvolatile chloride species [64].

The estimated fission product partitioning shown in Table 8 is based on sample analyses from the MSRE [70] and assumptions made by Robertson [71] about what elements would be held up within the chemical processing facility for a thermal spectrum $\mathrm{Th} / \mathrm{U}$ fuel cycle molten salt breeder reactor. The results show that many important fission products - including $\mathrm{Se}, \mathrm{Cd}, \mathrm{Sn}, \mathrm{Sb}$, and the lanthanides - are predicted to remain entirely within the fuel salt, whereas the semi volatile elements (Cs and I), noble metals, and nuclides with noble gas precursors $\left({ }^{90} \mathrm{Sr},{ }^{140} \mathrm{Ba}\right.$, and $\left.{ }^{91} \mathrm{Y}\right)$ are predicted to be partitioned between the salt and cover gas. A fraction of several important fission product elements is also predicted to adsorb or plate out onto metal surfaces or diffuse into the graphite moderator structures; these include Rb, $\mathrm{Cs}, \mathrm{Sr}, \mathrm{Y}, \mathrm{Zr}$, $\mathrm{Te}$, and the noble metals. It is assumed that a fraction of the $\mathrm{Y}, \mathrm{Zr}, \mathrm{Nb}, \mathrm{La}, \mathrm{Pr}, \mathrm{Nd}$, and $\mathrm{Pr}$ and a large fraction of the $\mathrm{Pa}$ will be partitioned and held up within the fuel chemistry plant. 
Table 8. Estimated distribution of important heat-producing fission products for a normally operating fluoride-fueled MSR (quantified as thermal power). Adapted from Robertson [72].

\begin{tabular}{|c|c|c|c|c|c|c|c|}
\hline \multirow{3}{*}{ Element } & \multicolumn{4}{|c|}{ At reactor shutdown } & \multicolumn{3}{|c|}{8 hour decay } \\
\hline & Salt & Off-gas & $\begin{array}{c}\text { Graphite/ } \\
\text { alloy }\end{array}$ & $\begin{array}{c}\text { Chemistry } \\
\text { plant }\end{array}$ & Salt & Off-gas & $\begin{array}{c}\text { Graphite } \\
\text { alloy }\end{array}$ \\
\hline & $k W$ & $k W$ & $k W$ & $k W$ & $k W$ & $k W$ & $k W$ \\
\hline $\mathbf{Z n}$ & 0.0002 & 0 & 0 & 0 & 0.00013 & 0 & 0 \\
\hline Ga & 0.26 & 0 & 0 & 0 & 0.0047 & 0 & 0 \\
\hline Ge & 1.8 & 0 & 0 & 0 & 0.083 & 0 & 0 \\
\hline As & 45 & 0 & 0 & 0 & 0.14 & 0 & 0 \\
\hline Se & 206 & 0 & 0 & 0 & 0.00023 & 0 & 0 \\
\hline $\mathrm{Br}$ & 4,220 & 0 & 0 & 0 & 0.014 & 0 & 0 \\
\hline $\mathbf{K r}$ & 1,130 & 2,370 & 250 & 0 & 0.016 & 2.8 & 0 \\
\hline $\mathbf{R b}$ & 5,560 & 2,930 & 290 & 0 & 0.0058 & 1 & 0 \\
\hline $\mathrm{Sr}$ & 4,270 & 374 & 40 & 1.5 & 131 & 220 & 23 \\
\hline $\mathbf{Y}$ & 4,750 & 140 & 17 & 170 & 267 & 79 & 7 \\
\hline $\mathbf{Z r}$ & 648 & 0 & 0 & 350 & 349 & 0 & 0 \\
\hline $\mathbf{N b}$ & 314 & 1,790 & 1,790 & 318 & 406 & 97 & 97 \\
\hline Mo & 69 & 835 & 835 & 0 & 0.024 & 145 & 145 \\
\hline Te & 25 & 1,240 & 1,240 & 0 & 0.003 & 30 & 30 \\
\hline $\mathbf{R u}$ & 2.5 & 160 & 160 & 0 & 0.002 & 88 & 88 \\
\hline $\mathbf{R h}$ & 4.1 & 52 & 52 & 0 & 0.0034 & 33 & 33 \\
\hline $\mathbf{P d}$ & 2 & 0.4 & 0.4 & 0 & 0.12 & 0.1 & 0.1 \\
\hline Ag & 14 & 0.1 & 0.1 & 0.2 & 1.8 & 0 & 0 \\
\hline Cd & 5.3 & 0 & 0 & 0 & 0.38 & 0 & 0 \\
\hline In & 14 & 0 & 0 & 0 & 0.28 & 0 & 0 \\
\hline Sn & 60 & 0 & 0 & 0 & 0.2 & 0 & 0 \\
\hline Sb & 5,450 & 0 & 0 & 0 & 14 & 0 & 0 \\
\hline Te & 510 & 1,970 & 1,970 & 0 & 3.2 & 78 & 78 \\
\hline I & 4,510 & 2,120 & 2,120 & 0 & 48 & 745 & 745 \\
\hline $\mathrm{Xe}$ & 1,080 & 2,770 & 414 & 0 & 28 & 180 & 22 \\
\hline Cs & 4,000 & 2,600 & 383 & 0 & 2.5 & 8.1 & 0 \\
\hline $\mathbf{B a}$ & 4,030 & 490 & 58 & 0 & 230 & 96 & 10 \\
\hline La & 4,620 & 470 & 50 & 68 & 1,380 & 450 & 16 \\
\hline $\mathrm{Ce}$ & 1,260 & 3 & 0.5 & 154 & 375 & 3 & 0.5 \\
\hline Pr & 1,740 & 0 & 0 & 492 & 230 & 0 & 0 \\
\hline Nd & 213 & 0 & 0 & 25 & 80 & 0 & 0 \\
\hline Pm & 150 & 0 & 0 & 12 & 72 & 0 & 0 \\
\hline Sm & 10 & 0 & 0 & 0.3 & 3.8 & 0 & 0 \\
\hline $\mathbf{E u}$ & 3.8 & 0 & 0 & 0.04 & 2.9 & 0 & 0 \\
\hline Gd & 0.055 & 0 & 0 & 0 & 0.017 & 0 & 0 \\
\hline $\mathbf{T b}$ & 0.0024 & 0 & 0 & 0 & 0.0016 & 0 & 0 \\
\hline $\mathbf{P a}$ & 500 & 0 & 0 & 5,000 & 485 & 0 & 0 \\
\hline
\end{tabular}




\subsection{RADIONUCLIDE TRANSPORT AND RETENTION PHENOMENA}

As stated in SECY-93-092, an MST is developed by modeling the transport of radionuclides from the fuel; through the reactor coolant system; through holdup volumes and barriers, including any mitigation features; and into the environment. A summary of the chemical and physical phenomena that control the transport and retention of radionuclides in a generic MSR is provided in Figure 8. Note, the fission process, which produces the radionuclides as well as changing the salt redox condition and generating the neutrons that transmute/activate materials is not included in Figure 8. The processes that can occur in the core vessel are the main focus of this section. However, some important transport phenomena might also apply to other areas of an MSR design (e.g., off-gas system, fuel processing facility, drain tank cell).

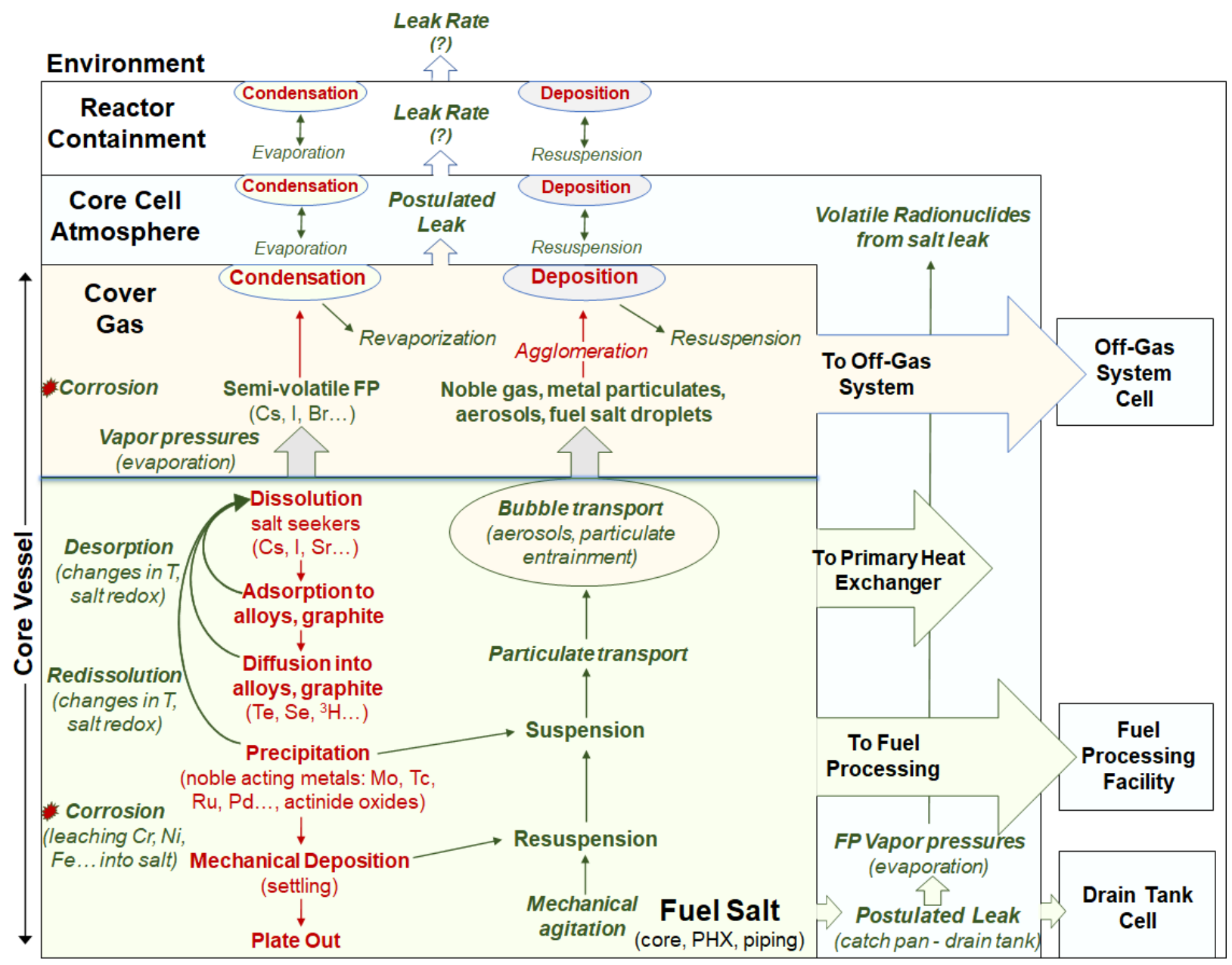

Figure 8. Schematic summary of radionuclide transport and retention phenomena pertaining to MSR core. Red text indicates retention processes, and green text indicates transport processes.

\subsubsection{Transport/Retention Processes Modeling with Thermochemical Data}

One of the foremost factors that determines whether a radionuclide will be retained or transported from the fuel salt is its chemical form, also referred to as chemical speciation. The chemical speciation of a radionuclide at any time during normal operation or an accident scenario determines whether that radionuclide will partition into the vapor, liquid, or solid phase. If a radionuclide is released to the environment, then its chemical speciation will affect transport and determine toxicity. The main factors 
that can influence chemical speciation in an MSR include total concentrations, fuel salt chemical composition, fuel salt redox potential, temperature, pressure, and reaction kinetics.

Grabaskas et al. recently developed a model to calculate the speciation of key fission products for SFRMST analyses by using a thermochemical database and the modeling software HSC Chemistry [42]. Specifically, the chemical speciation and phase distribution was calculated at equilibrium via the Gibbs free energy minimization method, which requires the enthalpy and entropy of formation and the heat capacity for each possible species that might form (Figure 9). The nonideal behavior of chemical species must be accounted for by the inclusion of excess Gibbs free energy terms, which were input as empirically determined activity coefficients in this SFR-specific example (Figure 9). The nonideal effects of mixing in MSR fuel salts are complex, and the excess Gibbs energy terms for MSR systems are best modeled via the CALPHAD method, as shown in Section 3.4.2.3.

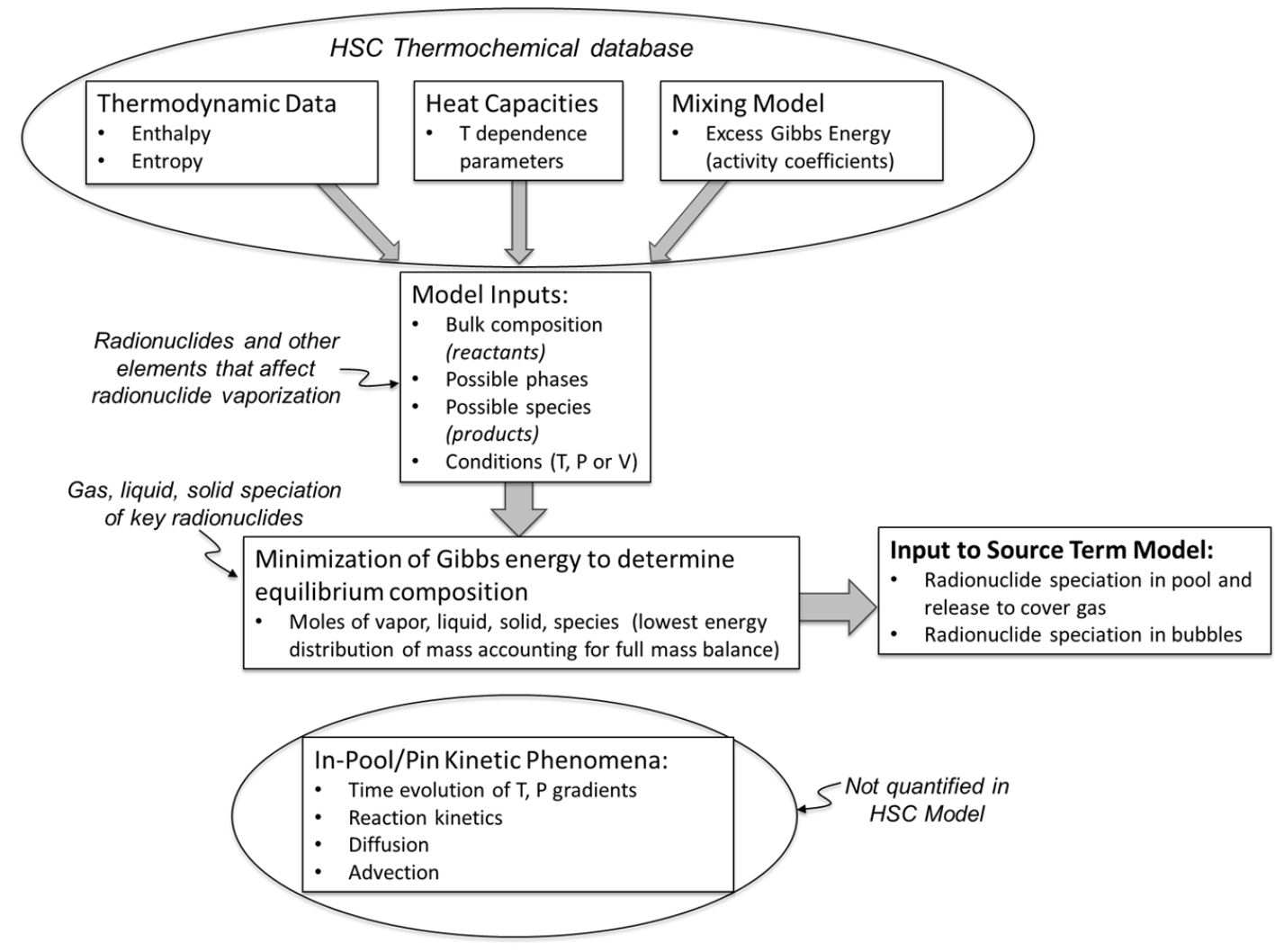

Figure 9. Schematic information flow for the thermochemical model used to calculate radionuclide chemical speciation for the sodium fast reactor MST (from Grabaskas et al. [42]).

A Gibbs free energy minimization methodology for source term analysis assumes equilibrium and does not consider reaction kinetics or physical processes that might create chemical gradients (e.g., advection and diffusion). When physically or kinetically limited processes for chemical species transport are deemed important, additional transport models are required (Section 3.4.2.5).

\subsubsection{Description of Transport and Retention Processes in a Generic MSR}

Chemically, liquid-fueled MSR concepts can be grouped into two categories based on the halide used in the fuel salt: fluoride or chloride. Fluoride-based MSRs have been operated successfully and have received more historical attention than chloride-based systems. Table 9 provides a partial list of candidate fuel salt compositions for MSR concepts to show the range of possible chemistries. 
Table 9. MSR concept fuel salt chemistry (adapted from Taira et al. [91]).

\begin{tabular}{|c|c|c|c|c|}
\hline Concept & Feed & Molten salt (mol \%) & $\begin{array}{l}\text { Neutronic } \\
\text { spectrum }\end{array}$ & Ref. \\
\hline \multicolumn{5}{|l|}{ Fluoride salts } \\
\hline MSRE & $\begin{array}{l}{ }^{238} \mathrm{U},{ }^{235} \mathrm{U},{ }^{233} \mathrm{U} \text { after } 2 \\
\text { years, }{ }^{239} \mathrm{Pu}\end{array}$ & $\begin{array}{l}\mathrm{LiF}-\mathrm{BeF}_{2}-\mathrm{ZrF}_{4}-\mathrm{UF}_{4} \\
(65-29.1-5-0.9)\end{array}$ & Thermal & {$[72],[73]$} \\
\hline MSBR & ${ }^{232} \mathrm{Th},{ }^{233} \mathrm{U}$ & $\begin{array}{l}\mathrm{LiF}-\mathrm{BeF}_{2}-\mathrm{ThF}_{4}-\mathrm{UF}_{4} \\
(71.6-16-12-0.4)\end{array}$ & Thermal & {$[74],[75]$} \\
\hline MSFR & ${ }^{232} \mathrm{Th},{ }^{233} \mathrm{U}$ & 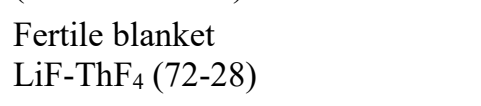 & Fast & {$[76],[77],[78]$} \\
\hline MOSART & TRU 2-3 mol\% & $\begin{array}{l}\text { LiF-NaF-BeF } \\
(15-58-27)\end{array}$ & Fast & {$[79]$} \\
\hline \multicolumn{5}{|c|}{ Chloride salts } \\
\hline WISE & $\begin{array}{l}\text { Natural fuel } \\
{ }^{238} \mathrm{U} \text { or }{ }^{232} \mathrm{Th}\end{array}$ & $\begin{array}{l}\mathrm{Na}^{37} \mathrm{Cl}_{-} \mathrm{An}^{37} \mathrm{Cl}_{3}{ }^{*}(60-40) \\
\mathrm{Pb}^{37} \mathrm{Cl}_{2}-\mathrm{An}^{37} \mathrm{Cl}_{3}{ }^{*}(60-40)\end{array}$ & Hard fast & {$[80]$} \\
\hline REBUS & TRU, U & $\begin{array}{l}\text { (U, TRU) } \mathrm{Cl}_{3}-\mathrm{NaCl} \\
\text { TRU: } 15.6 \text { at. } \%\end{array}$ & Fast & {$[66]$} \\
\hline MCFBR & TRU, ${ }^{238} \mathrm{U}$ & $\begin{array}{l}\text { Molten fuel: } \mathrm{PuCl}_{3}-\mathrm{NaCl}(15-85) \\
\text { Molten fertile material: } \mathrm{UCl}_{3^{-}} \\
\mathrm{NaCl}(65-35)\end{array}$ & Fast & {$[64],[81]$} \\
\hline
\end{tabular}

${ }^{*}$ An $=$ Actinide

The fuel salt composition, relative abundance of chemical species, type of fissile material, and fuel salt oxidation state play important roles in the possible transport and retention processes that can occur during normal operations or as a result of an accident. These transport and retention processes are discussed in the following section.

\subsubsection{Dissolution and Complexation}

Actinides are relatively soluble as fluoride and chloride complexes, but their solubility is heavily influenced by the redox potential of the fuel salt, temperature, and the presence of other metal fluoride or chloride complexes. Depending on fuel salt redox potential, uranium will exist as dissolved $\mathrm{UF}_{3}$ and $\mathrm{UF}_{4}$ complexes in fluoride fuel salts and as $\mathrm{UCl}_{3}$ and $\mathrm{UCl}_{4}$ complexes in chloride salts. Fluoride fuel salts with uranium fuel typically use a mixture of $\mathrm{UF}_{4}$ and $\mathrm{UF}_{3}$ to act as redox buffers to prevent the corrosion of structural metals by $\mathrm{UF}_{4}$ [82]. $\mathrm{A} \mathrm{UF}_{4} / \mathrm{UF}_{3}$ ratio on the order of 100 is estimated to provide enough $\mathrm{UF}_{3}$ reductant to protect metal surfaces [83]. Excessively reducing salt also must be avoided to prevent the development of uranium carbide. Actinide trifluorides have limited solubility in fluoride salts. The solubility of $\mathrm{PuF}_{3}$ in a range of fluoride fuel salt mixtures was $0.4-2.5 \mathrm{~mol} \%$ at $650^{\circ} \mathrm{C}$ and $0.16-1.0 \mathrm{~mol}$ $\%$ at $550^{\circ} \mathrm{C}[84]$.

The presence of more than one actinide species can influence actinide solubilities. For example, the solubility of $\mathrm{a} \mathrm{PuF}_{3}$ and $\mathrm{UF}_{3}$ mixture in a fluoride fuel salt is much less than the individual solubilities of $\mathrm{PuF}_{3}$ and $\mathrm{UF}_{3}$ [84]. Actinide trichlorides have a high solubility in chloride salts relative to their fluoride counterparts, and thus chloride salts can contain significant amounts of actinides. The molten chloride fast

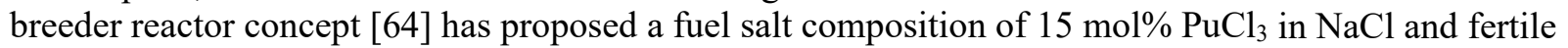
blanket salt composition of $65 \mathrm{~mol}_{0} \mathrm{UCl}_{3}$ in $\mathrm{NaCl}$ [64]. Actinide trichlorides are preferred over the more reactive actinide tetrachlorides [85]. Also, $\mathrm{UCl}_{4}$ 's boiling point is $791{ }^{\circ} \mathrm{C}$, so will have significant 
volatility. However, some actinide tetrachloride presence is favorable to minimize the disproportionation of actinide trichloride to actinide tetrachloride and actinide metal.

In addition to the actinides, it is important to understand the solubilities and complexation behavior of the fission and activation products in an MSR. An analysis of the MSRE fuel salt determined that the majority of group IA (e.g., Rb, Cs), group IIA (e.g., Sr, Ba), lanthanide, Y, and Zr fission or activation products that were generated during operation are salt soluble and remained homogenously distributed in the salt [86]. Although chemical speciation was not measured, it is inferred that these species formed stable fluoride complexes in the fuel salt and that the salt serves as a barrier against the release of these complexes.

Finally, the formation of fluoride or chloride compounds with fission products or metal alloy corrosion products, especially polyvalent fluorides/chlorides, in the fuel salt might decrease the solubility of actinides. The presence of $\mathrm{CeF}_{3}$ in a $\mathrm{LiF}_{-} \mathrm{BeF}_{2}(63-37 \mathrm{~mol} \%)$ salt mixture at a 1:1 and 5:1 molar ratio of $\mathrm{CeF}_{3}$ to $\mathrm{PuF}_{3}$ substantially decreases the solubility of $\mathrm{PuF}_{3}$ compared with $\mathrm{PuF}_{3}$ alone [84]. Therefore, it is prudent to monitor the salt chemistry to ensure the solubility of actinides throughout operation and to include appropriate margin to avoid approaching actinide solubility limits.

\subsubsection{Volatilization}

The volatile species are the most likely to be released from reactor containment during normal operation or an accident scenario. The driving force for the volatilization of a chemical species from the molten fuel salt is the vapor pressure of the chemical species. Chemical species that can undergo volatilization in an MSR fall into three categories: the fuel salt compounds, fission and activation products, and actinides. One of the most appealing features of MSRs is the reasonably low vapor pressures of the fuel salt compounds, even at temperatures greater than $1300 \mathrm{~K}$ (Table 10). Therefore, a significant vaporization of salt compounds during a heating event is unlikely. For these reasons, MSRs are unlikely to experience over-pressurization events derived from salt behavior and differ significantly from LWRs in this respect.

Table 10. Measured vapor pressures of fuel salt compounds in simulated fuel salt.

\begin{tabular}{|c|c|c|c|}
\hline \multicolumn{4}{|c|}{ Measured vapor pressures over $\mathrm{LiF}_{-} \mathrm{ThF}_{4}-\mathrm{CsF}(75.73-23.23-1.05 \mathrm{~mol} \%)^{1}$} \\
\hline Temperature & $1,100 \mathrm{~K}$ & $1,200 \mathrm{~K}$ & $1,300 \mathrm{~K}$ \\
\hline $\mathbf{L i F}_{(g)}$ & $0.5 \mathrm{~Pa}$ & $3.7 \mathrm{~Pa}$ & $19.4 \mathrm{~Pa}$ \\
\hline $\mathrm{ThF}_{4(\mathrm{~g})}$ & $0.004 \mathrm{~Pa}$ & $0.09 \mathrm{~Pa}$ & $1.9 \mathrm{~Pa}$ \\
\hline $\mathbf{C s F}_{(\mathrm{g})}$ & $0.07 \mathrm{~Pa}$ & $0.3 \mathrm{~Pa}$ & $0.7 \mathrm{~Pa}$ \\
\hline \multicolumn{4}{|c|}{ Measured vapor pressures over pure FLiNaK (LiF-NaF-KF: 46.5-11.5-42.0 mol \%) ${ }^{2}$} \\
\hline Temperature & $1,000 \mathrm{~K}$ & $1,100 \mathrm{~K}$ & -- \\
\hline $\mathbf{L i F}_{(\mathrm{g})}$ & $0.1 \mathrm{~Pa}$ & $3.1 \mathrm{~Pa}$ & -- \\
\hline $\mathbf{N a F}_{(\mathbf{g})}$ & -- & $0.4 \mathrm{~Pa}$ & -- \\
\hline $\mathbf{K F}_{(\mathbf{g})}$ & $0.5 \mathrm{~Pa}$ & $10.3 \mathrm{~Pa}$ & -- \\
\hline
\end{tabular}

${ }^{1}$ From Capelli et al [87]

${ }^{2}$ From Sekiguchi et al [88]

The volatile fission and activation products of interest that are expected to be released from fluoride or chloride fuel salts include: (1) noble gases (e.g., $\mathrm{Xe}$ and $\mathrm{Kr}$ ), (2) volatile halogen species (e.g., $\mathrm{HF}, \mathrm{F}_{2}$, $\mathrm{Cl}_{2}, \mathrm{Br}_{2}, \mathrm{I}_{2}, \mathrm{CsI}$ ), and (3) volatile tritium species (e.g., ${ }^{3} \mathrm{H}_{2(\mathrm{~g})},{ }^{3} \mathrm{HH}_{(\mathrm{g})}$, and ${ }^{3} \mathrm{HF}_{(\mathrm{g})}$ ) [29]. During normal operation, the noble gases will be released to any cover gas and any associated off-gas system. If a leak occurs, the noble gas fission products might accumulate in the head space of reactor containment and/or 
escape into the environment via the off-gas system. Considering the yield of noble gases through fission (nearly 1 atom per fission), the pressurization of enclosed spaces could occur and become an issue if a vent of off-gas is unavailable.

Both fission products, Cs and I can bind together to form CsI, which is volatile in common MSR fuel salt compositions (i.e., FLiNaK and $\mathrm{LiF}_{-} \mathrm{ThF}_{4}-\mathrm{UF}_{4}$ ) [89] [90] [88]. Additionally, CsI is considered one of the most important species transporting radioactive iodine under severe accident conditions for LWRs [91]. Tritium will also be produced in MSRs due to ternary fission or activation of the fuel salt, coolant, and core materials, especially by the activation of ${ }^{6} \mathrm{Li}$ in the thermal neutron spectrum. Tritium is soluble in the fuel salt as ${ }^{3} \mathrm{HF}$ or ${ }^{3} \mathrm{HCl}$ but can undergo volatilization as ${ }^{3} \mathrm{H}_{2(\mathrm{~g})},{ }^{3} \mathrm{HH}_{(\mathrm{g})}$, or halogen species (e.g., ${ }^{3} \mathrm{HF}(\mathrm{g})$ or $\left.{ }^{3} \mathrm{HCl}_{(\mathrm{g})}\right)$ and can diffuse through metal containment structures and the graphite moderator. Finally, nonvolatile decay products generated from volatilized species might condense on containment surfaces [70]. The ${ }^{89} \mathrm{Sr}$ and ${ }^{137} \mathrm{Cs}$ isotopes are decay products of the short-lived noble gas species ${ }^{89} \mathrm{Kr}$ $\left(\mathrm{t}_{1 / 2}=3.18 \mathrm{~min}\right)$ and ${ }^{137} \mathrm{Xe}\left(\mathrm{t}_{1 / 2}=3.83 \mathrm{~min}\right)$, respectively, and were detected outside the fuel salt in the MSRE [70].

Compared with certain fission products, the actinide fluoride and chloride complexes have much lower vapor pressures. However, due to their high radiotoxicity and long half-lives, an MST assessment requires detailed information on the vapor pressure of actinides as a function of fuel salt composition, total actinide concentration, and temperature. Also, $\mathrm{UCl}_{4}$ is more volatile than other actinide species anticipated to be present in MSR fuel salts [85].

Radiolysis is not expected to have a large influence on volatilization phenomena due to the high rate of recombination with the fuel salt expected at the temperatures of operation [86]. However, volatile radiolysis products (e.g., $\mathrm{F}_{2}$ and $\mathrm{Cl}_{2}$ ) that escape from the fuel salt might influence the local redox potential and the production of volatile chemical species. Evidence from the MSRE indicated the production of a significant amount of radiolytic $\mathrm{F}_{2}$ after reactor shutdown and the cooling of the fuel salt, which recombined with the $\mathrm{UF}_{4}$ remaining in the fuel salt [86]. The result was the production of volatile $\mathrm{UF}_{6(\mathrm{~g})}$ and the subsequent deposition of an estimated $4.4 \mathrm{~kg}$ of uranium in the auxiliary charcoal bed of the off-gas system [32] [86]. Because of the high volatility and radiotoxicity of $\mathrm{UF}_{6}$, opportunities for radiolytic $\mathrm{F}_{2}$ and $\mathrm{UF}_{4}$ to react should be monitored. Table 11 outlines volatilization phenomena that might occur during normal operation or a postulated accident for a generic MSR.

Table 11. Summary of volatilization phenomena.

\begin{tabular}{|c|c|c|c|c|c|c|}
\hline $\begin{array}{l}\text { Description of } \\
\text { phenomenon }\end{array}$ & $\begin{array}{c}\text { Source of } \\
\text { radionuclide } \\
\text { species }\end{array}$ & $\begin{array}{c}\text { Fate of radionuclide } \\
\text { species }\end{array}$ & $\begin{array}{c}\text { Experimental/ } \\
\text { modeling } \\
\text { details }\end{array}$ & $\begin{array}{l}\text { Relevant } \\
\text { accident } \\
\text { scenarios }\end{array}$ & Notes & Ref. \\
\hline $\begin{array}{l}\text { Volatilization of } \\
\text { medium-lived } \\
\text { noble gas fission } \\
\text { products (e.g., } \\
{ }^{85} \mathrm{Kr} \text { ) }\end{array}$ & $\begin{array}{l}\text { Fission products } \\
\text { of }{ }^{233} \mathrm{U},{ }^{235} \mathrm{U} \text {, or } \\
{ }^{239} \mathrm{Pu} \text { in fuel salt }\end{array}$ & $\begin{array}{l}\text { Release to cover gas } \\
\text { and out-gas system }\end{array}$ & $\begin{array}{l}\text { Evidence from } \\
\text { MSRE } \\
\text { operation }\end{array}$ & $\mathrm{N} / \mathrm{A}^{*}$ & None & {$[70]$} \\
\hline \multirow{2}{*}{$\begin{array}{l}\text { Volatilization of } \\
\text { short-lived noble } \\
\text { gas fission } \\
\text { products (e.g., } \\
{ }^{89} \mathrm{Kr} \text { and } \mathrm{Xe}^{137} \text { ) }\end{array}$} & \multirow[t]{2}{*}{$\begin{array}{l}\text { Fission products } \\
\text { of }{ }^{233} \mathrm{U},{ }^{235} \mathrm{U} \text {, or } \\
{ }^{239} \mathrm{Pu} \text { in fuel salt }\end{array}$} & $\begin{array}{l}\text { Release to cover gas } \\
\text { and out-gas system }\end{array}$ & $\begin{array}{l}\text { Evidence from } \\
\text { MSRE } \\
\text { operation }\end{array}$ & $\mathrm{N} / \mathrm{A}^{*}$ & None & {$[70]$} \\
\hline & & $\begin{array}{l}\text { Decay to nonvolatile } \\
\text { daughters (e.g., }{ }^{89} \mathrm{Sr} \\
\text { and }{ }^{137} \mathrm{Cs} \text { ) that might } \\
\text { condense on } \\
\text { containment surfaces } \\
\text { in the form of } \\
\text { transportable } \\
\text { particles. }\end{array}$ & $\begin{array}{l}\text { Evidence from } \\
\text { MSRE } \\
\text { operation }\end{array}$ & $\mathrm{N} / \mathrm{A}^{*}$ & None & {$[70]$} \\
\hline
\end{tabular}


Table 11. Summary of volatilization phenomena (continued).

\begin{tabular}{|c|c|c|c|c|c|c|}
\hline $\begin{array}{l}\text { Description of } \\
\text { phenomenon }\end{array}$ & $\begin{array}{c}\text { Source of } \\
\text { radionuclide } \\
\text { species } \\
\end{array}$ & $\begin{array}{c}\text { Fate of } \\
\text { radionuclide } \\
\text { species } \\
\end{array}$ & $\begin{array}{l}\text { Experimental/ } \\
\text { modeling details }\end{array}$ & $\begin{array}{l}\text { Relevant } \\
\text { accident } \\
\text { scenarios } \\
\end{array}$ & Notes & Ref. \\
\hline \multirow[t]{2}{*}{$\begin{array}{l}\text { Volatilization of } \\
\text { CsI }\end{array}$} & \multirow{2}{*}{$\begin{array}{l}\text { Both fission } \\
\text { products of }{ }^{233} \mathrm{U} \text {, } \\
{ }^{235} \mathrm{U} \text {, or }{ }^{239} \mathrm{Pu} \text { in } \\
\text { fuel salt. }{ }^{137} \mathrm{Cs} \text { is } \\
\text { a decay daughter } \\
\text { of }{ }^{137} \mathrm{I} .{ }^{131} \mathrm{I} \text { is a } \\
\text { decay daughter of } \\
{ }^{131} \mathrm{Sb} \text {. }\end{array}$} & $\begin{array}{l}\text { Release to cover } \\
\text { gas and out-gas } \\
\text { system. } \\
\text { Environmental } \\
\text { release via } \\
\text { atmospheric }\end{array}$ & $\begin{array}{l}\text { Vapor pressure } \\
\text { modeling in } \mathrm{LiF}- \\
\mathrm{ThF}_{4}-\mathrm{UF}_{4}(78.8- \\
16.9-4.2 \mathrm{~mol} \%) \\
\text { fuel containing Cs } \\
\text { and I }\end{array}$ & \multirow[t]{2}{*}{ N/A* } & $\begin{array}{l}\text { Ref [5] ran tests at } 1-50 \\
\text { mol \% CsI in FLiNaK at } \\
\text { temp. }=823-1,173 \mathrm{~K} . \\
\text { CsI vapor pressure varied } \\
\text { with mol \% CsI. }\end{array}$ & [89] \\
\hline & & $\begin{array}{l}\text { deposition. CsI is } \\
\text { highly water } \\
\text { soluble. Any semi- } \\
\text { volatile species } \\
\text { may condense on } \\
\text { surfaces or form } \\
\text { particulates. }\end{array}$ & $\begin{array}{l}\text { Vapor pressure } \\
\text { measurements in } \\
\text { LiF-NaF-KF } \\
(46.5-11.5-42 \\
\text { mol\%) containing } \\
\text { Cs and I }\end{array}$ & & $\begin{array}{l}\text { Ref [6] ran tests at } 1 \mathrm{~mol} \\
\% \mathrm{CsI} \text { with and without } \\
3.3 \mathrm{~mol} \% \mathrm{CsF} \text { in } \\
\text { FLiNaK at temp. }=900- \\
1,100 \mathrm{~K} . \mathrm{Cs} \text { and I had } \\
\text { highest vapor pressures } \\
\text { of any other element. }\end{array}$ & $\begin{array}{l}{[90]} \\
{[88]}\end{array}$ \\
\hline $\begin{array}{l}\text { Volatilization of } \\
\text { KI }\end{array}$ & $\begin{array}{l}\mathrm{K}=\text { Salt } \\
\text { component } \\
\mathrm{I}=\text { Fission } \\
\text { product of }{ }^{233} \mathrm{U}, \\
{ }^{235} \mathrm{U} \text {, or }{ }^{239} \mathrm{Pu}\end{array}$ & $\begin{array}{l}\text { Release to cover } \\
\text { gas and out-gas } \\
\text { system. } \\
\text { Environmental } \\
\text { release via } \\
\text { atmospheric } \\
\text { deposition. KI is } \\
\text { highly water } \\
\text { soluble. }\end{array}$ & $\begin{array}{l}\text { Vapor pressure } \\
\text { measurements in } \\
\text { FLiNaK }\end{array}$ & $\mathrm{N} / \mathrm{A}^{*}$ & $\begin{array}{l}\text { Vapor pressure of KI } \\
\text { under test conditions was } \\
\text { unexpectedly high (e.g., } \\
\left.10^{-4} \text { atm at } 1,000 \mathrm{~K}\right) \text {. }\end{array}$ & [90] \\
\hline $\begin{array}{l}\text { Volatilization of } \\
\text { tritium as }{ }^{3} \mathrm{HH} \text { or } \\
{ }^{3} \mathrm{H}_{2}\end{array}$ & $\begin{array}{l}\text { Activation } \\
\text { product of } \mathrm{Li} \\
\text { and/or Be in fuel } \\
\text { salt or coolant salt } \\
\text { (especially }{ }^{6} \mathrm{Li} \text { in } \\
\text { thermal neutron } \\
\text { spectrum). } \\
\text { Ternary fission } \\
\text { product. }{ }^{3} \mathrm{HH} \text { or } \\
{ }^{3} \mathrm{H}_{2} \text { can form } \\
\text { from }{ }^{3} \mathrm{H}^{+} \text {under } \\
\text { reducing } \\
\text { conditions. }\end{array}$ & $\begin{array}{l}\text { Release to cover } \\
\text { gas and out-gas } \\
\text { system. Diffusion } \\
\text { of tritium gas } \\
\text { species through } \\
\text { containment layers. }\end{array}$ & $\begin{array}{l}\text { Evidence from } \\
\text { MSRE }\end{array}$ & $\mathrm{N} / \mathrm{A}^{*}$ & $\begin{array}{l}{ }^{3} \mathrm{H}^{+} \text {can also corrode } \\
\text { alloy surfaces, producing } \\
{ }^{3} \mathrm{HH} \text { or }{ }^{3} \mathrm{H}_{2} \cdot{ }^{3} \mathrm{HH} \text { may } \\
\text { form depending on the } \\
\text { presence of }{ }^{1} \mathrm{H} \text { in reactor. }\end{array}$ & $\begin{array}{l}{[25]} \\
{[92]}\end{array}$ \\
\hline $\begin{array}{l}\text { Volatilization of } \\
\mathrm{UF}_{6} \text { from cooled } \\
\text { fuel salt }\end{array}$ & $\begin{array}{l}\text { Reaction between } \\
\mathrm{UF}_{4} \text { and } \mathrm{F}_{2} \text { or } \mathrm{F}^{0} \\
\text { (produced from } \\
\text { radiolysis) in } \\
\text { cooled fuel salt. }\end{array}$ & $\begin{array}{l}\text { Deposition in off- } \\
\text { gas system }\end{array}$ & $\begin{array}{l}\text { Evidence from } \\
\text { MSRE }\end{array}$ & $\begin{array}{l}\text { Under } \\
\text { Cooling }\end{array}$ & $\begin{array}{l}\text { Measurements taken } \sim 25 \\
\text { years after reactor } \\
\text { shutdown and estimated } \\
\text { loss of } 4.4 \mathrm{~kg} \text { of } \mathrm{U} \text { from } \\
\text { fuel salt as } \mathrm{UF}_{6} \text {. } \\
\text { Experimental evidence } \\
\text { indicates annual } \\
\text { reheating of cooled fuel } \\
\text { salt to } 200^{\circ} \mathrm{C} \text { to } \\
\text { recombine } \mathrm{F}_{2} \text { with fuel } \\
\text { likely led production of } \\
\mathrm{UF}_{6} \text {. }\end{array}$ & $\begin{array}{l}{[86],} \\
{[32]}\end{array}$ \\
\hline $\begin{array}{l}\text { Volatilization of } \\
\mathrm{UCl}_{4} \text { at elevated } \\
\text { temperatures }\end{array}$ & $\begin{array}{l}\text { Formation of } \\
\mathrm{UCl}_{4} \text { from } \mathrm{UCl}_{3} \\
\text { under oxidizing } \\
\text { conditions in } \\
\text { chloride fuel salt }\end{array}$ & $\begin{array}{l}\text { Deposition in off- } \\
\text { gas system }\end{array}$ & $\begin{array}{l}\text { Vapor pressure } \\
\text { data }\end{array}$ & $\mathrm{N} / \mathrm{A}^{*}$ & $\begin{array}{l}\mathrm{UCl}_{4} \text { has a boiling point } \\
\text { of } 791^{\circ} \mathrm{C}\end{array}$ & [85] \\
\hline
\end{tabular}

${ }^{*} N / A$ indicates that the process could occur during normal operations or an accident. 


\subsubsection{Precipitation}

The precipitation of chemical species in the MSR fuel salt will lead to particulates circulating within the primary coolant, which may lead to particulate settling and potential blockage of flow, and plate-out and increased decay heat in certain locations. Additionally, the precipitation of fissile material could violate the reactivity control FSF. Actinides and noble metals are the predominant chemical species that can precipitate in the MSR fuel salt. In the MSRE, noble metals (e.g., Nb, Mo, Tc, Ru, Rh, Pd, Ag, Sb, Te) were able to dissolve in the fuel salt to a minor extent, but they mainly deposited on surfaces [70].

As stated in Section 3.4.2.1, actinide fluoride and chloride complexes are soluble in fluoride and chloride fuel salts, respectively. However, their solubility depends heavily on the fuel salt redox potential, temperature, the presence of competing metals (i.e., lanthanides), and the presence of water or oxygen. The onset of reducing conditions in the fuel salt due to the loss of radiolytic $\mathrm{F}_{2}$ or $\mathrm{Cl}_{2}$ or the introduction of a reductant (e.g., liquid metal coolant during an accident scenario) could cause fuel salt components and actinides to precipitate out in their metallic form.

Table 12 shows the electrode potentials of primary fuel salt constituents in $\mathrm{LiF}_{-} \mathrm{BeF}_{2}(67-33 \mathrm{~mol} \%)$. The fission process is oxidizing. Metallic beryllium was periodically introduced into the MSRE fuel salt to prevent the fuel salt from becoming excessively oxidizing. Introducing too much of the reducing agent into the fuel salt would result in precipitating metal species from the fuel salt. At the onset of reducing conditions in the fuel salt, the metal species will precipitate in their metallic form according to their redox potentials: $\mathrm{Li}>\mathrm{Be}>\mathrm{U} \sim \mathrm{Zr}$ [70]. MSRE fuel salt included $5 \% \mathrm{ZrF}$ to minimize the potential for uranium reduction in the event of the fuel salt becoming excessively reducing.

Table 12. Reduction potentials of primary fuel salt constituents (adapted from Williams, et al. [87]).

\begin{tabular}{ccc}
\hline \multirow{2}{*}{ Half-cell reaction } & \multicolumn{2}{c}{$\mathbf{E}^{\circ}=$ reduction potential $(\mathbf{V})^{*}$} \\
\cline { 2 - 3 } & $\mathbf{4 5 0 ^ { \circ } \mathbf { C }}$ & $\mathbf{7 2 5}^{\circ} \mathbf{C}$ \\
\hline $\mathrm{Li}^{+}+\mathrm{e}^{-} \rightarrow \mathrm{Li}_{(\mathrm{s})}$ & -2.770 & -2.559 \\
$\mathrm{Be}^{2+}+2 \mathrm{e}^{-} \rightarrow \mathrm{Be}_{(\mathrm{s})}$ & -1.958 & -2.460 \\
$\mathrm{U}^{3+}+3 \mathrm{e}^{-} \rightarrow \mathrm{U}_{(\mathrm{s})}$ & -1.606 & -1.433 \\
$\mathrm{U}^{4+}+4 \mathrm{e}^{-} \rightarrow \mathrm{U}_{(\mathrm{s})}$ & -1.522 & -1.336 \\
$\mathrm{Zr}^{4+}+4 \mathrm{e}^{-} \rightarrow \mathrm{Zr}_{(\mathrm{s})}$ & -1.542 & -1.335 \\
$\mathrm{U}^{4+}+4 \mathrm{e}^{-} \rightarrow \mathrm{U}^{3+}$ & -1.268 & -1.045 \\
\hline
\end{tabular}

${ }^{*}$ Potentials referenced to $\mathrm{HF} / \mathrm{H}_{2}, \mathrm{~F}^{-}$in $0.67 \mathrm{LiF}-0.33 \mathrm{BeF}_{2}$

Williams et al. [87] states that the development of highly reducing conditions was one of the primary concerns of the original MSRE staff due to the "likelihood of catastrophic phase segregation" through the precipitation or plate-out of fuel salt components in their metallic form [86]. Thus, the redox chemistry of the fuel salt was periodically monitored to ensure that highly reducing conditions were not inadvertently caused by the redox control system.

In fluoride fuel salts, $\mathrm{UF}_{3}$ abundance relative to $\mathrm{UF}_{4}$ must be maintained to prevent the reaction of $\mathrm{UF}_{3}$ with moderator graphite to produce insoluble uranium carbides [83] [82] or the disproportionation of $\mathrm{UF}_{3}$ into $\mathrm{UF}_{4}$ and $\mathrm{U}^{0}$ [93]. Similarly, $\mathrm{UCl}_{3}$ might disproportionate into $\mathrm{UCl}_{4}$ and $\mathrm{U}^{0}$ in chloride salts [81]. Actinides, beryllium, or salt soluble fission or corrosion products (e.g., $\mathrm{Zr}, \mathrm{Ti}, \mathrm{Al}, \mathrm{Fe}, \mathrm{Cr}, \mathrm{Mn}, \mathrm{Mg}$ ) will react with $\mathrm{O}_{2}$ or $\mathrm{H}_{2} \mathrm{O}$ in the fuel salt or other reactor systems (e.g., fuel processing) to form insoluble metal oxides, which in excessive quantities might disrupt the fuel system [81]. 
Lanthanide fission products might also compete with actinides in the formation of soluble fluoride or chloride complexes in the salt, limiting actinide solubility. For example, the presence of $\mathrm{CeF}_{3}$ at a 1:1 and 5:1 molar ratio to $\mathrm{PuF}_{3}$ dramatically decreases $\mathrm{PuF}_{3}$ solubility in a $\mathrm{LiF}_{-} \mathrm{BeF}_{2}(63-37 \mathrm{~mol} \%$ ) fuel salt. Therefore, it is necessary to have a detailed understanding of the solubility of actinide fluoride and chloride complexes for a range of fuel salt compositions, including the effect of fission product presence, and temperatures.

Table 13 outlines precipitation phenomena that might occur during normal operation or a postulated accident for a generic MSR.

Table 13. Summary of precipitation phenomena.

\begin{tabular}{|c|c|c|c|c|c|c|}
\hline $\begin{array}{l}\text { Description of } \\
\text { phenomenon }\end{array}$ & $\begin{array}{c}\text { Source of } \\
\text { radionuclide } \\
\text { species }\end{array}$ & $\begin{array}{c}\text { Fate of } \\
\text { radionuclide } \\
\text { species }\end{array}$ & $\begin{array}{c}\text { Experimental/ } \\
\text { modeling } \\
\text { details }\end{array}$ & $\begin{array}{c}\text { Relevant } \\
\text { accident } \\
\text { scenarios }\end{array}$ & Notes & Ref. \\
\hline $\begin{array}{l}\text { Deposition } \\
\text { (plate-out) of } \\
\text { noble metals } \\
\text { onto metal or } \\
\text { nonmetal } \\
\text { surfaces in fuel } \\
\text { salt }\end{array}$ & $\begin{array}{l}\text { Fission } \\
\text { products of } \\
{ }^{233} \mathrm{U},{ }^{235} \mathrm{U} \text {, or } \\
{ }^{239} \mathrm{Pu} \text { in fuel } \\
\text { salt }\end{array}$ & $\begin{array}{l}\text { Retention in } \\
\text { fuel salt. Build } \\
\text { up on } \\
\text { containment } \\
\text { surfaces and } \\
\text { nonmetal } \\
\text { moderator. }\end{array}$ & $\begin{array}{l}\text { Evidence from } \\
\text { MSRE }\end{array}$ & $\mathrm{N} / \mathrm{A}^{*}$ & $\begin{array}{l}\text { Plate-out of highly radioactive noble } \\
\text { metals can cause increased heat } \\
\text { deposition in certain locations and } \\
\text { result in localized shielding } \\
\text { requirements. }\end{array}$ & $\begin{array}{l}{[70]} \\
{[85]}\end{array}$ \\
\hline $\begin{array}{l}\text { Precipitation of } \\
\text { uranium metal } \\
\text { in fuel salt under } \\
\text { strongly } \\
\text { reducing } \\
\text { conditions }\end{array}$ & $\begin{array}{l}\mathrm{UF}_{4} / \mathrm{UF}_{3} \text { or } \\
\mathrm{UCl}_{4} / \mathrm{UCl}_{3} \text { in } \\
\text { fuel salt. } \\
\text { Reduction } \\
\text { caused by } \\
\text { introduction of } \\
\text { reductant to } \\
\text { fuel salt. }\end{array}$ & $\begin{array}{l}\text { Settling of } \\
\text { uranium metal } \\
\text { in fuel salt. } \\
\text { Uncontrolled } \\
\text { criticality. }\end{array}$ & $\begin{array}{l}\text { Evidence for } \\
\text { creation of } \\
\text { reducing } \\
\text { conditions due } \\
\text { to radiolytic } \mathrm{F}_{2} \\
\text { generation from } \\
\text { MSRE. }\end{array}$ & $\begin{array}{l}\text { Normal } \\
\text { operations. } \\
\text { Inadvertent } \\
\text { introduction of } \\
\text { liquid metal } \\
\text { coolant (i.e., } \\
\text { NaK) to fuel } \\
\text { salt. } \\
\text { Fuel salt } \\
\text { cooling. }\end{array}$ & $\begin{array}{l}\text { Radiolytic generation and escape of } \\
\mathrm{F}_{2} \text { from fuel salt can create reducing } \\
\text { conditions that favor } \mathrm{U}(\mathrm{IV}) \mathrm{F}_{4} \\
\text { reduction to } \mathrm{U}(0) \text { metal. Inability of } \\
\text { radiolytic } \mathrm{F}_{2} \text { to recombine with fuel } \\
\text { salt due to fuel salt cooling can } \\
\text { promote this phenomenon. }\end{array}$ & [83] \\
\hline $\begin{array}{l}\text { Precipitation of } \\
\text { uranium metal } \\
\text { via } \\
\text { disproportion- } \\
\text { ation reactions }\end{array}$ & $\begin{array}{l}\text { Disproportion- } \\
\text { ation of } \mathrm{UF}_{3} \text { in } \\
\text { fluoride salt or } \\
\mathrm{UCl}_{3} \text { in } \\
\text { chloride salt }\end{array}$ & $\begin{array}{l}\text { Settling of } \\
\text { uranium metal } \\
\text { in fuel salt. } \\
\text { Uncontrolled } \\
\text { criticality. }\end{array}$ & $\begin{array}{l}\text { Chemical tests } \\
\text { for MSRE } \\
\text { development. }\end{array}$ & $\begin{array}{l}\text { Too much } \mathrm{UF}_{3} \\
\text { in fuel salt } \\
\text { relative to } \mathrm{UF}_{4} \text {. }\end{array}$ & $\begin{array}{l}4 \mathrm{UF}_{3}=3 \mathrm{UF}_{4}+\mathrm{U}^{0} \\
4 \mathrm{UCl}_{3}=3 \mathrm{UCl}_{4}+\mathrm{U}^{0}\end{array}$ & $\begin{array}{l}{[81]} \\
{[93]}\end{array}$ \\
\hline $\begin{array}{l}\text { Precipitation of } \\
\text { uranium } \\
\text { carbides }\left(\mathrm{UC}_{\mathrm{x}}\right)\end{array}$ & $\begin{array}{l}\text { Reaction } \\
\text { between } \mathrm{UF}_{3} \\
\text { and graphite } \\
\text { moderator }(\mathrm{C})\end{array}$ & $\begin{array}{l}\text { Settling in fuel } \\
\text { salt. } \\
\text { Uncontrolled } \\
\text { criticality. }\end{array}$ & $\begin{array}{l}\text { Evidence from } \\
\text { MSRE }\end{array}$ & N/A* & $4 \mathrm{UF}_{3}+\mathrm{xC}=3 \mathrm{UF}_{4}+\mathrm{UC}_{\mathrm{x}(\mathrm{s})}$ & $\begin{array}{l}{[83]} \\
{[82]}\end{array}$ \\
\hline $\begin{array}{l}\text { Precipitation of } \\
\text { actinide metal } \\
\text { oxides }\end{array}$ & $\begin{array}{l}\text { Actinides in } \\
\text { fuel salt or } \\
\text { fertile coolant } \\
\text { material. }\end{array}$ & $\begin{array}{l}\text { Settling in fuel } \\
\text { salt. } \\
\text { Uncontrolled } \\
\text { criticality. }\end{array}$ & $\begin{array}{l}\text { Evidence from } \\
\text { fluoride and } \\
\text { chloride salt } \\
\text { experiments. }\end{array}$ & $\begin{array}{l}\text { Exposure of } \\
\text { fuel to moisture } \\
\left(\mathrm{H}_{2} \mathrm{O}\right) \text { or } \mathrm{O}_{2}\end{array}$ & $2 \mathrm{H}_{2} \mathrm{O}_{(\mathrm{g})}+\mathrm{UF}_{4}=\mathrm{UO}_{2(\mathrm{~s})}+4 \mathrm{HF}_{(\mathrm{g})}$ & $\begin{array}{l}{[81]} \\
{[82]}\end{array}$ \\
\hline $\begin{array}{l}\text { Precipitation of } \\
\text { fission product } \\
\text { metal (Me) as } \\
\text { oxides }\end{array}$ & $\begin{array}{l}\text { Salt soluble } \\
\text { metal fission } \\
\text { products. }\end{array}$ & $\begin{array}{l}\text { Settling in fuel } \\
\text { salt. Disruption } \\
\text { of fuel salt } \\
\text { flow. }\end{array}$ & $\begin{array}{l}\text { Evidence from } \\
\text { chloride salt } \\
\text { experiments. }\end{array}$ & $\begin{array}{l}\text { Exposure of } \\
\text { fuel to moisture } \\
\left(\mathrm{H}_{2} \mathrm{O}\right) \text { or } \mathrm{O}_{2}\end{array}$ & $\begin{array}{l}\mathrm{MeCl}_{2}+\mathrm{H}_{2} \mathrm{O}=\mathrm{MeO}+2 \mathrm{HCl} \\
\mathrm{MeCl}_{2}+\mathrm{O}_{2}=\mathrm{MeO}+\mathrm{Cl}_{2}\end{array}$ & [81] \\
\hline $\begin{array}{l}\text { Precipitation of } \\
\text { actinide } \\
\text { trifluorides in } \\
\text { presence of } \\
\text { lanthanide } \\
\text { trifluorides }\end{array}$ & $\begin{array}{l}\text { Fuel salt } \\
\text { actinides. }\end{array}$ & $\begin{array}{l}\text { Settling in fuel } \\
\text { salt. } \\
\text { Uncontrolled } \\
\text { criticality. }\end{array}$ & $\begin{array}{l}\mathrm{PuF}_{3} \text { solubility } \\
\text { tests in } \mathrm{LiF}-\mathrm{BeF}_{2} \\
(63-37 \mathrm{~mol} \%) \\
\text { with competing } \\
\text { fluorides. }\end{array}$ & N/A* & $\begin{array}{l}\text { The presence of } \mathrm{CeF}_{3} \text { at a } 1: 1 \text { and } \\
\text { 5:1 molar ratio to } \mathrm{PuF}_{3} \text { dramatically } \\
\text { decreased } \mathrm{PuF}_{3} \text { solubility. } \\
\text { The presence of } \mathrm{BaF}_{2} \text { and } \mathrm{ThF}_{4} \text { also } \\
\text { decreased solubility of } \mathrm{PuF}_{3} \text {. }\end{array}$ & [84] \\
\hline
\end{tabular}

*N/A indicates that the process could occur during normal operations or during an accident. 


\subsubsection{Physical transport and retention phenomena}

Physical phenomena - including bubble bursting, spraying, misting, and aerosol transport — can be a source of radionuclides to the cover gas region, leading to the deposition of radionuclides on containment surfaces. During the MSRE operation, fuel salt droplets were released from the salt surface and deposited onto a stainless-steel metal strip in the pump bowl gas space during a 10 hour exposure period (Figure 10). The salt droplets formed from mist that was produced at the fuel surface, which is evident from the higher salt droplet density at the end of the strip nearest the salt surface.

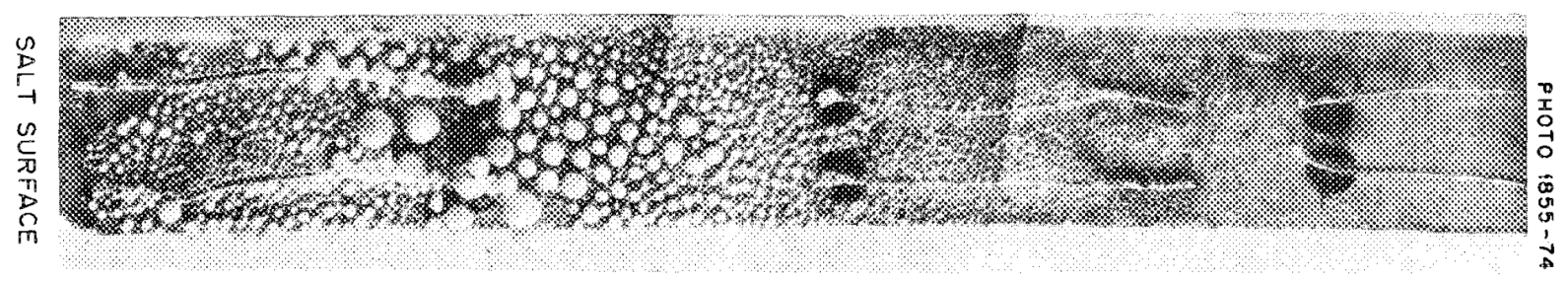

Figure 10. Salt droplets on a stainless-steel metal strip that formed due to exposure to the pump bowl gas space of the MSRE for 10 hours (from Compere et al. [70]).

For example, as part of MST analyses for the sodium fast reactor, the bubble transport processes were quantified with the IFR bubble code developed at Argonne National Laboratory [42]. Although bubble formation mechanisms will be different in MSRs, bubbles are expected to be a pathway to transportentrained radionuclides including fission gases during normal operations or an accident scenario. Source term assessments require multiple and possibly integrated models due to the significant range of potential phenomena under accident conditions.

The transport of radionuclides within the containment layers of an MSR can also be governed by advection and diffusion processes. A good example of diffusion-dominated transport involves the ability of tritium species to permeate through structural metals at the operating temperatures of most MSR designs in the form of $\mathrm{H}^{3} \mathrm{H}$ or ${ }^{3} \mathrm{H}_{2}$. The tritium diffusion rate depends on a variety of variables, including the type and thickness of the material, temperature, and partial pressure of diffusing tritium species at both sides of the material.

Another important physical process pertinent to modeling accident scenarios is liquid immiscibility (e.g., fuel salt and coolant salts). For example, a fast spectrum reactor might use liquid lead as a reflector blanket, which has low miscibility with chloride salts. Although miscibility is critical to understand the potential for fission product chemical species to be stabilized within the salt, miscibility does not imply that the fission products will be retained within the mixed salt. The full range of transport processes must be considered to adequately assess the release of radionuclides from a salt.

$\mathrm{R}$ radionuclide transport modeling in MELCOR is being extended to incorporate transport phenomena (Section 5.6.1.4). This is being performed under the FY20 NRC effort to enhance MELCOR to support non-LWR source term assessment. 


\section{INTEGRAL ACCIDENT MODELING TOOLS}

\subsection{BACKGROUND}

Integral accident modeling tools were developed to evaluate how accidents progress to situations in which radiological release to the environment occurs. They have evolved over several years in response to the need to increase the fidelity with which the interactions between distinct phenomena are characterized in evaluation of NPP response under accident conditions. The primary objective of integral accident modeling tools is estimating the environmental radiological release, referred to as source term.

The principal integral accident analysis tools developed for LWR technology are as follows.

- Modular Accident Analysis Program (MAAP): developed by EPRI.

- MELCOR: developed by Sandia National Laboratories with support from the NRC.

MAAP and MELCOR tools were developed from the response to the significant regulatory demands following the core melt accident at Three Mile Island, Unit 2 (TMI-2) in March 1979. Much of this effort occurred during the Industry Degraded Core Rulemaking (IDCOR), which was followed the Individual Plant Examinations requested by the NRC in Generic Letter 88-20, Individual Plant Examination for Severe Accident Vulnerabilities.

Throughout this period, industry and regulators invested in significant research and development efforts to understand the behavior of LWRs under severe accidents (beyond DBAs). A fundamental insight developed during these efforts was the extent to which accident progression and the potential for and magnitude of radiological release from an LWR depended on the sensitive interaction between the vast range of phenomena that occur during a severe accident.

This represented a significant departure from many of the traditional safety analysis philosophies, methods, and tools developed for demonstrating NPP performance within its design basis. In this situation, specific performance metrics remained influenced by a more limited set of phenomena. Characterization of these performance metrics typically required increased fidelity with which each of the relevant phenomena were known and modeled. The importance of interactions between different phenomena was generally less relevant, with the exception of some very specific abnormal operating or accident conditions.

By contrast, the development of integral modeling tools reflected the challenges encountered in the early attempts to characterize integral plant response under severe accident conditions during IDCOR. In the early efforts, independent computer codes had been developed for the treatment of specific accident phenomena. They were used in a generally serial fashion with each code performing independent calculations, using inputs from other codes, and providing outputs to other codes. This general process led to a relatively difficult workflow with an error prone process needed to transfer data between the codes and was is some respects deficient in characterizing accident progression. Numerous interactions between phenomena were simply neglected or poorly characterized. This led to an evolution of integral accident modeling tools, such as MAAP and MELCOR. These tools became the repository for the severe accident knowledge base that evolve for LWRs over the past few decades.

Through systematic improvements and targeted experimentation, the ability to estimate source terms for LWRs has improved considerably over the past few decades. However, the phenomena in MSRs significantly differ from LWRs and are thought to be significantly less complex. This is based on having a stable liquid-phase fuel form and a limited number of structural and functional materials within the 
containment. Minimization of the possible chemical reactions that can occur and the potential for the system to enter new physics regimes is a central premise to a simplified MSR accident response.

An MSR design must prevent or mitigate the extent of radiological release to the environment under all credible scenarios. The measures adopted by the design to meet these safety criteria will have an impact on the ultimate economic viability of the reactor design. Accurate assessment of the source term is therefore not just required for developing the design's safety cases but is central to its ultimate market viability.

\subsection{MSR INTEGRAL PLANT MODELING}

The steps for estimating an MSR MST are identified in Figure 11.

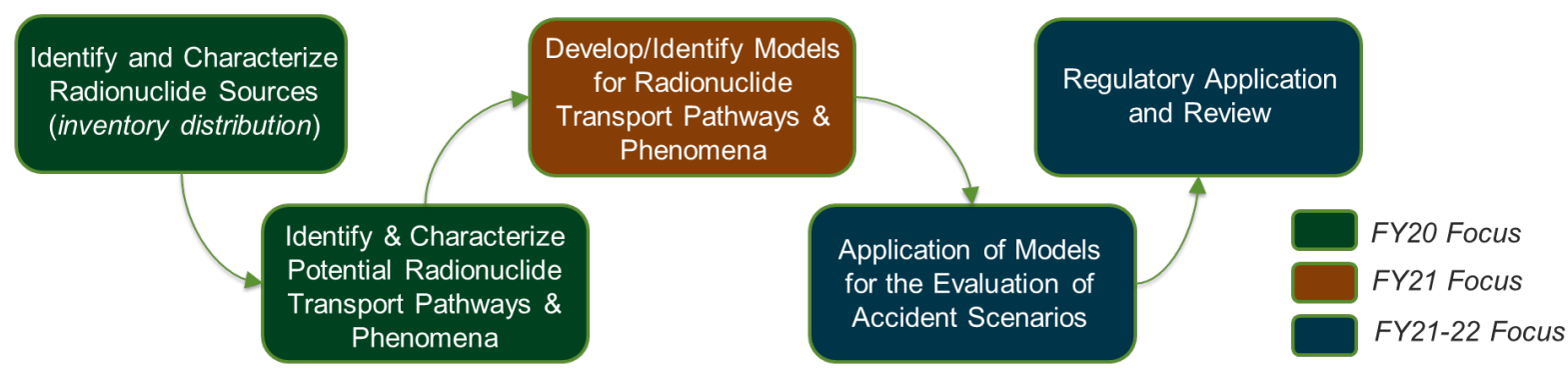

Figure 11. Methodology for developing an MST assessment capability for MSRs.

The inputs and links between the ongoing DOE Advanced Reactor Technologies, MSR campaign experimental and modeling projects, and MST development efforts described in this report are summarized in Figure 12.

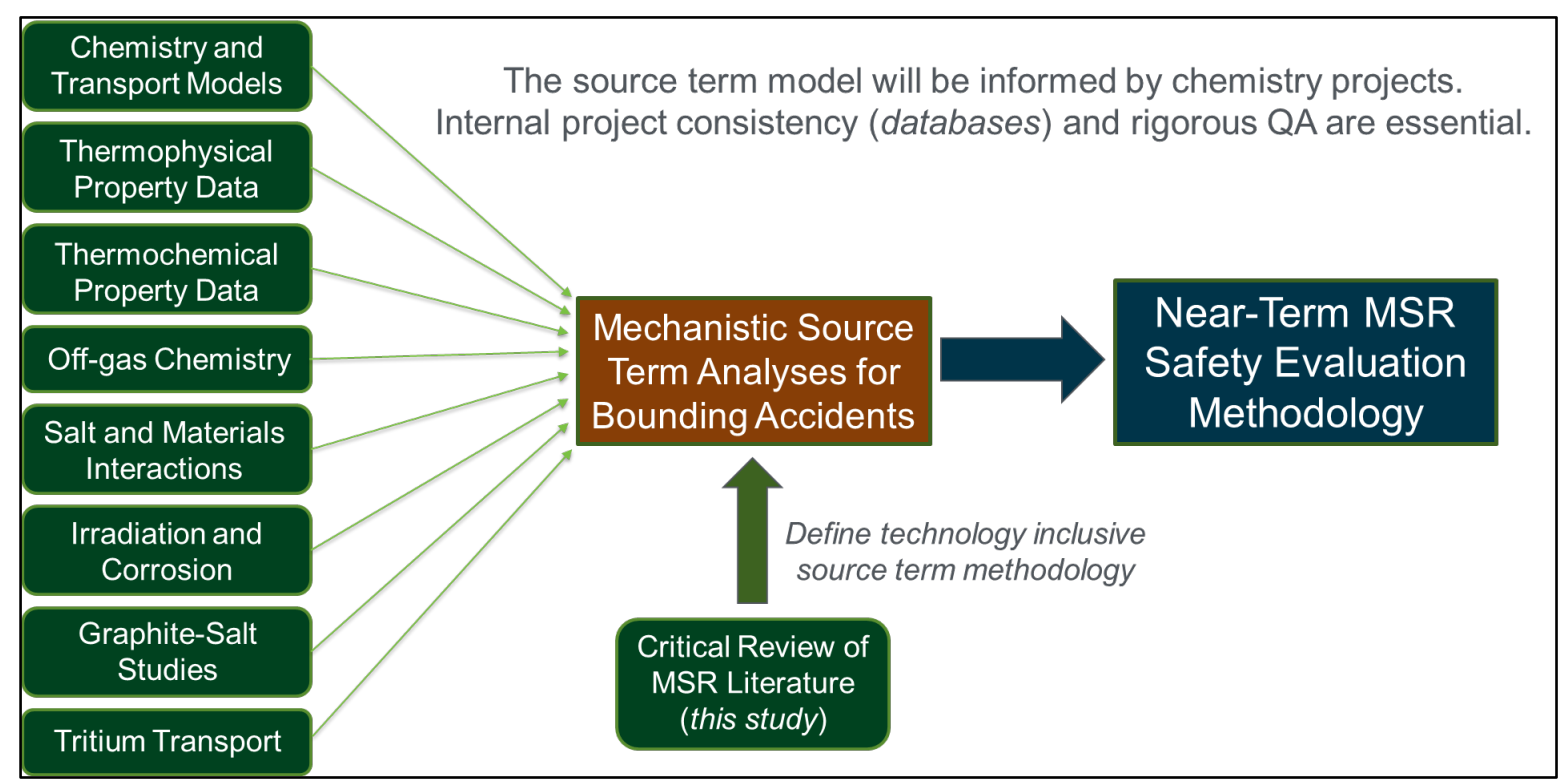

Figure 12. Diagram showing inputs from salt chemistry studies needed to develop and parameterize an MST model for MSRs. 


\subsection{INTEGRAL ACCIDENT MODELING TECHNOLOGY CHARACTERISTICS AND REQUIREMENTS}

MAAP and MELCOR are two of the principal integral accident modeling tools that have evolved to characterize radiological consequences in the event of an LWR BDBE. Each tool has a different level of readiness for application to evaluation of non-LWR integral accident modeling. Both tools present relevant guidance for provision of integral accident modeling technology to support licensing of advanced nuclear energy technologies, including MSR designs.

MAAP and MELCOR tools have been developed and applied over many years, gaining significant pedigree. This has proven critical in application to support regulatory decision-making. In light of this experience, there are a number of considerations of relevance to specifying a development and deployment philosophy for an integral accident modeling tool for MSRs. Since MELCOR is being actively developed to support NRC readiness for licensing non-LWR technologies, it is a reasonable integral accident modeling tool for near-term needs. Subsequent discussion focuses on MELCOR.

The evaluation of public health risk posed by the operation of NPPs, and other facilities with radioactive material, is the fundamental mission of the NRC. This risk arises from the accidental release of radioactive material from a nuclear facility. The magnitude and timing of that release is the "accident source term", which cannot be determined experimentally. It must be estimated using computer models based on the best available knowledge and technology, derived from both experimentation and state-ofpractice numerical solution methods. To estimate accident source terms for existing nuclear power reactors, the NRC uses the MELCOR computer code.

MELCOR is a systems-level computer code developed at Sandia National Laboratories for the estimation of releases of radioactive materials for both prescriptive DBAs, and for the more highly varied beyond DBAs that have the most severe public health and safety consequences. It is the primary tool for the NRC to mechanistically evaluate how accident progression can result in radiological release to the environment for LWR and non-LWR designs.

The MELCOR computer code system is distinctly different from other computer codes used for the analysis of NPP component performance, plant response under abnormal operational occurrences, or evaluation of safety system effectiveness under DBA scenarios. These are more generally design codes used in the demonstration of adequate performance of NPP SSCs to maintain the plant within a design envelope under a range of postulated upset events.

Design codes are typically focused on evaluation of the performance of either one or a small set of plant SSCs under well-defined conditions. The goal of these performance evaluations is to demonstrate successful operation of plant SSCs under upset events, maintaining the NPP within its design envelope. A robust design basis is a principal means of assuring with high confidence that operation of an NPP does not pose an unacceptable risk to the public.

The calculation of radiological release is an essential component to determine the consequences to public health and safety from a reactor accident. Consequence, together with the estimated frequency of a radioactive release (i.e., the probability for each year of reactor operation that the estimated release occurs), enables public health risk to be estimated. To support this, MELCOR has been developed to satisfy the following characteristics or requirements: 


\subsubsection{Requirement \#1: Integral Plant Analysis}

Events at NPPs leading to radiological release to the environment potentially involve a range of physical processes and phenomena challenging engineered and passive barriers designed to prevent radiological release to the environment. As a result, events leading to radiological release to the environment require characterization of physical effects over a broad range of spatial length scales, from the size of a fuel pin to dimensions of a containment or auxiliary building. This requires the MELCOR code system to adequately capture (assumed or modeled) all relevant physical processes and phenomena across an entire NPP to adequately characterize the potential for and magnitude of fission product release to the environment.

The development of MELCOR as an integrated tool was a very significant advancement in the capability for performing severe accident analysis for source term characterization. Before the development of MELCOR, separate effects codes within STCP were run independently and results were manually transferred between codes leading to a number of challenges for transferring data, ensuring consistency in data and properties, and in capturing the coupling of physics.

\subsubsection{Requirement \#2: Resolution of Accident Progression Time Scales}

The physical processes that characterize radiological release to the environment occur over a relatively wide range of time scales. For example, dissipation of decay heat from nuclear fuel (fast) can lead to a pressure increase in a containment atmosphere (slow) that, if unmitigated, could lead to stress on the containment within tens of hours or days.

\subsubsection{Requirement \#3: State-of-the-Art Validated Modeling}

The state-of-knowledge of the full range of physical processes and phenomena represented in MELCOR has evolved in the nearly 40 years since the TMI-2 core damage accident. This has involved significant effort to forensically evaluate actual core damage events, such as TMI-2, and more recently the three core damage events at Fukushima Daiichi. Significant effort to understand a range of physical phenomena relevant to fission product barrier failure has been performed through separate-effect tests in both the United States and internationally. However, most of the effort has been focused on LWRs.

Models that encapsulate state-of-the-art knowledge in reactor accident transport phenomena have been developed. These models have relatively stringent requirements for adequately representing radiological release to the environment. In addition to the development of these models for implementation in MELCOR, validation of models against separate effect tests and reactor-scale events is a central component, requiring appreciable levels of effort.

For the purposes of supporting near-term design, licensing, and deployment of advanced nuclear energy technologies, MELCOR is at the highest technology readiness level for performing source term assessments [94]. As a result, it is being adopted by the NRC for performing independent assessments of non-LWR licensing submissions. It is possible for both a vendor and the NRC to use the code to develop and independently review a safety case as independent source term codes are not necessary to license a new reactor in the United States. 


\subsection{COMPONENTS IN CREATION OF A PLANT MODEL FOR AN INTEGRAL ACCIDENT ANALYSIS}

MELCOR has primarily been applied to support development of PRAs and a range of beyond DBA assessments for BWR, PWR and VVER technologies. The key accident phenomena represented by MELCOR

- Control volume fluid hydrodynamics

- Reactor and enclosure structural heat transport

- Fuel temperature excursion and failure

- Core degradation including effective representation of material eutectic interactions

- In-vessel damage progression and reactor vessel failure

- Ex-vessel damage progression including core-concrete interaction

- Fission product vapor and aerosol (particulate) transport, including deposition and resuspension

MELCOR is structured around several distinct packages that represent unique classes of phenomena of critical importance to accident behavior in radiological facilities. These packages can be used independently or in conjunction to allow for a unique characterization of hazardous processes in different facilities.

MELCOR implements a generalized solution of the aerosol transport equations based on the so-called sectional model [95]. This is implemented in the RN package. While the most extensive application of the modeling of aerosol dynamics in the RN packages has been to fission product transport, MELCOR allows for user-specified particulates. This enables a flexible adaption of MELCOR to different aerosol transport problems in a range of facilities different from LWRs.

The principal aerosol quantities of interest are the mass and composition of aerosol particles and their distribution throughout the reactor coolant system and containment. The calculation of aerosol agglomeration and deposition processes is based on the MAEROS [95] computer code, but without direct inclusion of condensation or evaporation within the MAEROS solution framework. Vapor condensation on and evaporation from aerosol particles are handled separately to reduce the stiffness of the differential equation set and to ensure consistency with the calculation of these processes by other models and packages.

Fission products may be aerosolized as they are released from different radiological sources in a facility. MELCOR can represent these sources as solid or liquid fuel in reactors, spent fuel repositories, and other waste systems. When models for the release of fission products from such sources do not exist in the code, a user may define these releases using user-defined (i.e., control) functions. Other events and processes that occur late in the accident, such as core-concrete interactions, pool boiling, direct containment heating, deflagrations, and resuspension may also generate aerosols. High structural temperatures may also result in aerosolization of nonradioactive materials.

The modeling of aerosol dynamics in MELCOR evolved from the earlier MAEROS code [95]. MAEROS is a multisectional, multicomponent aerosol dynamics code that evaluates the size distribution of each type of aerosol mass, or component, as a function of time. This size distribution is described by the mass in each size bin, or section. Each section may have a different chemical composition as described by the masses of various components for that section. In other words, a section is an aerosol size group and a component is a particular type of aerosol material. Since MELCOR operates on a radionuclide class structure, as discussed earlier, a mapping between RN classes and MAEROS aerosol components must be specified by the user. 
Throughout this development, MELCOR evolved in conjunction with a range of validation studies. The continual validation of the phenomenology represented in the code has proven essential to establish the pedigree of the MELCOR code in application to regulatory decision-making. A schematic diagram showing the various analysis packages in MELCOR is shown in Figure 13.

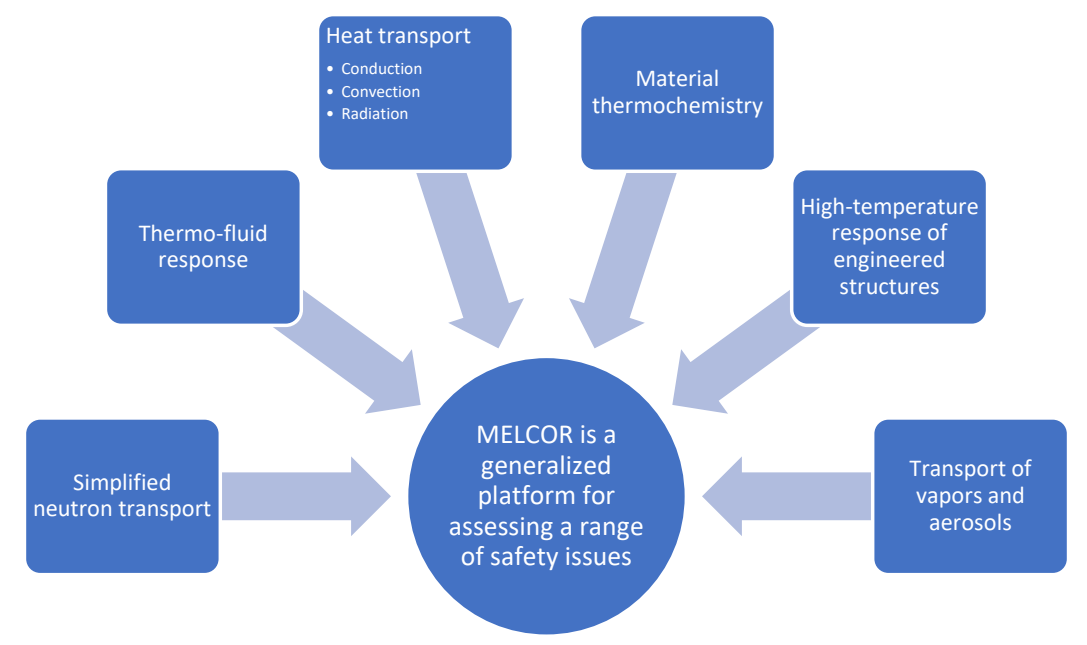

Figure 13. Summary of the MELCOR integral accident analysis phenomenological package.

\subsubsection{Development of MELCOR Radiological Facility Models}

MELCOR has a flexible input model that allows users to develop different facility models to represent a range of radiological release scenarios. It is not limited to or specific to nuclear power reactors. A MELCOR simulation has two steps:

- MELGEN: input is specified, processed, and checked; and

- MELCOR: time advancement of the problem based on the input to MELGEN and any additional input to MELCOR.

For the purposes of illustration, the following describes the overall structure of a MELCOR input model for a facility.

- MELGEN section

This section comprises a number of package-specific inputs that define the geometry, initial and boundary conditions, facility control functions, event scenario triggers, and a number of additional phenomenological model specifications for the facility and event scenario being simulated.

- MELCOR section

This section includes a number of package-specific inputs that reflect how the execution of the evolution of the facility state is simulated.

For the simulation of many facilities, the foundational input is for the packages capturing the hydrodynamics phenomenology. MELCOR is a control volume code designed to represent physical volumes in a homogenized manner, assuming that over the volume the hydrodynamic properties of different fluids are homogeneous. Different fluid components are treated in the MELCOR hydrodynamics formulation. For example, 
In the actual hydrodynamics modeling, MELCOR relies on (1) the Control Volume Hydrodynamics $(\mathrm{CVH})$ package and (2) the Flow Path (FL) package, which are responsible for modeling the thermalhydraulic behavior of coolant liquids and gases. The former is concerned with control volumes and their contents, the latter with the connections that allow transfer of these contents between control volumes. Equations of state for the hydrodynamic materials are contained in the Control Volume Thermodynamics (CVT) package, which in turn makes use of properties associated with working fluids as part of the equation of state (EOS) package as well as the Non-Condensable Gas (NCG) package.

Control volumes are intended to represent physical volumes over which the thermal hydraulic state variables can be treated as effectively homogeneous. Examples of the thermal hydraulic information tracked by the $\mathrm{CVH}$ package are

- Temperature

- Liquid/vapor mass

- Pressure

- Steam quality

A control volume can thus be components such as pipes, vessel, and rooms. For each control volume, the MELCOR code allows users to inject mass and enthalpy sources.

Flow paths in MELCOR allow mass and energy transfer to occur between control volumes. This includes the transport of particulates carried in the fluids (e.g., fission products). Such flow paths generally have negligible volume and are intended to model facility components such as:

- Piping connections

- Doors

- Valves

- Pumps

- Natural circulation through openings, such as ducts

- Flow inside a large volume that has been divided into multiple control volumes

MELCOR also allows users to represent heat structures within and defining the boundaries of control volumes. These also serve as surfaces on which particulate material can deposit (e.g., fission product deposition). The properties of heat structures are introduced to the overall calculation via the MP package.

An overall structure for how the different packages supporting modeling of hydrodynamic phenomena in MELCOR is provided in Figure 14. 


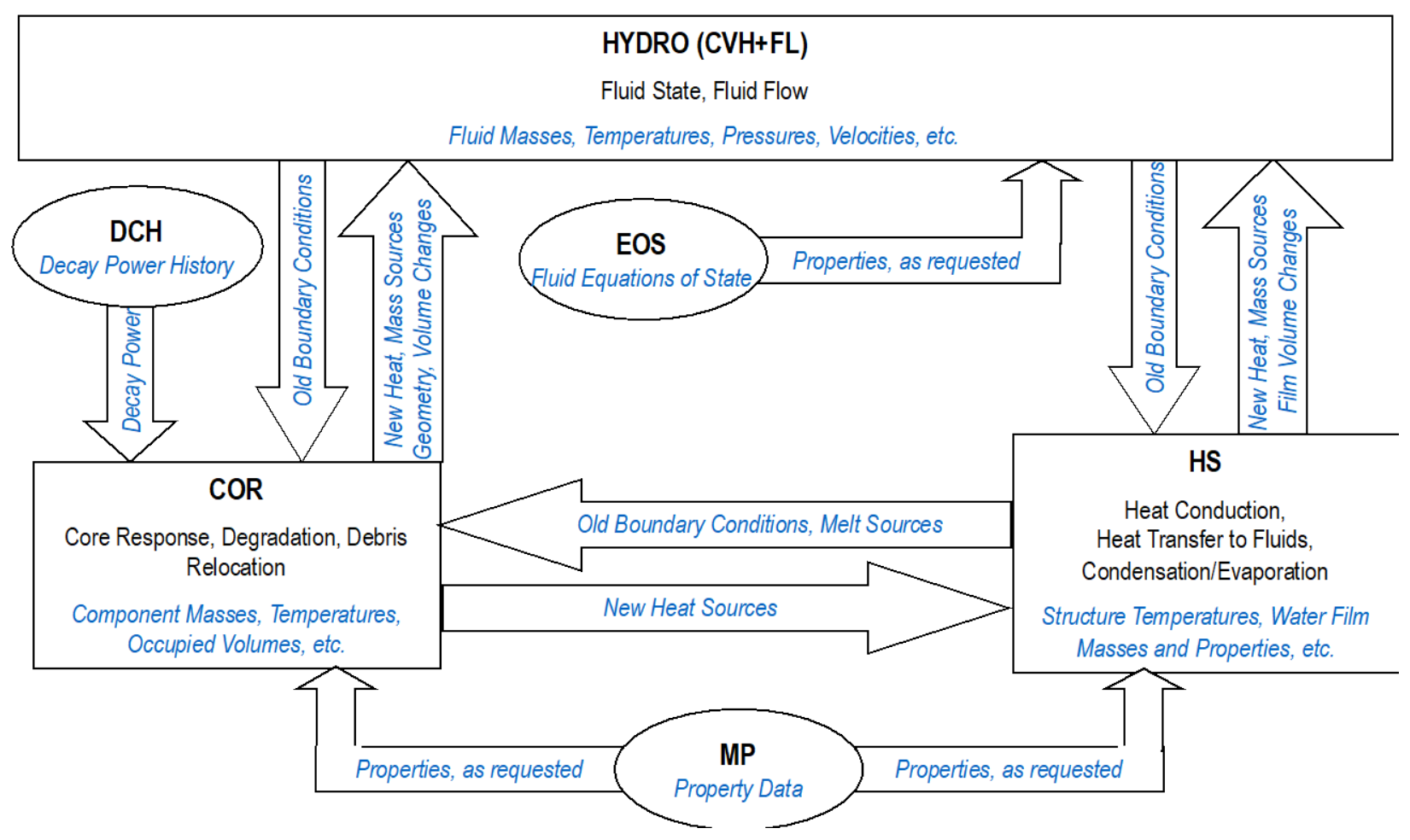

Figure 14. Illustration of connection between packages supporting hydrodynamic modeling.

\subsubsection{System Description and Event Scenarios}

The starting point for a source term calculation is a realistic representation of the system and the selection of relevant event scenarios. The State-of-the-Art Reactor Consequence Analysis (SOARCA) of Peach Bottom [96], Surry [97] and Sequoyah [98] demonstrated that developing and exercising appropriate fidelity representation of systems allows users to capture the full range of realistic behavior during radionuclide release scenarios. Accounting for all systems realistically allows for transport of radionuclides through the system to the environment to be accurately modeled, ensuring that the behavior of the radionuclides within the core region, primary systems, secondary systems, and containment is captured.

To develop a source term, appropriate event scenarios must be selected. These scenarios can either be internally initiated (accident), externally initiated (weather or security), or postulated (no direct cause stated). The full range of accident initiators, pathways and scenarios can be taken into account through uncertainty analyses and PRA studies that account for uncertainties in phenomenology, initial conditions, and boundary conditions. Examples of this methodology can be seen in the SOARCA uncertainty analyses [126], [127], [128] uncertainty analyses of the Fukushima-Daiichi accident [99] and the Vogtle Level 3 PRA.[100]

In an MSR, the presence of a molten, flowing fuel that is undergoing fission throughout the primary circuit makes an accurate representation of the primary circuit more complex. Within MSR systems, the chemical composition of the salt and the location of elements produced from fission is a major uncertainty at present. Resolving this uncertainty is important to developing an accurate description of a reactor system before a radionuclide release event occurs [101] [102]. Methods have been proposed incorporating Gibbs free energy minimization chemical thermodynamics into severe accident codes such as MELCOR to accurately determine molten salt characteristics [89] and other independent efforts are currently under development. 


\subsubsection{Radionuclide Inventory}

The total mass of all radionuclides within the system must be calculated and used as an input to the system model. Such calculations are performed with neutronic analysis software such as the SCALE code system [103]. Traditionally, radionuclide inventories are determined for different points in a reactor's operating cycle: beginning of cycle, middle of cycle and end of cycle. These different radionuclide inventories will result in different releases to the environment given the same accident scenario, with end of cycle radionuclide inventories being much higher due to increased irradiation time. For MSRs, the calculation of the initial radionuclide inventory has necessitated the development of neutronic analysis software that takes into account fuel salt additions and removals in addition to the myriad of chemical interactions that occur. In MSRs direct fission products can readily be found throughout the primary system, as opposed to only neutron activation products and leaked radionuclides from fuel.

MSR systems also contain radionuclides in systems attached to the primary circuit. MSRs contain off-gas systems that remove gases from the circulating salt in the primary circuit. These gases contain radioactive nuclides. MSRs systems may contain on-line processing features, which would be an additional concentration of radionuclides away from the core.

\subsubsection{System Behavior and Radionuclide Transport}

Within a reactor system it is necessary to capture the behavior of major sub-systems and their generally coupled interactions. Reactor plant systems and their responses to off-normal or accident conditions that must be captured include but are not limited to:

- Thermal-hydraulic response of the primary reactor coolant system, the reactor cavity, the containment, and the confinement buildings

- Heat up of reactor vessel lower head from relocated fuel materials and thermal and mechanical loading and failure of the vessel lower head, and transfer of core materials to the reactor vessel cavity

- Core-concrete (or other material) attack and ensuing aerosol generation

- Tritium production and transport,

- Fission product release (aerosol and vapor), transport, and deposition

- Behavior of radioactive aerosols in the reactor containment building, and aerosol mechanics in the containment atmosphere such as particle agglomeration, thermophoresis, and gravitational settling

- Impact of engineered safety features on thermal-hydraulic and radionuclide behavior

The phenomena that must be captured in the development of an MST are dependent upon the system itself.

\subsubsection{Modeling of Event Consequence}

Following the creation of a MST, the consequence of the source term needs to be assessed. To do this the consequence onsite and offsite must be assessed. Within the U.S, this means assessing the dose to workers and the public and associated consequences. To do this, both calculations of the behavior of radionuclides on-site and off-site are performed. This is done modeling the behavior of local weather conditions and site characteristics. Radionuclides are tracked as they exit the containment into ancillary systems or the environment and are transported and dispersed within the atmosphere.

Important physics for consequence assessment include but are not limited to:

- Atmospheric transport and dispersion

- Wet and dry deposition 
- Meteorology

- Exposure pathways

- Dose to workers and the public

- Health effects

Consequence assessment provides guidance to regulators, governments, and other local authorities as to what emergency phase, intermediate phase, and long-term phase protective actions must be implemented to ensure public safety.

\subsection{ACTIVITIES TO SUPPORT DEPLOYMENT AND APPLICATION OF MELCOR TO MSR PLANTS}

This section discusses the path to close gaps to deploy MELCOR for assessment of MSRs. The discussion motivates follow-on R\&D effort to establish MELCOR as a production-ready computer code in the nearterm.

An MSR plant has a number of activity sources that could contribute to off-site radiological consequences. These sources include:)

- Fuel salt in the fluid-fueled reactor

- Blanket salt

- Fuel/blanket processing plant (if so equipped)

- Support systems

- Emergency systems

As part of the NRC non-LWR vision and strategy for computer code development, an assessment has been performed to evaluate areas in which the MELCOR code must be enhanced for MSRs. Reference [94] details this assessment, which is summarized in the remainder of this subsection.

\subsubsection{Material Equation of State and Thermophysical Properties}

The MELCOR modeling framework has evolved to flexibly incorporate new models for fluid equations of state and thermophysical properties. While these models must be provided by users, the modeling framework allows a user to readily adapt a MELCOR model of a facility to a new working fluid. Thus, despite the heritage of MELCOR as an LWR integral accident modeling code, it is not restricted to only modeling systems comprised of light water.

MELCOR is currently capable of modeling the equation of state for FLiBe (nominal $66 \% \mathrm{LiF}, 34 \% \mathrm{BeF}_{2}$ ). A soft sphere model, modified form of Helmholtz free energy, which is a function of temperature and density, is the basis of the MELCOR equation of state model for FLiBe. This method has been demonstrated to reproduce FLiBe experimental data with good accuracy [104]. MELCOR developers and users have independently verified the accuracy of FLiBe equation-of-state/property models.

\section{Deployment and Application Goals:}

- Develop uncertainty model for FLiBe thermo-physical properties

- MELCOR uncertainty propagation to identify importance of uncertainty to source term assessment

- Thermophysical properties must be developed for specific salt systems of interest to developers 


\subsubsection{Material and Fission Product Thermochemistry}

Material thermochemistry phenomena are important to the representation of high-temperature reactor behavior MSRs. MELCOR has no general provision for predicting chemical equilibrium of control volume contents for in-vessel materials.

Considering the modeling goals and the physics in play, MELCOR must have or be able to predict a "final" composition of a mixture of fuel salt and fission products. Several chemical species (consisting of several chemical elements overall) and several phases must generally be considered at once by the chosen computational method. Special separate effects of chemical processing should also be modeled.

There is no general provision in MELCOR for predicting how a given mixture of chemical species interacts. However, there are perhaps some insights to glean from the method by which the MELCOR cavity (CAV) package treats chemistry in the context of core/concrete interactions. Oxidation of molten metals by concrete decomposition gases, simultaneous reduction of those gases, and even condensed phase reactions between oxides and metals are all aspects of this chemistry problem.

The molten salt thermodynamic database (MSTDB) is currently being used to develop the chemical speciation of fission products in a molten salt. This supports solubility and vapor pressures for fission products in the molten salt. It does not entirely determine fission product release from the molten salt. MELCOR is incorporating additional transport models to characterize transport of fission products.

\section{Deployment and Application Goal:}

- Assess relevance of knowledge gaps in underlying thermochemical database

- Molten salt fission product thermochemistry uncertainty model derived from MSTDB

- Uncertainty propagation with MELCOR to identify importance of uncertainties in source term assessments

\subsubsection{Neutronic Response and Fission Product Transmutation}

Phenomena not traditionally considered for LWR beyond design basis assessment involve the coupling of neutron transport with the fluid and fission product transport processes inside the reactor. LWRs can experience events that lead to fission product release from the fuel initiated by reactivity transientsreferred to as Anticipated Transients without Scram (ATWS) scenarios. The modeling of these scenarios to characterize radiological consequences typically requires effective models of the energy addition to the core due to fission power. This is traditionally performed using a Chexal-Layman correlation, bypassing the need to perform even a simple calculation of neutron kinetics.

In the case of a fluid-fueled MSR, such a simplification is not possible. During normal operation and any transient in an MSR, local power generation and thermophysical properties are coupled to the fluid and fission product transport. This is a key characteristic of a fluid-fueled reactor that introduces different modeling requirements from solid-fueled systems.

MELCOR has the capability to perform point reactor kinetics equation (PRKE) calculations via the core (COR) package [105]. The model application space, however, is currently limited to solid fuels, when fission products and hence delayed neutron precursors stay at their location of birth and are not subject to advection. Nuclear data (delayed neutron group data, delayed neutron fraction, mean generation time, etc.) were taken from external sources and reflect ${ }^{235} \mathrm{U}$ fission with a thermal spectrum. Certain reactivity effects (fuel Doppler, moderator density, user-supplied external) can be modeled, and reactivity coefficients were borrowed from separate neutronics calculations of an HTGR system. The stiff system of 
differential equations is handled with a matrix exponential approximation via the Pade $(3,3)$ rational function. This approach is accurate and does not restrict the calculation time-step beyond requirements of the hydraulic solution. The existing PRKE model can be readily leveraged in terms of its existing data structures and code architecture. Certain physics may need to be added to the PRKE model, e.g., delayed neutron precursor drift and reactivity effects related to circulating fuel. Additionally, the fluid-fuel concept is such a departure for MELCOR and the COR package that a "new" PRKE model capable of operating independently of COR may be required.

\section{Deployment and Application Goal:}

- Validation of MELCOR point kinetics and fission product transmutation in MSRs

\subsubsection{Fission Product Transport in Molten Salt}

Fission products are assumed to be in the following states:

- Soluble fission products

- Insoluble fission products

- Colloidal suspension

- Gas/liquid interphase colloid

- Surface deposit

- Fission product gases resident in bubbles formed due to salt agitation

MELCOR is implementing a generalized transport model that captures the movement of fission product compounds between these different states. The transport coefficients between these states are the fundamental data needed in this model.

\section{Deployment and Application Goals:}

- Assess state-of-knowledge with respect to transport coefficients

- Develop best-estimate transport coefficients

- Assess relevance of knowledge gaps in underlying transport coefficient

- Develop uncertainty model for transport coefficients

- Uncertainty propagation with MELCOR to identify importance of uncertainties in source term assessments

\subsubsection{Validation of Reactor Decay Heat Removal Functions}

MELCOR can be directly applied to assess the performance of decay heat removal systems, as discussed previously. Since these systems are likely to be passive, performance can only be assessed with tools that can represent the physical performance of these systems under a range of normal and likely degraded modes of operation. MELCOR is currently being used to assess the performance of passive safety systems for HTGRs, HPRs and FHRs.

\section{Deployment and Application Goals:}

- Validate MELCOR modeling of MSR decay heat removal system under design basis operation

- Develop model to represent the range of degraded operational states for decay heat removal system

- Establish performance profile under bounding accident scenarios of decay heat removal functions 


\section{EXPERIMENTAL VALIDATION OF ACCIDENT MODELS}

\subsection{INTRODUCTION TO EXPERIMENTAL PLAN TO VALIDATE SALT SPILL SOURCE TERM MODELS}

This section presents an overview of experimental work thought to be needed to develop and validate new thermal-hydraulic and source term models for an MSR dose consequence assessment resulting from significant, potentially bounding, accidents involving the rupture the primary loop.

Figure 15 shows a schematic layout of a posited salt spill accident within the primary loop containment cell of the MSBR experiment design. The steel guard pan and drain tank are protective measures that will likely be an element of any large MSR design to avoid the undesirable interaction of the spilled fuel salt with any concrete surfaces. The interaction of fuel salt and concrete results in concrete dehydration and gas generation, which could lead to containment pressurization. This can be avoided by covering concrete structures that could receive a salt spill with steel or some other appropriate alloy. The steel guard pan would be angled such that the spilled salt would flow by gravity into a passively cooled drain. ${ }^{\dagger \dagger}$

\footnotetext{
Tit It is important to note that if the catch pan were to fail, there could be salt contact with concrete. In the PRISM (sodium-cooled fast reactor), the NRC questioned what would happen if a steel liner in a room containing a sodium spill failed, resulting in sodium contact and interaction with underlying concrete. Several large-scale tests were conducted at Sandia to look at sodium interaction with concrete, and a code was developed to assess this type of interaction. When concrete decomposes, it gives off first free water, and then bound water and $\mathrm{CO} 2$, both of which will affect the salt chemistry and could cause a pressure stress on containment seals.
} 


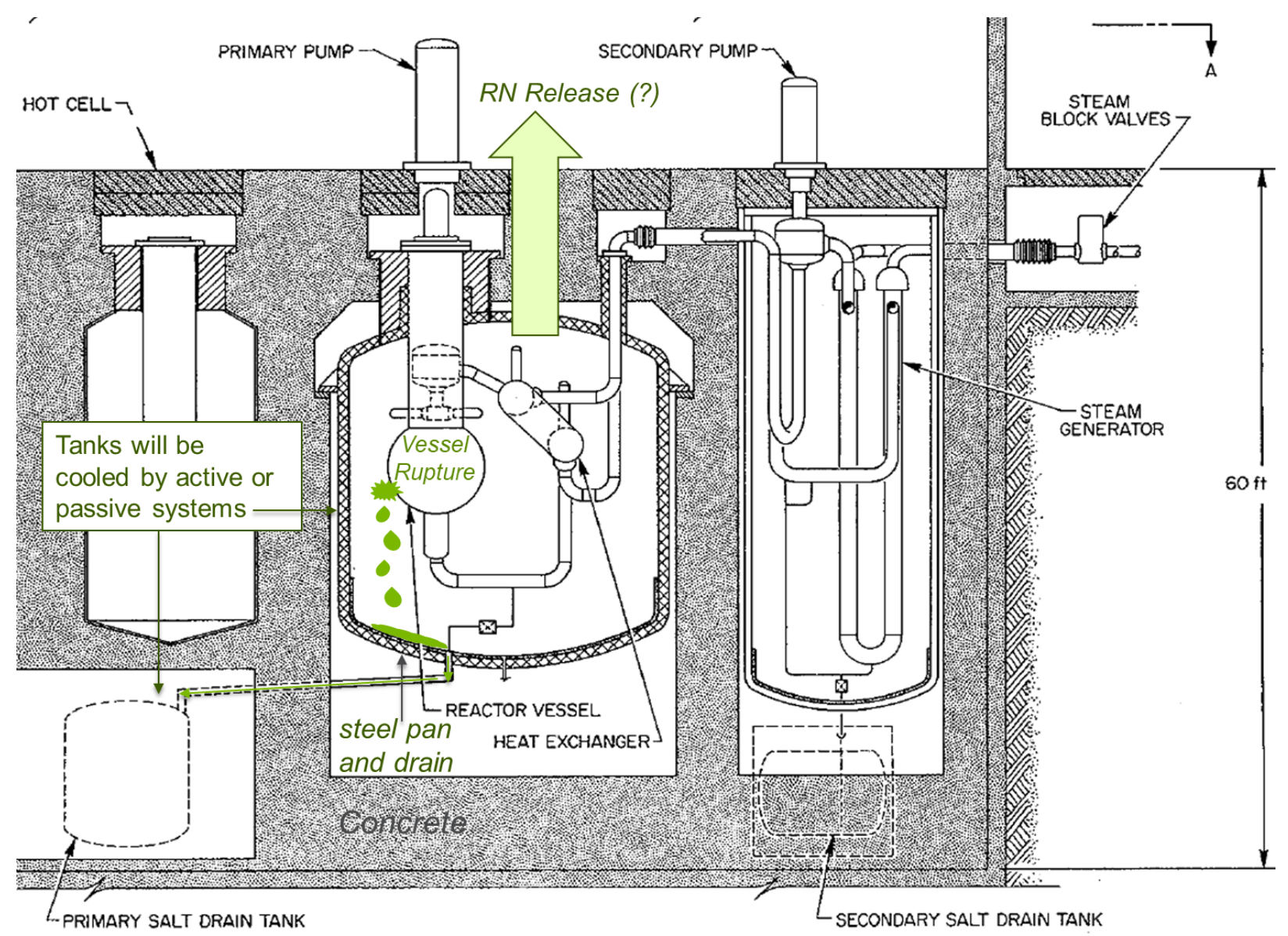

Figure 15. Schematic diagram of salt spill in primary containment cell due to a vessel rupture event (adapted from McWherter [106]).

The effectiveness of designs to reject decay heat from spilled salt is of primary concern due to uncertainties as to the mechanisms of cooling and the undesirable implications of an uncontrolled rise in salt temperatures. Such negative implications include:

- the vaporization and transport of fission products such as Cs and I and possibly actinides within containment (a possible radionuclide source term),

- the generation and transport of corrosive gaseous fluoride or chloride species that could cause accelerated corrosion of alloys within the containment cell,

- the heating and possible degassing of concrete $\left(\mathrm{H}_{2} \mathrm{O}\right.$ and $\mathrm{CO}_{2}$ release) below the catch pan.

In addition to thermal radiation and convection, decay heat likely must be rejected from the spilled fuel salt by cooling systems between the steel catch pan and concrete or within the concrete itself. Drain tanks will also be cooled by either active or passive means. The amount of decay heat that must be rejected from the fuel salt spill will depend on the power density of the salt. It is estimated that the fuel salt will continue to produce $\sim 7 \%$ of full power immediately after fission stops. This implies that several tens of megawatts of heat must be rejected for several days after salt is spilled from a large reactor $(2,500$ MWth). The corresponding power densities for MSR fuel salts will range from $20-50 \mathrm{MW} / \mathrm{m}^{3}$ at shutdown.

Accident progression for fuel salt loop rupture depends on the type and configuration of the passive decay heat removal system (Section 4.1.2.1). Regardless of the type of heat removal system employed for a 
given MSR, questions remain regarding the processes involved in decay heat rejection from a spilled mass of salt. By quantifying these processes, the planned experiments may inform design decisions regarding which decay heat removal system is most efficient and safe for a given fuel salt composition and primary loop design.

A proposed experimental plan is divided into two major activities. The first activity involves measurement of the fuel salt properties that will be needed to parameterize the new thermo-hydraulic and radionuclide release models over the accident temperature range. The second activity involves engineering scale ( $\mathrm{kg}$ quantities of salt), thermal-hydraulic studies of salt spill accident scenarios.

Significant uncertainties remain as to the thermal and chemical consequences of a salt spill event. The measurements and experiments described in this section will provide the fundamental data needed to reduce these uncertainties and will facilitate the development and validation of thermal-hydraulic and MST models for such an event.

\subsection{SOURCE TERM MODEL FOR SALT SPILLS}

The early developmental work on MSRs, such as the 1960s-1970s MSRE, MSBR, MSDR and the denatured MSR development project (DMSR), all concluded that the MCA involved a breach in the primary system leading to a spill of fuel salt into containment (e.g., Rosenthal et al [107], Engel et al [108]). Additionally, on-going developmental work on modern MSR concepts identifies a fuel salt spill from a rupture in the primary system as the primary bounding accident (e.g., Yoshioka and Kinoshita [109]). As perhaps the first attempt to mechanistically model the release of key fission products and actinides during a salt spill accident, the work of Kalilainen et al. [89] provides a useful guide for future MSR MST development projects.

\subsubsection{Salt Spill Simulation Design and Methodology}

The MSR reference design used for the Kalilainen et al. MST study was the European Commissionfunded molten salt fast reactor (MSFR) project. The MSFR is a fast neutron spectrum reactor with a nominal fuel salt composition of $\mathrm{LiF}_{-} \mathrm{ThF}_{4}-\mathrm{UF}_{4}$ (77.5-20-2.5 mol\%). A simplified diagram of the major components of the MSFR design is shown in Figure 16. 


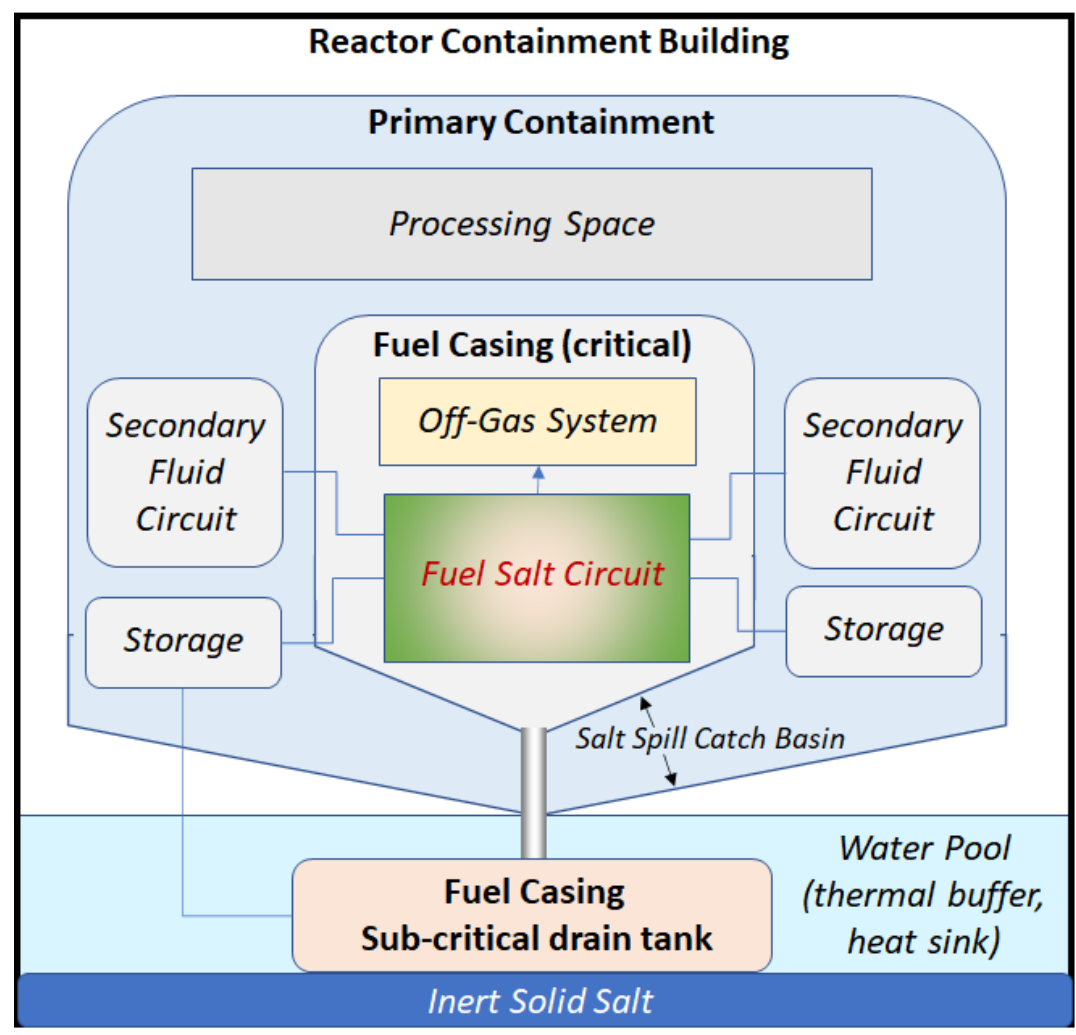

Figure 16. Schematic diagram showing the major components of the MSFR primary fuel salt loop (adapted from Kloosterman [110]).

The accident scenario modeled by Kalilainen et al. involved a postulated rupture of the fuel salt circuit and primary fuel casing leading to fuel salt draining onto the catch basin (i.e., the "floor") within the primary containment shown in Figure 16. The containment atmosphere is assumed to be pure nitrogen. The purpose of the study was to model the temperature evolution of the spilled salt, the evaporation behavior of the salt and the release of Cs and I species during evaporation.

Calculations to determine the composition of the fuel salt assume that the MSFR fuel is reprocessed using a batch-wise extraction and processing rate of $40 \mathrm{~L}$ per day. For this process, volatile fission products were continuously removed while soluble fission products were not removed. The fission product composition of the fuel salt assumed 200 equivalent full power years of operation to provide a realistic maximum radionuclide content [89].

A simplified schematic of the MSFR fuel cycle and the context of the salt spill accident assumed by Kalilainen et al. is shown in Figure 17. The concentration of iodine in the fuel salt is relatively low as the iodine precursor isotopes of $\mathrm{Sb}$ and Te are largely removed by the off-gas system with a cycle time of 43 seconds [89]. Similarly, the Cs concentration in the fuel salt is also relatively low because its precursor isotopes of Te and Xe are also largely removed by the off-gas system.

It is noted that the rate and efficiency at which metals such as $\mathrm{Sb}$ and Te will be partitioned to the off-gas is strongly dependent on the sweep gas system design and the redox conditions of the salt [89]. However, for this MSFR salt spill study it was assumed that the cycle time for the removal of metallic fission products (e.g., $\mathrm{Sb}$ and $\mathrm{Te}$ ) is the same as the noble gases (43 seconds) [89]. The initial composition of the fuel salt based on these assumptions is shown in Table 14. 


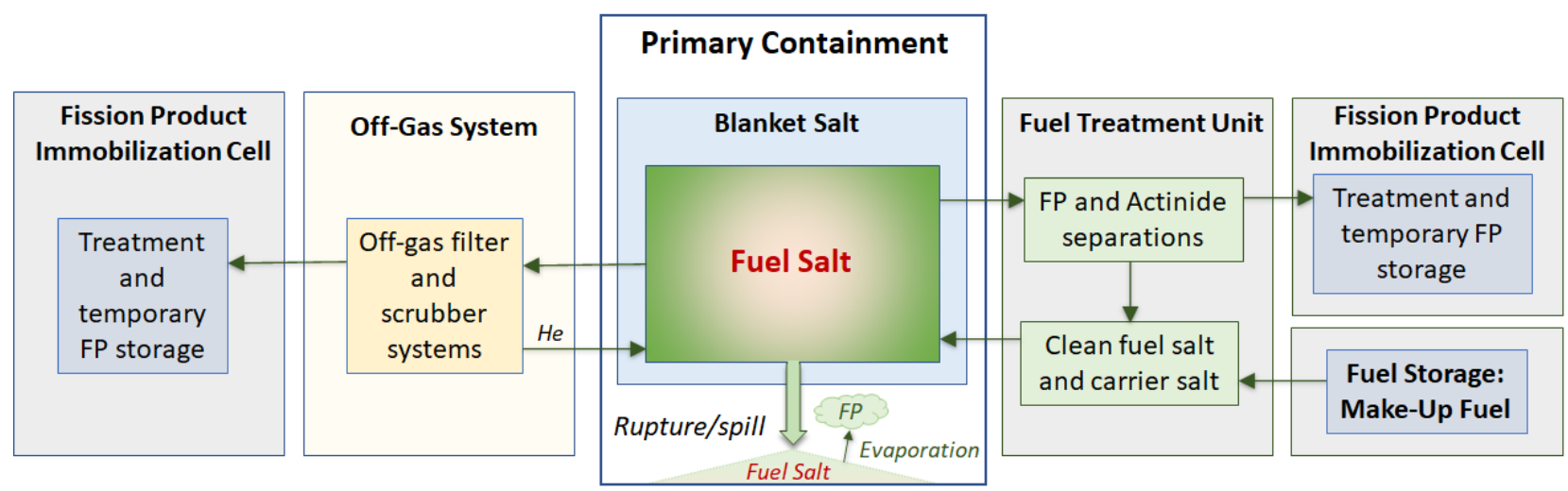

Figure 17. Simplified fuel cycle flow diagram for the MSFR showing the context of a fuel salt spill accident (adapted from Kalilainen et al.[89] ).

Table 14. Initial composition of fuel salt used in salt spill simulation (adapted from Kalilainen et al. [89]).

\begin{tabular}{cccc}
\hline Initial composition of fuel salt & $\mathbf{( m o l} \%)$ & Initial masses in initial fuel salt & (kg) \\
\hline $\mathrm{LiF}$ & 78.8 & $\mathrm{Li}$ & $4,720.0$ \\
$\mathrm{ThF} 4$ & 16.9 & $\mathrm{Th}$ & $3,3910.0$ \\
$\mathrm{UF} 4$ & 4.2 & $\mathrm{U}$ & $8,650.0$ \\
$\mathrm{Cs}$ & $9.8 \times 10^{-3}$ & $\mathrm{Cs}$ & 11.0 \\
$\mathrm{I}$ & $5.8 \times 10^{-5}$ & $\mathrm{I}$ & 0.06 \\
& & $\mathrm{~F}$ & $2,6787.0$ \\
\hline
\end{tabular}

The MSFR containment geometry and decay heat removal that was assumed for this study was a simplified design based on Wang et al [111]. The confinement volume, geometry, initial conditions, and boundary conditions can all have significant effects on source term modeling results. However, since the Kalilainen et al. study focused specifically on developing fission product release models that account for nonideality of the fuel salt chemistry, a relatively simple primary containment system was assumed [89].

Time zero for the salt spill simulations is assumed to be at the moment the fuel salt has spilled onto the containment floor, and as the salt was assumed to form a uniform layer. The initial heating rate of the salt due to decay heat is $6^{\circ} \mathrm{C}$ per minute and the initial salt temperature was assumed to be $27^{\circ} \mathrm{C}$. This low initial salt temperature was assumed so that the salt component and fission product speciation could be studied over a broad temperature range [89]. The temperature evolution of the salt and the containment atmosphere calculated by the MELCOR model are shown in Figure 18a. Figure 18b shows the pressure generated in containment due to the fuel salt heat up; accounting for salt component and fission product vapor pressures as calculated by the coupled MELCOR-GEMS model. The results show that, for the containment geometry described above, the spilled fuel salt reaches a maximum temperature of $1,225^{\circ} \mathrm{C}$ approximately 3 hours after the spill occurs [89]. 

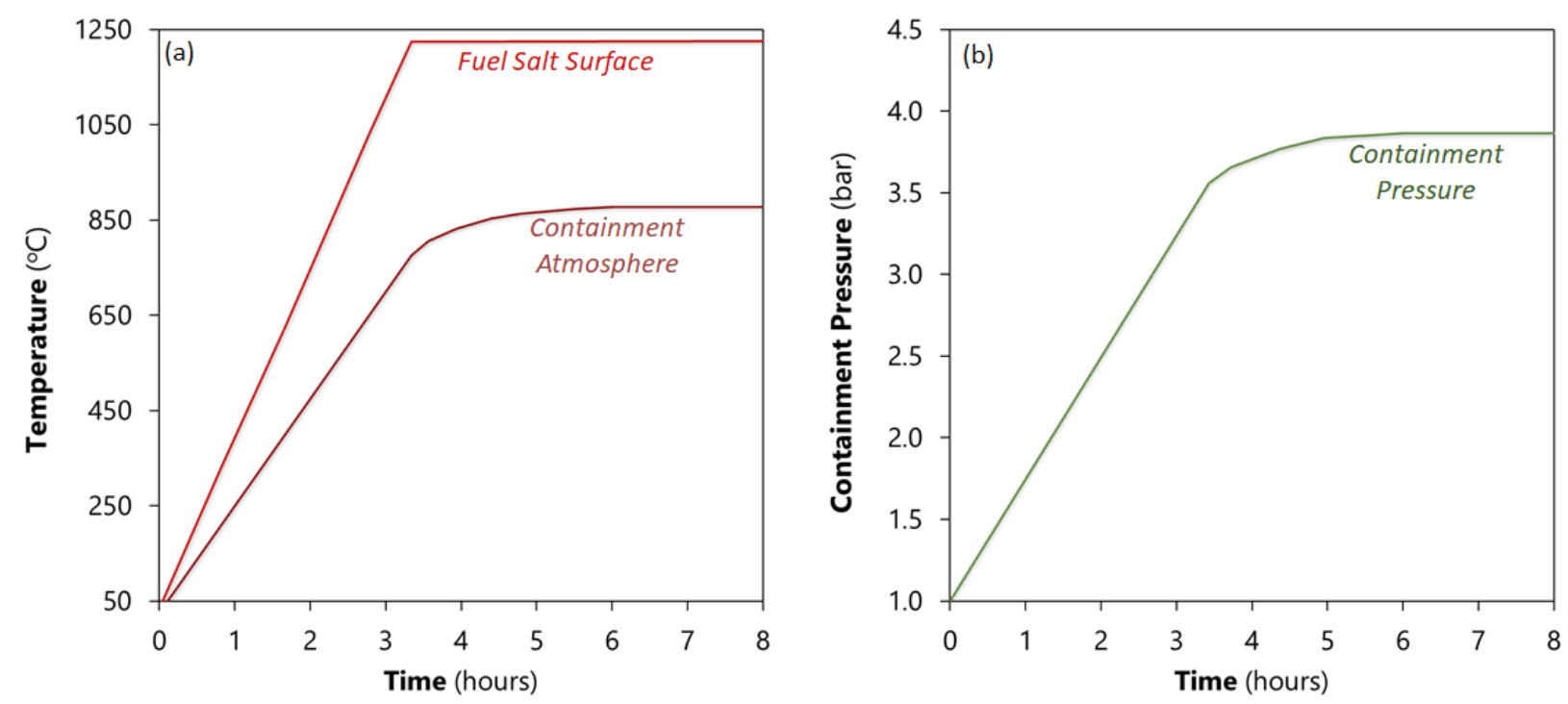

Figure 18. Temperature and pressure evolution of fuel salt and containment atmosphere following the salt spill (adapted from Kalilainen et al.,[89]).

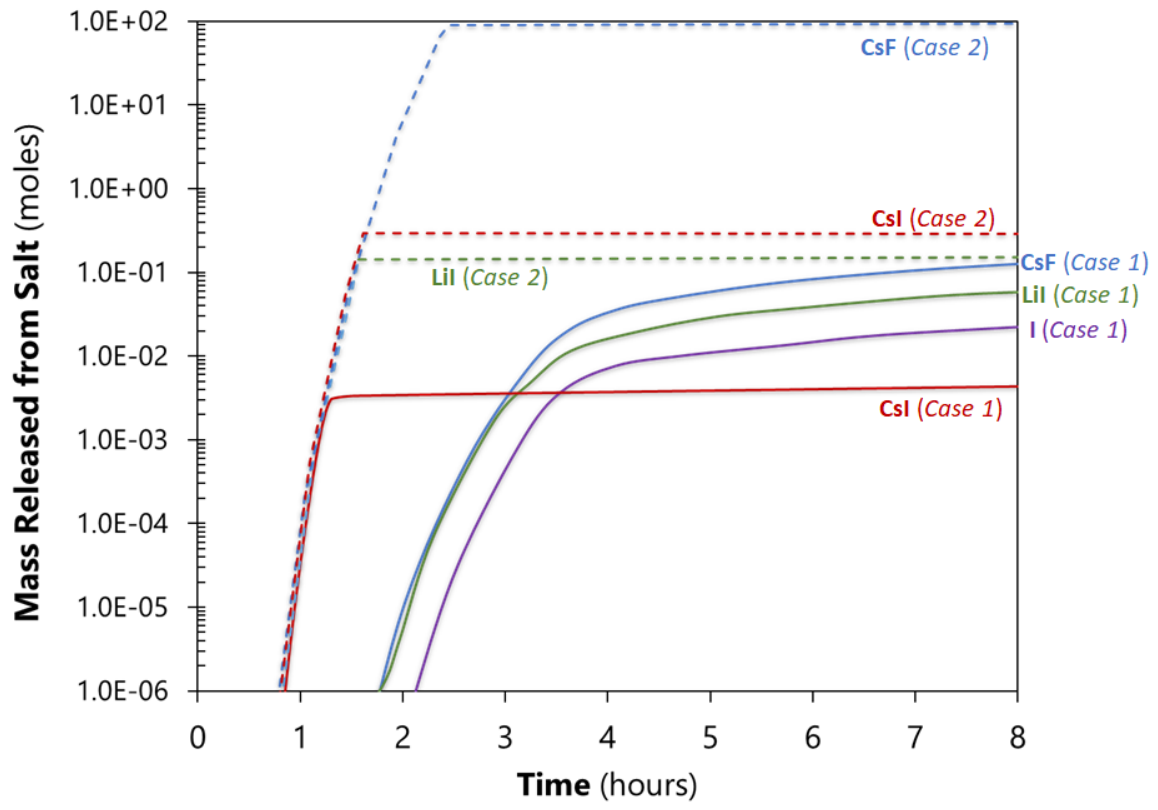

Figure 19. Vapor species released from evaporating salt for the Kalilainen et al. [89] Case 1 (accounts for nonideal behavior) and Case 2 (does not account for nonideal behavior) simulations (adapted from Kalilainen et al. [89]).

The Kalilainen et al. salt spill simulation study found that the thermal-hydraulic variables and parameters that showed the strongest effect on the fuel salt evaporation and fission product vaporization behavior were the salt and containment atmosphere temperatures and the containment pressure and the mass transfer coefficient at the salt surface $\left(k_{i}\right.$ in Eq. (2).

As shown in Figure 19 the evaporated masses of $\mathrm{Li}, \mathrm{UF}_{3}$ and $\mathrm{UF}_{4}$ are considerably lower for the coupled MELCOR-GEMS model that accounts for the nonideal mixing (Case 1) relative to the MELCOR stand- 
alone case that uses pure phase vapor pressures (Case 2). This is due to the species interactions as quantified by the relationships shown in Eq. (2).

\subsubsection{Conclusions and Recommendations Based on Salt Spill Simulation Case Study}

Overall, the simulation results show that the retention of all key species modeled (CsI, CsF, $\mathrm{LiI}_{\text {, }} \mathrm{ThF}_{4}$, $\mathrm{UF}_{4}, \mathrm{UF}_{3}$ ) is significantly increased when the excess Gibbs energy of mixing is considered. This indicates that using pure phase and ideal mixing assumptions for modeling the release of fission products and actinides from molten salts will likely lead to inaccurate results. It was also found that the vapor phase speciation of iodine is significantly affected by the amount of free fluoride in the salt mixture [89]. Future studies must account for a larger range of fission products (particularly $\mathrm{Sr}, \mathrm{Ru}, \mathrm{Ce}, \mathrm{Cd}, \mathrm{Sn}, \mathrm{Y}, \mathrm{Te}, \mathrm{Ba}$ and $\mathrm{Zr}$ in addition to the major actinides). Future studies also need to consider the effects of chemical kinetics and radiolysis, especially at temperatures below $400^{\circ} \mathrm{C}$.

A limitation with the present approach is the lack of information on the thermo-physical and thermohydraulic behavior of the salt. For example, the salt is assumed to be a flat, homogeneous mass of liquid, while in actuality there may be inhomogeneities and solid polycrystalline crusts that form on the top and or bottom of the spilled salt mass. These and other data gap issues require focused experimental.

\subsection{THERMO-PHYSICAL PROPERTIES NEEDS FOR THERMAL-HYDRAULIC ANALYSIS OF SALT SPILL BEHAVIOR}

\subsubsection{Fuel Salt Property Measurements}

The development of a physico-chemical model for a salt spill accident progression will require quantification of the thermo-hydraulic behavior of the spilled fuel salt. Thermal-hydraulic analysis of salt spill accidents will require an extensive set of thermophysical and thermochemical property data for fuels salts of interest. The temperature range over which these properties must be known will depend on the type of fuel salt, the reactor design, and the nature of the accident. As discussed in Section 6.2, results from the Kalilainen et. al. simulation indicate a maximum temperature for the spilled fuel salt of approximately $1,300^{\circ} \mathrm{C}$. Therefore, the likely experimental range for further quantifying the salt spill scenario will require the capacity to maintain salt temperatures over a range of 600 to $1,300^{\circ} \mathrm{C}$. Table 15 identifies the salt properties that must be measured and the corresponding measurement techniques available at ANL, ORNL, INL and other laboratories. 
Table 15. Required salt property data and corresponding measurement techniques.

\begin{tabular}{|c|c|}
\hline Property & Measurement Technique \\
\hline $\begin{array}{l}\text { Density of liquid and possible solids (localized salt } \\
\text { (crust) }\end{array}$ & $\begin{array}{l}\text { Archimedes Method } \\
\text { Optical methods }\end{array}$ \\
\hline $\begin{array}{l}\text { Thermal conductivity of liquid and possible solids } \\
\text { (localized salt crust) }\end{array}$ & $\begin{array}{l}\text { Laser Flash Analysis System } \\
\text { Variable gap }\end{array}$ \\
\hline $\begin{array}{l}\text { Heat capacities of liquid and possible solids (localized } \\
\text { salt crust) }\end{array}$ & Differential Scanning Calorimeter \\
\hline Liquid Viscosity & Rotating Spindle Viscometer \\
\hline Salt boiling temperature & Differential Scanning Calorimeter \\
\hline Latent heat of fusion of solid fuel salt & Differential Scanning Calorimeter \\
\hline $\begin{array}{c}\text { Liquidous/Solidus temperatures, including the impact of } \\
\text { salt impurities (e.g., steel corrosion products, fission } \\
\text { products) }\end{array}$ & Differential Scanning Calorimeter \\
\hline Surface tension of fuel salt liquid & $\begin{array}{l}\text { Suspended bob method: variation of Archimedes } \\
\text { Method for Density }\end{array}$ \\
\hline Radiation emissivity & Infrared Camera \\
\hline $\begin{array}{l}\text { Volume expansion coefficient of fuel salt and possible } \\
\text { solid crusts }\end{array}$ & Archimedes Method \\
\hline $\begin{array}{c}\text { Simulated (non-radioactive) fission product vapor } \\
\text { pressure measurements (Cs, I, Sr, } \mathrm{Ru}, \mathrm{Ce})\end{array}$ & $\begin{array}{l}\text { In-line mass spectrometry } \\
\text { Knudsen cell mass spectrometry }\end{array}$ \\
\hline Uranium vapor pressure measurements & $\begin{array}{l}\text { In-line mass spectrometry } \\
\text { Knudsen cell mass spectrometry }\end{array}$ \\
\hline Evaporation coefficients & Langmuir - thermogravimetric analysis \\
\hline $\begin{array}{c}\text { Aerosol analyses of gas samples taken for vapor pressure } \\
\text { measurements }\end{array}$ & $\begin{array}{c}\text { Filter and microscopic characterization SEM-EDS } \\
\text { Particle size analysis }\end{array}$ \\
\hline
\end{tabular}

Results from the property measurements identified in Table 15 can be used to parameterize thermohydraulic models for the selected fuel salts at the relatively high accident temperatures. These models will be used to guide the engineering scale experiments discussed in Section 6.3.4 and can form the basis for new accident progression and consequence models to be incorporated into reactor accident progression codes such as MELCOR.

\subsubsection{Surrogate Fission Products}

As described in the radionuclide radiotoxicity discussion in Section 3.3.2, some of the most important fission products from a dose consequence perspective are nuclides of $\mathrm{Cs}, \mathrm{I}, \mathrm{Sr}, \mathrm{Ru}$, and $\mathrm{Ce}$ (Figure 5). The release of these fission product elements as vapor species or particulates (aerosols) will be quantified by doping the simulated fuel salt with relevant concentrations of these elements, sampling the gas space over the salt as a function of temperature and analyzing the gas samples by mass spectrometry (see Table 15). Actinides pose a considerably greater dose consequence hazard than fission products (e.g., Figure 5) and thus the vapor pressure of uranium and plutonium species (e.g., $\mathrm{PuF}_{3}, \mathrm{UF}_{4}, \mathrm{UCl}_{4}$ ) also must be determined.

\subsubsection{Laboratory-Scale Corrosion Tests}

A series of electrochemical corrosion experiments should be performed to quantify and characterize the corrosion behavior of the catch pan material in the experimental surrogate fuel salts. Corrosion tests must 
span the full temperature range of the salt spill accident scenario, which should be limited to approximately $2 / 3$ of the melting temperature of the catch pan material. Thus, tests will be performed under conditions as high as $1,000^{\circ} \mathrm{C}$.

\subsubsection{Engineering Scale Experiments: Salt Spill Morphology and Spreading}

Argonne has extensive experimental experience with melt spreading behavior for ex-vessel LWR accident scenarios (e.g., Farmer [112]) as well as convective cooling of melts within crucible-type geometries (e.g., Farmer [113]). These studies have been used to parametrize and validate MELCOR models for LWR accident scenarios and have led to generalized observations that are applicable to the MSR fuel salt spill scenarios being considered. One such observation is that the salt spill "pour" rate and salt temperature have a significant impact on the morphology and eventual location of the post-spread fuel salt accumulation. These are two parameters that must be accounted for in the engineering scale tests.

Key issues that the engineering scale tests can address are as follows.

- What is the extent of spreading of the liquid salt once the reactor vessel or primary circuit pipe is breached as a function of the salt pour rate and temperature? It is possible that a mound of salt will form on the catch pan at low temperatures and flowrates? ${ }^{\text {to }}$ For a pour of this type, will the material that flows down the vent line to the drain tank freeze inside the pipe and plug it?

- Once the material is inside the drain tank, a situation will develop in which the melt pool, heated by decay of fission products inside the salt, dissipates heat to the tank walls and cooling system. The equilibrium temperature reached by the salt once in the tank will be determined by the natural convection heat transfer coefficients to the tank sidewalls, bottom surface, and top surface. Heat transfer will also need to factor in the convective/radiative heat transfer from the melt upper surface to the upper tank structures. It is important to know: (1) values of these heat transfer coefficients (usually modeled and then confirmed through experiments) and (2) the time-dependent decay heat level in the salt volume that will establish the salt pool equilibrium temperature and the rate at which the decay heat can be dissipated to the surrounding environment/heat rejection system. The equilibrium salt temperature also affects fission product release from the molten salt pool.

- Structural questions regarding the consequences of the possible warping of steel liners and catch pans exposed to high-temperature salts are also important. Extensive warping could lead to a failure of the designed function of the catch pan or liner and salt drainage especially over time.

- Findings from Fukushima indicate that melt released from the reactor vessel can extensively freeze on and below the vessel structure and not be cooled by water injected to the containment floor to cool the melt. Decay heat from material frozen on structures is dumped directly to the containment atmosphere and could stress containment seals. Applying these insights to a salt-cooled reactor, solidified salt on the catch pan will remain in place for decades until the plant is eventually taken down and the salt recovered. This raises concerns about long-term corrosion of the liner and whether it could eventually fail. Fukushima illustrated that long-term containment response and integrity following an accident had not been fully thought through. Long-term containment is now being considered by the NRC and others.

- Another concern is that salt frozen on the liner will continue to dissipate heat both upwards into containment and downwards to the underlying concrete. Typically, insulation would be placed

\footnotetext{
HFor example, a large and deep (i.e., 2-3 m) accumulation of core debris has been found beneath the reactor vessel
} at Unit 3 at Fukushima Daiichi. 
between a catch pan and the concrete to minimize heating of the concrete during a spill as heat up of the concrete can release $\mathrm{H}_{2} \mathrm{O}$ and $\mathrm{CO}_{2}$ without direct contact by hot salt. This gas production can place additional loads (by pressurization) on the catch pan. Even when insulated, there is a possibility for the underlying concrete to eventually heat up since concrete is an extremely poor heat sink (thermal conductivity $<1 \mathrm{~W} / \mathrm{m}-\mathrm{K}$ ).

Potential thermal-hydraulic tests to consider are summarized in Table 16. An indication of how these tests might be instrumented and conducted is also provided in Table 16. Both spreading and tank retention experiments are proposed. As with the thermophysical and thermochemical laboratory scale tests, the salt samples will be doped with non-radioactive Cs, I, Sr, Ru and Ce. Aerosol size and concentration in the test vessel gas space will be characterized by periodically drawing samples through cascade impactors. Chemical composition of these aerosols will be determined using SEM-EDS and ICP/OES; this collection of data will be used to evaluate the fission product release fractions. Gas space chemical composition will be characterized by drawing a continuous sample through an on-line gas mass spectrometer at a fixed cover-gas flowrate so that the release rate of isotopes can be determined. Post-test examinations will include metallurgical analysis of the steel/salt interface to further characterize the extent of interaction.

Regarding the size of these tests, the amount of salt to be used will be based in part on a thermalhydraulic scaling analysis aimed at preserving key variables between the experiments and the reactor (e.g., melt temperature and heat flux at the retention tank boundary are likely important to preserve as this can impact the tank surface corrosion rate). Based on surface-to-volume considerations, the salt mass is preliminarily projected to be in the range of 10 to $100 \mathrm{~kg}$. Tests can be performed on both the fluoride and chloride salts. 
Table 16. Engineering-scale thermal-hydraulic tests to address salt behavior during large scale salt spill scenario. Tests will be performed with both fluoride and chloride salts.).

\begin{tabular}{|c|c|c|}
\hline Test type & Attributes & Rationale \\
\hline Spreading & $\begin{array}{l}\text { Produce molten salt in a melt generator and then } \\
\text { drop on a steel plate leading to a vent line. } \\
\text { Measure leading edge penetration, local salt } \\
\text { temperatures, local plate temperature and stress } \\
\text { response, and post-test spread distribution on the } \\
\text { steel plate and in the vent line. Vary melt } \\
\text { temperature and flowrate to determine extent of } \\
\text { melt penetration. The molten salt will be doped } \\
\text { with fission products (Cs, I, Sr, Ru, Ce) to } \\
\text { characterize fission product release during this } \\
\text { phase. }\end{array}$ & $\begin{array}{l}\text { If the reactor vessel fails, salt must relocate } \\
\text { across a catch pan and then flow through a } \\
\text { vent line to a tank. Data from these types of } \\
\text { tests can be used to qualify salt spreading } \\
\text { models to support plant design and licensing } \\
\text { processes, and to characterize fission product } \\
\text { release into containment during this phase. }\end{array}$ \\
\hline $\begin{array}{l}\text { Tank retention } \\
\text { and long-term } \\
\text { cooling }\end{array}$ & $\begin{array}{l}\text { Produce molten salt in a melt generator and pour it } \\
\text { into a simulant retention tank. The tank would be } \\
\text { equipped with either Calrod heater(s) or electrodes } \\
\text { for direct electrical heating of the salt (a better } \\
\text { simulation of decay heat) if the salt electrical } \\
\text { conductivity is in a range where this is feasible } \\
\text { (i.e., reasonable voltage/current requirements). The } \\
\text { tank would be instrumented to measure salt } \\
\text { temperature at various axial and radial locations. } \\
\text { The interior surface temperature of the tank walls } \\
\text { will be measured at several locations, as well as } \\
\text { the heat flux from the wall to the heat rejection } \\
\text { system. This will allow convective heat transfer } \\
\text { coefficients in the pool to be determined. The tank } \\
\text { will also be equipped with a salt draw sample } \\
\text { system, as well as a gas phase sampling and } \\
\text { analysis system. Input power (simulating decay } \\
\text { heat) would be varied to get heat transfer and } \\
\text { fission product release information at a variety of } \\
\text { salt pool temperatures. }\end{array}$ & $\begin{array}{l}\text { Once the salt is inside the vent tank, a } \\
\text { situation will develop in which the melt pool, } \\
\text { heated by decay of fission products inside the } \\
\text { salt, dissipates heat to the tank walls and } \\
\text { cooling system. The equilibrium temperature } \\
\text { at this point is determined by the natural } \\
\text { convection heat transfer coefficients to the } \\
\text { tank sidewalls, bottom surface, and top } \\
\text { surface. Heat transfer up will also need to } \\
\text { factor in the convective-radiative heat } \\
\text { transfer from the melt upper surface to the } \\
\text { upper tank structures. It is important to } \\
\text { determine the heat transfer coefficients as } \\
\text { these will determine the equilibrium } \\
\text { temperature at which the decay heat can be } \\
\text { dissipated to the surrounding environment. } \\
\text { The equilibrium salt temperature is, in turn, } \\
\text { important to know as this affects fission } \\
\text { product release from the pool. }\end{array}$ \\
\hline
\end{tabular}

\section{DEVELOPMENT NEEDS AND FUTURE WORK}

MSR reactor characteristics permit designs with a high degree of confidence in retaining radionuclides under all credible accident scenarios. The systematic evaluation of the release mechanisms and pathways of the stored energy sources within containment combined with potential external events enable the development of a reasonably complete list of severe accidents for preliminary evaluation.

Maintaining low pressure and continuing to remove decay heat from fuel salt, even after a significant boundary rupture, are key elements to avoiding cascading accidents and ensuring the containment of all credible accidents. Achieving a sufficient understanding of the chemical and physical behavior of the fuel salt so that it can be adequately modeled under normal and accident conditions underpins accident progression analysis. Accident progression evaluation is central to the development of an MST, which in turn allows consequence evaluation for accident scenarios. 
NPP safety begins with understanding the plant and fuel behavior. An MSR's readily understandable high degree of passive safety could simplify the safety adequacy evaluation process without requiring undue conservatisms or compromising safety. An early phase safety adequacy evaluation assessment is instructive until increasingly more detailed and higher fidelity models can be used to provide reasonable assurance of adequate protection.

Bounding consequence evaluation is one but not the only acceptable safety adequacy demonstration method. Developing adequate reliability information to provide reasonable assurance that accidents with unacceptably high consequences have sufficiently low probability is another acceptable method. The costbenefit trade-off between methods will vary with the data available and the complexity of design and designers will have to choose their approach to adequate safety demonstration.

Reactors with liquid fuels are different and have been considered different since their inception. Multiple licensing aspects of MSRs are interconnected due to the liquid nature of the fuel. Fissile material control and accountability (10 CFR Part 74), reactor safety (10 CFR Part 50), fissile material possession and use (10 CFR Part 70), and safeguards monitoring (10 CFR Part 75) should be evaluated in an integrated manner. MSRs share features with fuel processing plants. Radionuclides are distributed across the plant and move as part of normal operation; physical and chemical radionuclide separations are part of normal operations. The NRC has a well-developed fuel cycle facility safety adequacy evaluation path that also be applicable to MSRs.

A number of important technical gaps remain related to MSR safety evaluation. These identified gaps point to the need for future development work as noted below.

\subsection{IMPORTANCE OF EXCESS GIBBS FREE ENERGY IN THERMODYNAMIC MODELING OF VAPOR PRESSURE FOR MST}

Kalilainen et al. calculated the release of fission products and salt compounds from spilled LiF-ThF $\mathrm{F}_{4}-\mathrm{UF}_{4}$ fuel salt in one of the first attempts to realistically model radionuclide release from an MSR under severe accident conditions [89]. Specifically, evaporation from a salt surface that spilled on the floor of a confinement building was simulated by coupling the Gibbs Energy Minimization Software (GEMS) with the severe accident code MELCOR.

The recommended approach to model MSR chemistry is the CALPHAD method, which enables the linkage of solution phase models to chemical and physical properties [114]. By using this method, Kalilainen et al.[84] describes the molten salt solution as a collection of multiple binary mixtures. The Gibbs free energy of each binary mixture in the molten salt solution is described by Eq. (2).

$$
G=G^{r e f}-T \Delta S+G^{E X}
$$

where $G^{r e f}$ is the weighted average of the Gibbs energies of each mixing constituent in a binary mixture (i.e., the "end members"), $\mathrm{T}$ is the temperature, and $\Delta S$ is the configurational entropy. These first two terms in Eq. (2) are related to ideal mixing. $G^{E X}$ is the parameter describing nonideal behavior due to mixing.

Kalilainen et al.[84] emphasizes the importance of including the excess Gibbs free energy for mixing the salt solution components in the coupled thermodynamic and accident progression model [89]. The excess Gibbs energy for different binary fluoride and iodide systems was calculated empirically from published excess enthalpies and phase equilibria information (liquidus and solidus temperatures) and pure compound vapor pressures by using the Redlich-Kister (Guggenheim) mixing model: 


$$
G_{i j}^{E X}=R T x_{i} x_{j}\left[a_{0}+a_{1}\left(x_{i}-x_{j}\right)+a_{2}\left(x_{i}-x_{j}\right)^{2}+\ldots\right]
$$

where $a_{0}, a_{1}$, and $a_{2}$ are dimensionless fitting parameters; and $x_{i}$ and $x_{j}$ are the mole fraction of species $i$ and $j$ in the binary system, respectively. The fitting parameters for the binary systems considered in the study are provided in Table 17.

Table 17. The Redlich-Kister mixing model fit parameters calculated for binary systems in the molten salt (from Kalilainen et al.[89]).

\begin{tabular}{llll}
\hline \multicolumn{1}{c}{ Pair } & \multicolumn{1}{c}{$\boldsymbol{a}_{\mathbf{0}}$} & \multicolumn{1}{c}{$\boldsymbol{a}_{\mathbf{1}}$} & $\boldsymbol{a}_{\mathbf{2}}$ \\
\hline LiF-ThF & -22105 & -22951 & -7122 \\
$\mathrm{LiF}-\mathrm{CsF}$ & -16000 & 0 & 0 \\
CsI-LiI & -21478 & 4557 & -2607 \\
CsI-CsF & -2842.8 & 0 & 0 \\
LiF-LiI & -650 & 1036 & 338 \\
$\mathrm{ThF}_{4}-\mathrm{ThI}_{4}$ & -62000 & 0 & 0 \\
$\mathrm{LiI}_{4} \mathrm{ThI}_{4}$ & -22105 & -22951 & -7122 \\
LiF-UF $_{4}$ & -30046 & -31196 & -9681 \\
CsF-ThF $_{4}$ & -145000 & 0 & 0 \\
CsI-ThI $_{4}$ & -19575 & 5763 & 4090 \\
\hline
\end{tabular}

The modeled evaporation behavior of $\mathrm{UF}_{4(\mathrm{~g})}$ and $\mathrm{CsI}_{(\mathrm{g})}$ is markedly different when the effects of salt mixing were considered than when just the pure compound vapor pressures were used (Figure 20). The model that included salt mixing showed an overall reduced fission product release and delayed release timing due to the effect of mixing on vapor pressures in comparison with pure compound simulations.

(a)

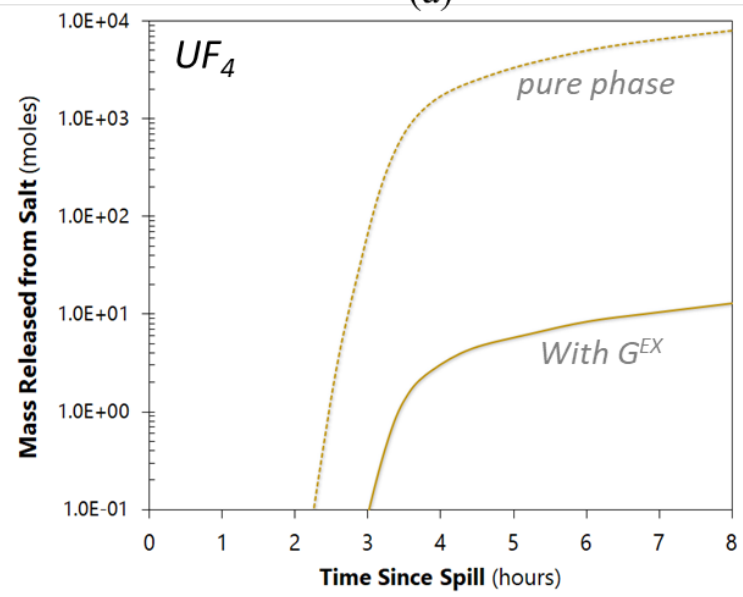

(b)

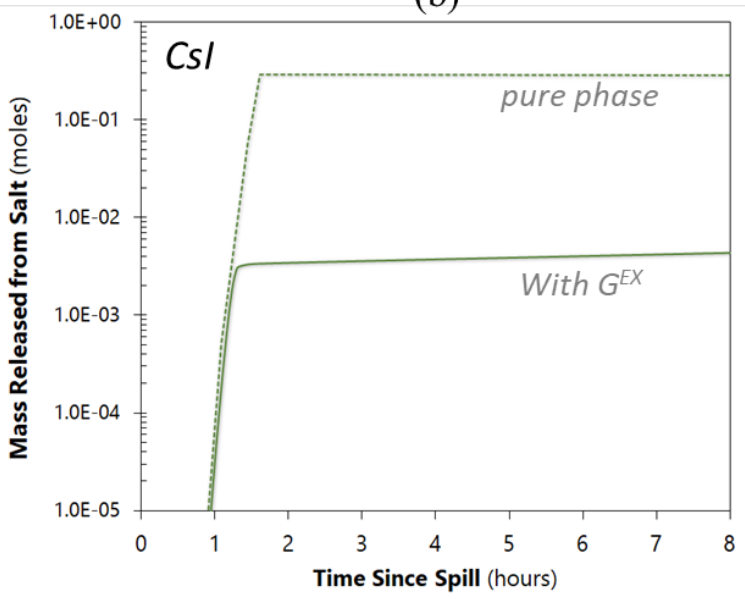

Figure 20. Analysis of (a) $\mathrm{UF}_{4}$ and (b) CsI volatilization after spill of $\mathrm{LiF}_{-} \mathrm{ThF}_{4}-\mathrm{UF}_{4}$ fuel salt containing Cs and I showing the importance of experimentally quantifying nonideality with Gibbs excess energy terms (adapted from Kalilainen et al.[89]).

Gibbs free energy minimization calculations that ignore the excess Gibbs energy functions can lead to inaccurate descriptions and predictions of the chemical behavior of a molten salt. Also, below $400^{\circ} \mathrm{C}$, reaction kinetics and radiolysis will govern chemical behavior rather than thermodynamic equilibrium. 
The nonideal solution behavior (quantified by excess Gibbs energy) of molten salts manifests in several ways that can influence the salt behavior during both normal and accident conditions. The effects include:

- an increase or decrease in melting temperatures relative to those predicted assuming ideal behavior,

- the occurrence of miscibility regions not predicted by ideal behavior models, and

- significant deviations in species vapor pressures relative to those predicted by ideal models.

For molten salts, the excess Gibbs energies are generally negative, which causes a decrease of the melting temperatures relative to ideal behavior and a relative decrease in vapor pressures of the molten salt components. Kalilainen et al. quantified the effects of nonideal behavior by performing some simulations in which the excess Gibbs energy was accounted for (Case 1, the best estimate modeling case) and other simulations in which the default MELCOR pure compound species vapor pressures were used (Case 2). The pure phase vapor pressures do not account for nonideality and thus generally over predict species vapor pressures. This can be seen in Figure 21, which shows some example simulation results. Other example results highlighting the dramatic difference between Cases 1 (accounts for nonideality) and Case 2 (does not account for nonideality) are shown in Figure 20 and in Figure 21.

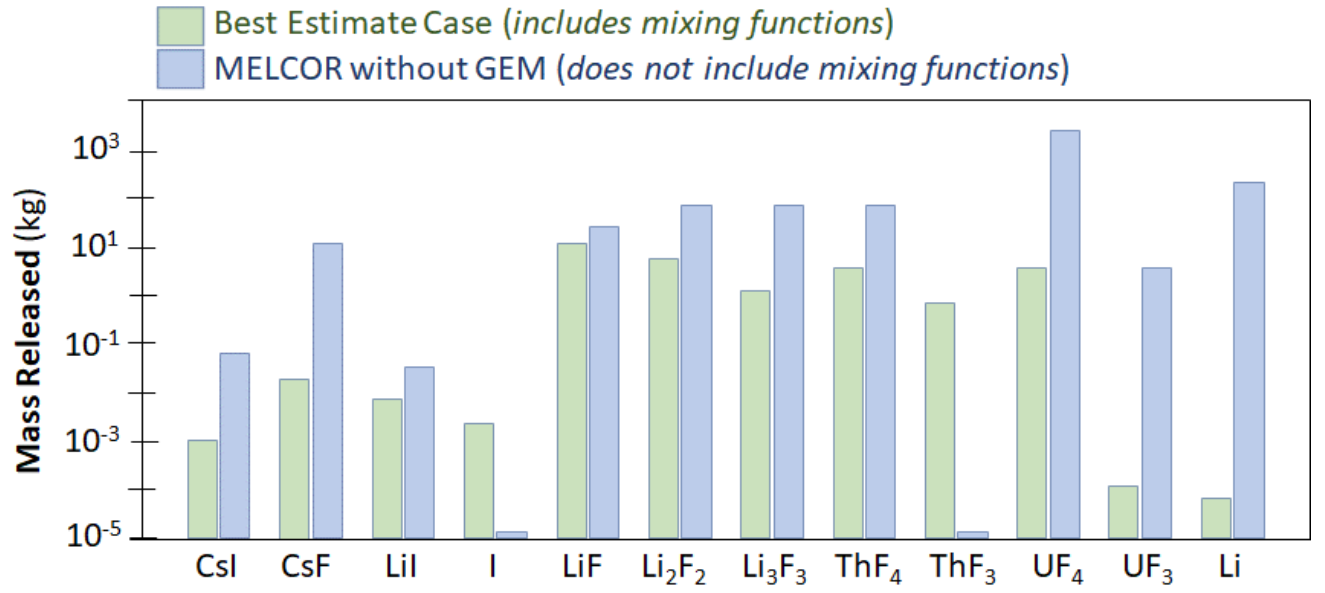

Figure 21. Example results comparing simulations that account for nonideality (green) and those that use pure phase vapor pressures (blue) (adapted from Kalilainen et al.[84]). Both sets of results are for the end of the simulation where the salt temperature has reached approximately $1,225^{\circ} \mathrm{C}$. Pure phase vapor pressures were not calculated for $\mathrm{I}$ and $\mathrm{ThF}_{3}$.

\subsection{RISK-INFORMED DECISION-MAKING}

An Electric Power Research Institute (EPRI) white paper identified benefits from a broader adoption of risk-informed approaches [115], as follows:

- measurable safety benefits that can be demonstrated through an understanding of how operational changes lead to risk reduction,

- intangible safety benefits arising from a focus on the safety improvement, and

- operational benefits arising from higher quality, greater plant flexibility, and reduced complexity.

The drive toward using risk as a means of focusing regulatory attention and facilitating more flexible operational strategies was noted in the EPRI white paper [115] as key ways in which operational costs could be reduced. Key risk-informed initiatives adopted by the nuclear industry are: 
- Maintenance Rule (a)(2),

- Maintenance Rule (a)(4) and configuration risk management,

- regulatory oversight process,

- risk-informed allowed outage time changes,

- changes to emergency technical specifications,

- risk-informed mode change assessments,

- risk-informed missed surveillance evaluations,

- in-service inspection, and

- containment testing.

NEI 18-04 [116] provides a guideline for a technology-inclusive, risk-informed, performance-based (TIRIPB) process for selection of licensing basis events (LBEs), safety classification of SSCs and associated risk-informed special treatments; and determination of defense in depth adequacy for non-LWRs [120]. NEI 18-04, also referred to as the $L M P$, has gained considerable attention across the industry and has formally received approval by the NRC in SECY-19-0117 as an acceptable method for safety assessment [120] [15].

One of the main outcomes of the LMP process is to plot event sequences (or event sequence families) on a frequency-consequence curve, as shown in Figure 22. In this way, reactor designers can calculate the plant risk based on how often an event is likely to occur and how severe it is likely to be. The y-axis of Figure 22 is the frequency of the event sequence. Event sequence frequencies are generally quantified using PRA methods, such as event tree and fault tree models. System and component reliabilities may be used, along with uncertainties, to probabilistically assess the frequency of event sequences.

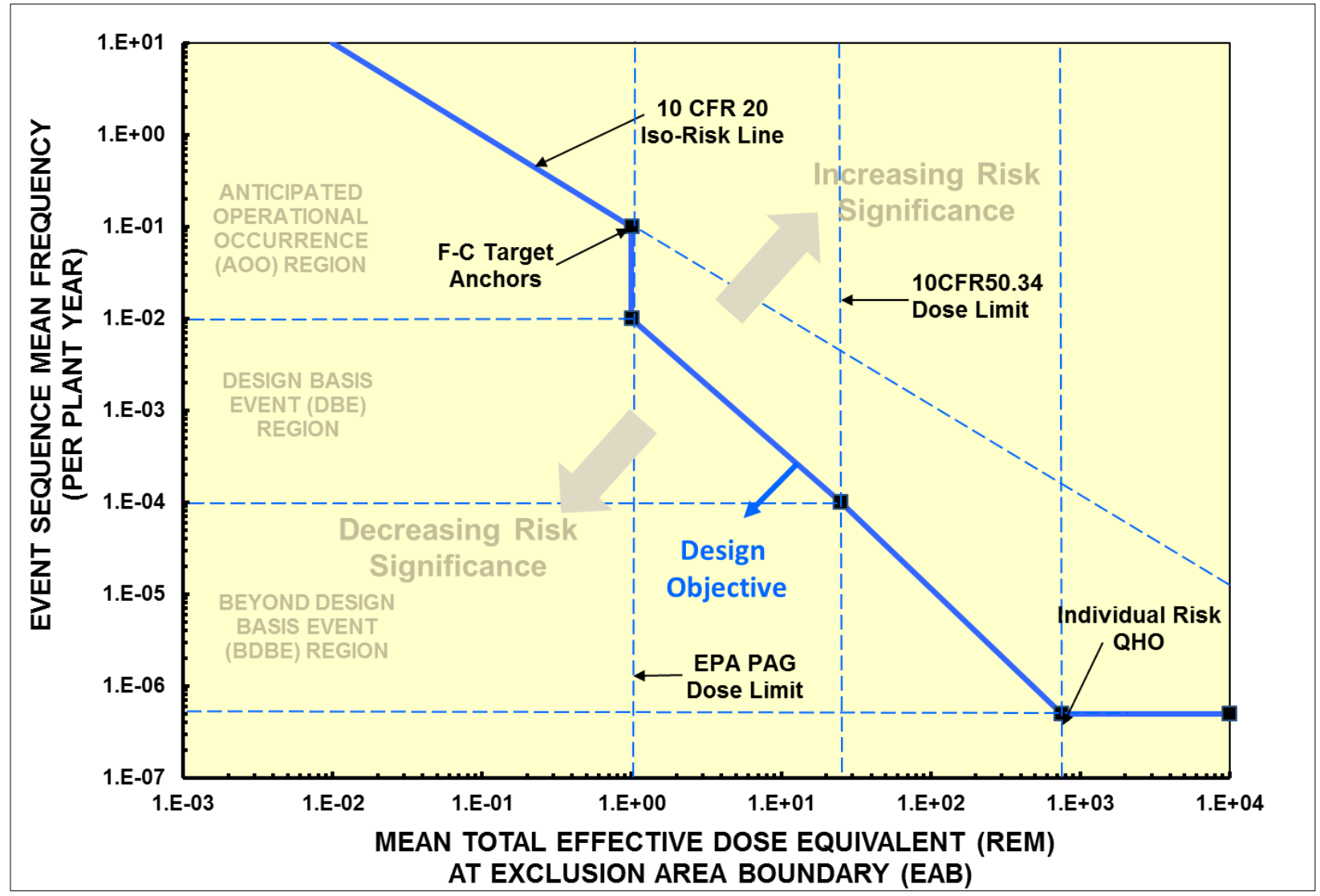

Figure 22. LMP frequency-consequence curve to assess event significance and classification [120] 
Traditional PRA methods remain relatively uncertain when addressing a range of events where it is difficult to quantify frequencies of occurrence due to either a lack of basic data or the operational experience to reveal emergent system failure modes. PRA methods show substantial benefit in supporting the identification of combinations of basic SSC random failures that can result in loss of safety function for a complex engineered system, such as one designed with significant levels of redundancy. This is a main purpose of an internal events PRA, which has proven to very effective at determining the inherent robustness of an engineered system to random SSC and operational failures.

Following TMI-2, the role of internal event PRA expanded to help understand the robustness of LWRs to a broader range of SSC and operational failures. The fact that WASH-1400 was able to identify the significant contribution of small break LOCAs to overall risk of core damage provided an illustration of the benefits that could be derived from application of PRA in nuclear energy. PRAs identified significant contributors to core damage in LWRs, allowing for operational focus to be placed on the most risksignificant scenarios. The improvements in overall NPP safety in the United States have also been accompanied by increased efficiency in operations and maintenance. Overall, the extensive deployment of PRA in the US nuclear industry has led to both safety and economic improvements.

Despite the significant benefits attained from PRAs, the application of this methodology to MSRs has some challenges to be considered.

\subsubsection{Passive System Degradation Characterization}

A challenge arises in situations where system function involves more complex physical processes. How they degrade or ultimately fail to support a safety function involves more complex physical processes and modes of operation than typical active SSCs. For example, consider the behavior of a heat removal system that relies on a circulating fluid motion between a heat source and a heat sink. In an active system, this fluid motion is established by a mechanical pump. The pump head is generally very large, and the forced circulation is robustly maintained by the large pressure gradient established in the system by this pump head. However, a passive heat removal system may also be devised that relies on natural circulation flows between a heat source and a heat sink. Thus, the ways in which a passive system can evolve to some future state, in response to an external perturbation, must be considered in a probabilistic manner.

A generalized method for evaluating passive system behavior under a range of uncertainties would be advanced by a vendor in establishing the licensing basis. While a specific methodology is not necessary, the following characteristics would be reflective of a robust passive system reliability evaluation:

- Step 1: Identification of factors influencing initial and boundary conditions for passive system.

- Step 2: Characterization of variability attached to initial and boundary conditions (i.e., technical basis for uncertainty distributions).

- This type of variability is termed aleatory because it reflects uncertainty that can never be eliminated with more knowledge.

- Step 3: Identification of relevant physical phenomena, processes and parameters affecting the behavior of a passive system.

- Step 4: Characterization of variability in physical modeling parameters used in the quantitative evaluation of passive system response

- This type of variability is termed epistemic because it reflects uncertainty in the modeling of physical processes arising from limitations in knowledge. With enhanced knowledge these uncertainties could be reduced. 
The overall output of this type of probabilistic assessment is to identify the range of plant evolution scenarios that can be realized. This is particularly important when assessing the performance of plant systems under a range of likely degradation states. That is, the set of plant states that are possible given uncertainty in the perturbations to which a plant could be subjected, as well as how a plant may evolve in response to a given perturbation. Figure 23 provides a schematic illustration of the outcome of this type of probabilistic analysis, which provides a set of "paths" along which the plant state can evolve. These paths are depicted in Figure 23 using a "horse tail" plot, where each path is overlaid on top of each other to illustrate the range of temporal evolution of a particular parameter characterizing system response. Evaluation of specific decay heat removal processes and their potential range of responses requires systematic study.

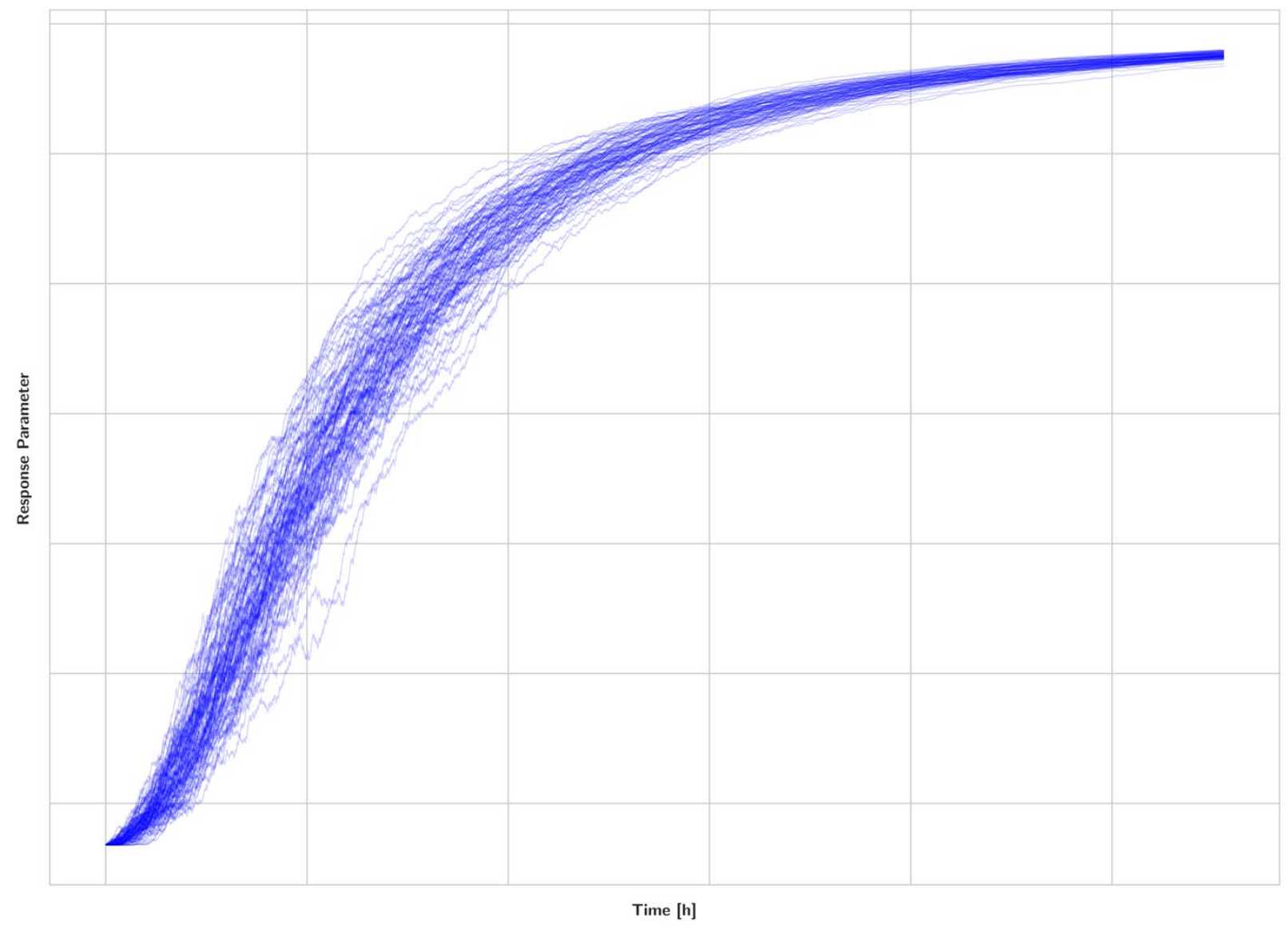

Figure 23. Illustration of evolution paths for plant subjected to initiating perturbation.

\subsection{ADDITIONAL RECOMMENDATIONS}

1. Early phase safety assessments would benefit from being piloted on an example facility. However, safety evaluation inevitably involves detailed, proprietary design information. Using or developing publicly available reactor system models with sufficient details and performing a preliminary safety adequacy evaluation is recommended. 
2. MSR accident progression evaluation is based upon understanding fuel salt properties and performance. It is recommended that relevant fuel salt property data of sufficient quality continue to be developed for use in safety evaluation.

3. Additional testing and modeling is required to provide confidence in the ability to maintain passive cooling in the event of large fuel spill accidents. Demonstration of heat transfer property information for large fuel salt spills is recommended.

4. The liquid, distributed, changing nature of the fuel salt makes establishing the location and quantities of radionuclides within an MSR distinctly different from solid-fueled reactors. It is recommended that the development and validation of an MSR radionuclide accountancy capability [117] continue as a high priority.

5. MSR accident progression depends on the plant configuration and on having adequate models of the fuel salt chemistry and physics. It is recommended that the capabilities of existing NPP accident progression modeling tools be expanded to include likely fuel salt property models and a set of reasonably assumed MSR configurations.

6. Tritium control is required to meet radionuclide concentration release requirements and might be especially challenging for reactors that use lithium or beryllium in their core. Processes and technologies for tritium management under normal operations should be developed and demonstrated. 


\section{REFERENCES}

1 US Nuclear Regulatory Commission, Policy Statement on the Regulation of Advanced Reactors, 73 FR 60612, NRC-2008-0237, October 2008, ML082750370.

2 US Nuclear Regulatory Commission, Non-Light Water Review Strategy Staff White Paper Draft, ML19275F299, September 2019.

3 Amir Afzali, Technology Inclusive Content of Application Project For Non-Light Water Reactors, Definition of Fundamental Safety Functions for Advanced Non-Light Water Reactors, Draft Report Revision B, November 2019, Southern Company, ML19343B648.

4 SRM-SECY-18-0096, Functional Containment Performance Criteria for Non-Light-WaterReactors, December 2018, ML18338A502.

5 SRM-SECY-19-0117, Staff Requirements - SECY-19-0117-Technology-Inclusive, Risk-Informed, and Performance-Based Methodology to Inform the Licensing Basis and Content of Applications for Licenses, Certifications, and Approvals for Non-Light-Water-Reactors, May 2020, ML20147A504.

6 US Nuclear Regulatory Commission Regulatory Guide 1.233, Guidance For a TechnologyInclusive, Risk-Informed, and Performance-Based Methodology to Inform The Licensing Basis and Content of Applications for Licenses, Certifications, and Approvals for Non-Light-Water Reactors, June 2020, ML20091L698.

7 Derek A. Widmayer, Minutes of the Advisory Committee on Reactor Safeguards Future Plant Design Subcommittee Meeting June 19, 2018, ML18310A204.

$8 \quad$ Nuclear Energy Institute, Integrated Safety Analysis: Why It Is Appropriate for Fuel Recycling Facilities, September 2010, attachment to ML102581149.

$9 \quad$ NUREG-1537, Part 2, Guidelines for Preparing and Reviewing Applications for the Licensing of Non-Power Reactors, Chapter 13, Accident Analyses, February 1996.

1010 CFR 100.11 Determination of exclusion area, low population zone, and population center distance, Footnote 1.

11 SECY-18-0096, Functional Containment Performance Criteria for Non-Light Water Reactors, United States Nuclear Regulatory Commission, Washington, DC, September, 2018, ML18114A546.

12 US Nuclear Regulatory Commission: Advisory Committee on Reactor Safeguards, Review of Advanced Reactor Computer Code Evaluations, Washington, DC, 2019, ML19302F015.

13 Haihua Zhao and Hongbin Zhang, An Innovative Hybrid Loop-Pool Design for Sodium Cooled Fast Reactor, 2007, INL/CON-07-12657, ANS/ENS International Meeting.

14 David E. Holcomb, Alex Huning, Askin G. Yigitoglu, Michael D. Muhlheim, W. P. Poore, and George F. Flanagan, ORNL/TM-2019/1246, July 2019, DOI: 10.2172/1561637. 
15 NUREG-1537, Part 1, Guidelines for Preparing and Reviewing Applications for the Licensing of Non-Power Reactors, Chapter 13, Accident Analyses, February 1996.

16 S. E. Beall, P. N. Haubenreich, R. B. Lindauer, and J. R. Tallackson, MSRE Design and Operation Report, Part V, Reactor Safety Analysis Report, ORNL-TM-732, August 1964, p. 177.

17 George T. Mazuzan and J. Samuel Walker, Controlling the Atom: The Beginnings of Nuclear Regulation 1946-1962, NUREG-1610, U.S. NRC Reprint 1997, p. 229.

18 Jaw-Nan (Joe) Wang, Seismic Design of Tunnels - A Simple State-of-the-Art Design Approach, Parsons Brinkerhoff Inc., June 1993. p. 15.

19 Applied Nucleonics Company, Inc. Seismic Assessment of Underground and Buried Nuclear Power Plants, ATR-78(7652-01)-2, September 1977, DOI: 10.2172/6638940.

20 International Atomic Energy Agency, Safety related terms for advanced nuclear plants, IAEATECDOC-626, September 1991.

21 A. M. Clayton, Thermal Shock in Nuclear Reactors, Progress in Nuclear Energy, 12(1), 1983, pp 57-83, DOI: 10.1016/0149-1970(83)90025-2.

22 R. P. Wichner, Some Consequences of Tubing Failure In The MSBR Heat Exchanger, ORNLMSR-73-17.

23 Charles W. Forsberg, Alternative Passive Decay-Heat Systems for the Advanced High-Temperature Reactor, Proceedings of ICAPP '06 Reno, NV USA, June 4-8, 2006, paper 6055.

24 Zohuri, Bahman, Direct Reactor Auxiliary Cooling System, in Heat Pipe Applications in Fission Driven Nuclear Power Plants, pp.203-218 2019, DOI: 10.1007/978-3-030-05882-1_7.

25 A. N. Smith and M. Bell, Distribution of Decay Heat in the MSBR Off-Gas System, in Molten-Salt Reactor Program Semiannual Progress Report for Period Ending February 28, 1969, ORNL-4396, p. 94-95.

26 S. S. Kirslis and F. F. Blankenship, Hot-Cell Tests on Fission Product Volatilization from Molten MSRE Fuel in Molten-Salt Reactor Program Semiannual Progress Report for Period Ending February 29, 1968, ORNL-4254, p. 100-113.

27 R. B. Lindauer, MSRE Design and Operations Report Part VII - Fuel Handling and Processing Plant, ORNL-TM-907, May 1965.

28 R. B. Lindauer and C. K. McGlothlan, Design, Construction, and Testing of a Large Molten Salt Filter, ORNL-TM-2478, March 1969.

29 J. McFarlane, N. D. Bull Ezell, G. D. DelCul, D. E. Holcomb, K. Myhre, A. Lines, S. Bryan, H. Felmy, and B. J. Riley, Fission Product Volatility and Off-Gas Systems for Molten Salt Reactors, ORNL-TM-2019-1266, PNNL-28974, August 2019, DOI: 10.2172/1560441.

30 Michael Davies, Alloy Selection for Service in Caustic Soda, $2^{\text {nd }}$ ed., Nickel Institute, 2019, https://www.nickelinstitute.org/media/4341/nickelpub10019_causticsoda_20pg.pdf.

31 Ebasco Services Inc., 1000 MW(e) Molten-Salt Breeder Reactor Conceptual Design Study, TID26156, February 1972, Safety Bases for Chemical Processing - section 7.2.2. 
32 A. S. Icenhour, D. F. Williams, L. D. Trowbridge, L. M. Toth, and G. D. Del Cul, An Overview of Radiolysis Studies for the Molten Salt Reactor Remediation Project, Proceedings of Global 2001, Paris, France September 2001.

33 https://www.ornl.gov/scale

34 https://www.nrc.gov/about-nrc/regulatory/research/safetycodes.html

35 SECY-93-092, Issues Pertaining to the Advanced Reactor (PRISM, MHTGR, and PIUS) and CANDU 3 Designs and Their Relationship to Current Regulatory Requirements, p. 7-8.

36 Jerden, J., Grabaskas, D., Bucknor, M., Development of a Mechanistic Source Term Approach for Liquid-Fueled Molten Salt Reactors, ANL/CFCT-19/4, July 2019.

37 NRC, Accident Source Terms for Light-Water Nuclear Power Plants, US Nuclear Regulatory Commission report NUREG-1465, 1995.

38 US Nuclear Regulatory Commission, "Issues Pertaining to the Advanced Reactor (PRISM, MHTGR, and PIUS) and CANDU 3 Designs and their Relationship to Current Regulatory Requirements," US Nuclear Regulatory Commission SECY-93-092, 1993.

39 US Nuclear Regulatory Commission, "Policy Issues Related to Licensing Non-Light Water Reactor Designs," U.S. Nuclear Regulatory Commission report SECY-03-0047, 2003.

40 US Nuclear Regulatory Commission, "Second Status Paper on the Staff's Proposed Regulatory Structure for New Plant Licensing and Update on Policy Issues Related to New Plant Licensing," US Nuclear Regulatory Commission report SECY-05-0006, 2005.

41 R. Yoshioka, Y. Shimazu, K. Mitachi, "Guidelines for MSR Accident Analysis,” Thorium Energy Conference (ThEC12), Shanghai, October 2012.

42 D. Grabaskas, M. Bucknor, J. Jerden, A. J. Brunett, M. Denman, A. Clark, R. S. Denning, "Regulatory Technology Development Plan-Sodium Fast Reactor: Mechanistic Source Term-Trial Calculation," ANL-ART-49, 2016.

43 D. Gérardin, C. A. Uggenti, S. Beils, A. Carpignano, S. Dulla, E. Merle, D. Heuer, A. Laureau, M. Allibert, "A methodology for the identification of the postulated initiating events of the Molten Salt Fast Reactor," Nuclear Engineering and Technology 51, 1024 -1031, 2019.

44 U.S. Atomic Energy Commission, "Calculation of Distance Factors for Power and Test Reactor Sites," Washington, DC, 1962.

45 US Nuclear Regulatory Commission, "Accident Source Terms for Light-Water Nuclear Power Plants," Washington, DC, 1995.

46 US Nuclear Regulatory Commission, "Alternative Radiological Source Terms for Evaluating Design Basis Accident at Nuclear Power Plants," Washington, DC, 2000.

47 Idaho National Laboratory, “Mechanistic Source Term White Paper,” INL/EXT-10-17997, 2010.

48 US Nuclear Regulatory Commission, “Assessment of White Paper Submittals on Fuel Qualification and Mechanistic Source Terms (Revision 1) - Next Generation Nuclear Plant," ML14174A845, 2014. 
"Probabilistic Risk Assessment Standard for Advanced Non-LWR Nuclear Power Plants," ASME/ANS, ASME/ANS RA-S-1.4-2013, December 9, 2013.

50 US Nuclear Regulatory Commission, "Accident Source Terms and Siting for Small Modular Reactors and Non-Light Water Reactors," U.S. Nuclear Regulatory Commission report SECY-16$0012,2016$.

51 Zachry Brands, Inc, "RADTRAD-NAI: RADionuclide Transport Removal and Dose Estimation," [Online]. Available: https://www.numerical.com/software/radtrad/index.php [Accessed 26 June 2020]

52 N. Bixler, “About MACCS," Sandia National Laboratories, June 2020 [Online]. Available: https://maccs.sandia.gov/maccs.aspx [Accessed 26 June 2020].

53 US Nuclear Regulatory Commission, "RASCAL Overview," [Online]. Available: https://ramp.nrcgateway.gov/RASCAL\%20Overview [Accessed 26 June 2020].

54 N. C. Andrews, R. O. Gauntt, L. L. Humphries, R. Y. Lee, M. Salay and H. Esmaili, "SAND201814032 PE: Building a Source Term within the MELCOR/NRC Framework," Sandia National Laboratories, Albuquerque, 2018.

55 D. L. Louie and L. L. Humphries, "SAND2017-3200: NSRD-10: Leak Path Factor Guidance Using MELCOR," Sandia National Laboratories, Albuquerque, NM, 2017.

56 "DOE Standard: Preparation of Nonreactor Nuclear Facility Documented Safety Analysis," United States Department of Energy, Washington, D.C., DOE-STD-3009-2014, November 2014.

57 "Airborne Release Fraction/Rates and Respirable Fractions for Nonreactor Nuclear Facilities," United States Department of Energy, Washington, DC, DOE-HDBK-3010-94, December 1994.

58 D. Powers, "Aerosol Penetration of Leak Pathways - An Examination of the Available Data and Models," Albuquerque, NM, 2009.

59 "NSRD-10: Leak Path Factor Guidance using MELCOR," Sandia National Laboratories, Albuquerque, NM, SAND2017-3200, March 2017.

60 W. K. Ergen, A. D. Callihan, C. B. Mills \& Dunlap Scott, The Aircraft Reactor ExperimentPhysics, Nuclear Science and Engineering: 2, 826-840, 1957.

61 E. S. Bettis, L. G. Alexander, and H. L. Watts, Design Studies of a Molten-Salt Reactor Demonstration Plant, ORNL-TM-3832, June 1972.

62 R. B. Briggs, Tritium in Molten-Salt Reactors, Reactor Technology, 14(4), Winter 1971-1972, 335342.

63 M. J. Bell, Calculated Radioactivity of the MSRE Fuel Salt, ORNL/TM-2970, 1970.

64 M. Taube, "Fast Reactors Using Molten Chloride Salts as Fuel," EIR-Bericht Nr. 332, 1978.

65 L. Burris, I. Dillon, Estimation of Fission Product Spectra In Discharged Fuel From Fast Reactors, Report: ANL-5742, July 1957. 
66 A. Mourogov, P. Bokov, "Potentialities of the fast spectrum molten salt reactor concept: REBUS3700," Energy Conversion and Management, 47, 2761-2771, 2006.

67 K. Eckerman, A. Wolbarst, A. Richardson, Limiting Values of Radionuclide Intake and Air Concentration and Dose Conversion Factors for Inhalation, Submersion, and Ingestion, Report, EPA-520/1-88-020, September 1988.

68 R. Steunenberg, R. Pierce, L. Burris, "Pyrometallurgical and Pyrochemical Fuel Processing Methods," Progress in Nuclear Energy Series III, Process Chemistry, vol. 4(New York: Pergamon Press, 1969), p. 461-504.

69 J. Zhang, Electrochemistry of actinides and fission products in molten salts-Data review, Journal of Nuclear Materials 447, 271-284, 2014.

70 E. Compere, S. Kirslis, E. Bohlmann, F. Blankenship, W. Grimes, Fission Product Behavior in the Molten Salt Reactor Experiment, ORNL-4865, October 1975.

71 R. Robertson, Conceptual Design Study of a Single-Fluid Molten-Salt Breeder Reactor, ORNL4551, June 1971.

72 P. N. Haubenreich and J. R. Engel, "Experience with the Molten-Salt Reactor Experiment," Nuclear Applied Technology, 8(2), 118-136, 1970.

73 W. R. Grimes, "Molten Salt Reactor Chemistry," Nuclear Applied Technology, 8(2), 137-155, 1970.

74 E. S. Bettis and R. C. Robertson, "The design and performance features of a single-fluid molten salt breeder reactor," Nuclear Applied Technology, 8(2), 190-207, 1970.

75 M. E. Whatley, L. E. McNeese, W. L. Carter, L. M. Ferris, and E. L. Nicholson, "Engineering development of the MSBR fuel recycle," Nuclear Applied Technology, 8(2), 170-178, 1970.

76 S. Delpech, E. Merle-Lucotte, D. Heuer, et al., "Reactor physic and reprocessing scheme for innovative molten salt reactor system," Journal of Fluorine Chemistry, 130(1), 11-17, 2009.

77 E. Merle-Lucotte, M. Allibert, M. Brovchenko, V. Ghetta, D. Heuer, and P. Rubiolo, "Preliminary design assessment of the molten salt fast reactor," In Actes de la conférence European Nuclear Conference ENC2012, Manchester, UK, 2012.

78 L. Mathieu, D. Heuer, E. Merle-Lucotte, et al., "Possible configurations for the thorium molten salt reactor and advantages of the fast non moderated version," Nuclear Science and Engineering, 161(1), 78-89, 2009.

79 V. Ignatiev, O. Feynberg, et al., "Progress in development of $\mathrm{Li}, \mathrm{Be}, \mathrm{Na} / \mathrm{F}$ molten salt actinide recycler and transmuter concept," In Proceedings of ICAPP, Nice, France. pp. 3004-3013, 2007.

80 I. Slessarev and P. Bokov, "On potential of thermo-nuclear fusion as a candidate for external neutron source in hybrid systems (applied to the "WISE" concept)," Annals of Nuclear Energy, 30(16), 1691-1698, 2003.

81 M. Taube and J. Ligou, "Molten Chlorides Fast Breeder Reactor Problems and Possibilities," EIRBericht Nr. 215, 1972. 
82 L. M. Toth, G. D. Del Cul, S. Dai, and D. H. Metcalf, "Molten fluoride fuel salt chemistry," In AIP conference proceedings, 346(1), 617-626, 1995.

83 J. Zhang, C. W. Forsberg, M. F. Simpson, S. Guo, S. T. Lam, R. O. Scarlat, F. Carotti, K. J. Chan, P. M. Singh, W. Doniger, and K. Sridharan, "Redox potential control in molten salt systems for corrosion mitigation," Corrosion Science, 144, 44-53, 2018.

84 C. J. Barton, "Solubility of Plutonium Trifluoride in Fused-Alkali Fluoride-Beryllium Fluoride Mixtures," The Journal of Physical Chemistry, 64(3), 306-309, 1960.

85 G. F. Flanagan, D. E. Holcomb, and W. P. Poore III, "Molten Salt Reactor Fuel Qualification Considerations and Challenges," ORNL/LTR-2018/1045, November 2018.

86 D. F. Williams, G. D. Del Cul, and L. M. Toth, "A Descriptive Model of the Molten Salt Reactor Experiment After Shutdown: Review of FY 1995 Progress," ORNL/TM-13142. 1996.

87 E. Capelli, O. Beneš, and R. J. M. Konings, "Thermodynamics of soluble fission products cesium and iodine in the Molten Salt Reactor," Journal of Nuclear Materials, 501, 238-252, 2018.

88 Y. Sekiguchi, K. Uozumi, T. Koyama, and T. Terai, "Fundamental study on the vaporization of cesium and iodine dissolved in LiF-NaF-KF molten salt," Journal of Nuclear Materials, 522, 136143. 2019.

89 J. Kalilainen, S. Nichenko, and J. Krepel, "Evaporation of materials from the molten salt reactor fuel under elevated temperatures," Journal of Nuclear Materials. p. 152134, 2020.

90 M. Taira, Y. Arita, and M. Yamawaki, "The Evaporation Behavior of Volatile Fission Products in FLiNaK Salt,” The Open Access Journal of Science and Technology, 5(5), 1-17, 2017.

91 A. L. Wright, NUREG/CR-6193, Primary Circuit Fission Product Release and Transport, Oak Ridge National Laboratory, Oak Ridge, United States of America, 1994.

92 J. E. Phillips and C. E. Easterly, "Sources of Tritium," ORNL/TM-6402, 1980.

93 W. R. Grimes, Molten-Salt reactor Program Semiannual Progress Report ORNL-3708, pp 238, 1964.

94 US Nuclear Regulatory Commission, "NRC Non-Light Water Reactor (Non-LWR) Vision and Strategy, Volume 3: Computer Code Development Plans for Severe Accident Progression, Source Term, and Consequence Analysis," 2019.

95 F. Gelbard, "MAEROS User Manual," 1982.

96 US Nuclear Regulatory Commission, "NUREG/CR-7155: State-of-the-Art Reactor Consequence Analyses Project - Uncertainty Analysis of the Unmitigated Long-Term Station Blackout of the Peach Bottom Atomic Power Station, Draft Report," US Nuclear Regulatory Commission, Washington, DC, 2012.

97 K. Ross, N. Bixler, S. Weber, C. Sallaberry, and J. Jones, "State-of-the-Art Reactor Consequence Analysis Project - Uncertainty Analysis of the Unmitigated Short-Term Station Blackout of the Surry Power Station, Draft Report,” US Nuclear Regulatory Commission, Washington, DC, 2015. 
98 Severe Accident Analysis Department, Sandia National Laboratories, "NUREG/CR-7245: State-of -the-Art Reactor Consequence Analyses (SOARCA) Project - Sequoyah Integrated Deterministic and Uncertainty Analyses," US Nuclear Regulatory Commission, Washington, DC, 2019.

99 Albright, Lucas Iain, Andrews, Nathan, Humphries, Larry L., Gauntt, Randall, and Jevremovic, Tatjana, "Core Damage Progression Uncertainty Analysis: Fukushima Daiichi Unit 1." SAND2019-9706C, 2019.

100 US Nuclear Regulatory Commission, "Level 3 PRA Project," 26 December 2017. [Online]. Available: https://www.nrc.gov/about-nrc/regulatory/research/level3-pra-project.html. [Accessed 26 June 2020].

101 D. W. Hummel, Y.-S. Chin, M. Yetsir and G. A. Glowa, "Phenomena Identification and Rankng Table (PIRT) for a Severe Accident in a Molten Salt Small Modular Reactor," Canadian Nuclear Laboratories, Chalk River, ON, 2020.

102 Oak Ridge National Laboratory, "Technology and Applied R\&D Needs for Molten Salt Chemistry: Innovative Approaches to Accelerate Molten Salt Reactor Development and Deployment," Oak Ridge National Laboratory, Oak Ridge, TN, 2017.

103 W. A. Wieselquist, "SCALE," Oak Ridge National Laboratories, [Online]. Available: https://www.ornl.gov/scale [Accessed 26 June 2020].

104 P. Humrickhouse and B. Merrill, "Revised Equation of State for FLiBe in MELCOR," 2017.

105 S. Rodriguez, "Development of Design and SImulation Model and Safety Study of Large-Scale Hydrogen Production Using Nuclear Power," Sandia National Laboratories, 2007.

106 J. R. McWherter, Molten Salt Breeder Experiment Design Bases, ORNL-TM-3177, November 1970 .

107 M. Rosenthal, P. Haubenreich, R. Briggs, The Development Status of Molten-Salt Breeder Reactors, ORNL-4812, August 1972.

108 J. Engel, H. Bauman, J. Dearing, W. Grimes, H. McCoy, Development Status and Potential Program for Development of Proliferation-Resistant Molten-Salt Reactors, ORNL/TM-6415, March 1979.

109 R. Yoshioka and K. Motoyasu, "Liquid fuel, thermal neutron spectrum reactors." In Molten salt reactors and thorium energy, p. 281-373. Woodhead Publishing, 2017.

110 J. Kloosterman, Safety Assessment of the Molten Salt Fast Reactor (SAMOFAR), in Molten Salt Reactors and Thorium Energy (Editor: T. J. Dolan), p. 565-569, Woodhead Publishing, June 2017.

111 S. Wang, M. Massone, A. Rineiski, E. Merle-Lucotte, A. Laureau, D. Gérardin, D. Heuer, M. Allibert, "A passive decay heat removal system for emergency draining tanks of molten salt reactors," Nuclear Engineering and Design, 341, 423e431, 2019.

112 M. Farmer, The MELTSPREAD Code for Modeling of Ex-Vessel Core Debris Spreading Behavior, Code Manual - Version3-beta, ANL/NE-17/20, September 2017. 
113 M. Farmer, The CORQUENCH Code for Modeling of Ex-Vessel Corium Coolability under Top Flooding Conditions Code Manual - Version4.1-beta, ANL-18/22, August 2018.

114 J. W. McMurray, T. M. Besmann, J. Ard, B. Fitzpatrick, M. Piro, J. Jerden, M. Williamson, B. S. Collins, B. R. Betzler, and A. L. Qualls, "Multi-physics simulations for molten salt reactor evaluation: Chemistry modeling and database development," ORNL/SPR-2018/864. June 2018.

115 EPRI, "Safety and Operational Benefits of Risk-Informed Initiatives," Palo Alto, CA, 2008.

116 Nuclear Energy Institute, "NEI 18-04: Risk-Informed Performance-Based Guidance for Non-Light Water Reactor Licensing Basis Development - Draft Report Revision N," Nuclear Energy Institute, Washington, DC, 2020.

117 David J. Diamond, Nicholas R. Brown, Richard Denning, and Stephen Bajorek, Phenomena Important in Modeling and Simulation of Molten Salt Reactors, BNL-114869-2018-IR, Section 5.2, "Inventory Control and Distribution," ML18124A330. 